On Uncertainty, Market Timing and the Predictability of Tick by Tick Exchange Rates

Roman Kozhan and Mark Salmon 


\title{
On Uncertainty, Market Timing and the Predictability of Tick by Tick Exchange Rates
}

\author{
Roman Kozhan Mark Salmon*
}

April 2008

\begin{abstract}
This paper examines the predictability of exchange rates on a transaction level basis using both past transaction prices and the structure of the order book. In contrast to the existing literature we also recognise that the trader may be subject to (Knightian) uncertainty as opposed to risk regarding the structure by which exchange rates are determined and hence regarding both the model he employs to make predictions and the reliability of any conditioning information. The trader is faced with a two stage decision problem due to this uncertainty; first he needs to resolve a question of market timing as to when to enter the market and then secondly how to trade. We provide a formalisation for this two stage decision problem. Statistical tests indicate the significance of out of sample ability to predict directional changes and the economic value of predictability using one week of tick-by-tick data on the USD-DM exchange rate drawn from Reuters DM2002 electronic trading system. These conclusions rest critically on the frequency of trading which is controlled by an inertia parameter reflecting the degree of uncertainty; trading too frequently significantly reduces profitability taking account of transaction costs.
\end{abstract}

Financial Econometrics Research Centre, Warwick Business School

Key words: Knightian uncertainty, market timing, predictability, high-frequency data.

JEL Classification: D81, F31, C53

*Address for correspondence: Warwick Business School, The University of Warwick, Scarman Road, Coventry, CV4 7AL, UK; tel: +44 247652 2853; e-mail: Roman.Kozhan@wbs.ac.uk and Mark.Salmon@wbs.ac.uk. We would like to thank Martin Evans, Rich Lyons, Chris Neely, Carol Osler, Dagfinn Rime, Paul Weller, Lucio Sarno and participants at the ESF Exploratory workshop on the High Frequency Analysis of Foreign Exchange Markets held at Warwick in June 2006 for their comments on an earlier version of this paper. 


\section{Introduction}

Considerable research has been devoted over a number of years to examining the predictability of foreign exchange rates following the classic paper by Meese and Rogoff (1983). One reasonable interpretation of this work is that it has been found to be difficult to convincingly overturn their result regarding the inability of standard "macro" based exchange rate models to beat a random walk in out of sample forecasting exercises. Clearly this broad statement could be qualified as research has appeared which claims to provide evidence of predictability in particular exchange rates and over particular sample periods (see for instance Abhyankar, Sarno and Valente (2005)) but the general impression remains that standard fundamentals based models do not consistently dominate a random walk.

At the same time there has been a major development in what has become known as the New Micro Approach to Exchange Rates (see for instance Lyons (2001)) in which attention is focussed more on the characteristics and micro structure of the FX market itself rather than the macro fundamentals that drive the traditional theories of exchange rate determination. In the light of Messe and Rogoff's results this distinction is critical since any statement regarding predictability is necessarily conditional on the information set employed. A variable may appear to be completely unpredictable if irrelevant data is used as the conditioning information and yet may be highly predictable if the correct conditioning data is used. While both approaches, micro and macro, seek to explain the same exchange rate which is determined on a tick by tick basis in the spot market, they obviously differ critically in the information sets they use to explain exchange rate movements and hence forecast.

In this paper we present what we believe to be the first rigorous tests of predictability of an exchange rate using irregularly spaced tick by tick FX data where the information set involves both the past price history and information on the structure of the order book. Secondly we attempt to formally recognise the uncertainty that a foreign exchange trader faces given that any model he uses to generate forecasts and trading decisions will be incorrect in ways that he cannot capture in a unique probability distribution. We therefore allow our trader's decisions to reflect Knightian Uncertainty rather than simply risk. In short we find clear evidence of predictability both in terms of directional change and economic value after taking account of transactions costs when the frequency of trades is controlled. The predictors are based on genetic algorithms applied to the tick by tick data and evaluated over a three day out of sample period. White's reality check is employed to insulate the results from any data snooping bias. The prediction rules are also compared with the results from applying several classic Technical Rules which are shown to indicate substantially less predictability and profitability than the GA trading rules we employ. A further some- 
what surprising result is that the we find little or no advantage in allowing the predictor to exploit information in the order book. This result is exactly the opposite of what we had expected before carrying out the empirical work but would be consistent with the market price acting as a sufficient statistic and hence that no further information is useful.

Our objective is not to re-examine the question of the predictability of technical rules but to mirror the way in which technical rules appear to be used in practice by currency traders when making their trading decisions. In the first place, there is considerable evidence (see for instance Taylor and Allen (1992), Lui and Mole (1996)) that traders largely use technical rules only for short run decision making, which justifies our use of tick by tick data. Traders also do not follow a single rule but form an impression as to where the market is moving on the basis of a number of technical indicators, dropping those that appear not to have worked well 11 Secondly we formalise the sequential decision making seen in financial markets where an initial decision must be taken as to when to enter the market - the question of market timing - alongside the decision of how to trade. The market timing decision is intimately related to the degree of uncertainty the trader faces; when he is confident in the direction the market is moving he will act quickly and when he is uncertain he will show inertia and be reluctant to trade.

Our results would seem to justify the investment that has been made by a number of financial institutions to develop and apply automatic trading systems 2 , This does suggest the correct interpretation of the Messe and Rogoff conclusion lies in the fact that the correct conditioning information set had not been used rather than that exchange rates are in fact unpredictable. In addition we show that even when you have the correct information it is critically how and when it is used that determines if profitability will appear since unless the frequency of trading is controlled, profitability disappears. The frequency of trading is controlled by means of an "inertia" parameter reflecting the degree of uncertainty and ensures the system can only trade when the predicted price change is beyond some threshold level (taking transactions costs into account). Human traders clearly do not trade in real time as frequently as our unconstrained trading rules would suggest and so restricting the frequency of trades simple reflects reality.

In the next sections we briefly review the existing literature in this area and then discuss the derivation and application of the Genetic Algorithm trading rules, the testing procedures we have employed before turning to report our results.

\footnotetext{
${ }^{1}$ We have benefited from detailed discussions with the chief currency trader at the Bank of England and the Royal Bank of Scotland regarding their use of technical analysis.

${ }^{2}$ We know, for instance, of one major bank that has an automatic trading system in place that inspects 1200 currency pairs in real time and we are told delivers profits of the order of 500 million Euro annually.
} 


\section{$2 \quad$ Predictability and Market Timing}

Most existing statistical analysis suggests at best weak predictability in the FX market. At the same time, we can clearly observe trends, ex post, in exchange rates over particular periods of time which might imply ex ante short term predictability if the correct conditioning information can be found and potentially short term arbitrage opportunities. To state the obvious; the issue of market timing is intimately connected to the degree of predictability in a market. Even if there is no predictability over a long period or on average, it may be possible to forecast at some point of time over a short period. It may be more important to identify these moments in time rather than attempting to find a predictor which has good properties on average as is traditionally the case.

In the paper we use a two stage combined predictor in which the first step provides a market timing indicator and the second gives a forecast of the future exchange rate and a related trade. The market timing indicator effectively serves as a filter, extracting irrelevant or uncertain information and noise from the time series data and then the trader uses this filtered information set to take decisions in the market.

The more formal description of the individual's preferences is given in the following section.

\subsection{Uncertainty Aversion and Inertia}

An investor in real life is invariably faced with different types of uncertainty while making trading decisions in a market. This uncertainty might be due to changing market structure, estimation error or model uncertainty, lack of information, imprecision of information of imperfect trading signals. Risk is defined by the probability of events described by an assumed model structure and a unique probability distribution. We are more concerned with capturing the uncertainty in decision making, beyond risk, which results if there is a lack of knowledge about which model and probability distribution to use. Risk calculus, as employed for instance in VaR or expected utility calculations, is relatively straightforward and provides a confidence interval as the basis for action. However, when we recognise that incorrect decisions can follow from inaccuracy in the assumed model or probability distribution we need to employ additional tools to decide whether to trust a predictor or not. Each transaction is costly because of transaction costs and if future prices do not change as predicted by the model the investor will inevitably lose money. In order to filter weak trading signals we need some rule that suggests you only trade if the predicted value exceeds some threshold that reflects the degree of uncertainty.

Knight's characterisation (Knight 1921) of uncertainty refers to situations when there is no unique probability model supporting traders' decisions. In this case ex- 
pected utility fails to be an appropriate model by which to predict or make trading decisions. Technical indicators may in fact reflect the Knightian concept of uncertainty more accurately than expected utility based predictors since they are often viewed as distribution free methods of predicting future prices. However, even technical rules are recognised as being imprecise and may deliver incorrect forecasts which is why technical analysts tend to use several technical indicators simultaneously or interval based rules like Bollinger Bands or stop-loss strategies.

The use of these strategies brings some inertia to the trading process which makes trading less frequent. This notion of trading inertia is entirely consistent with the question of market timing since it implies that the investor does not trade at every feasible point of time but does so by trying to choose the best moment when to enter the market.

There are several ways how the theory of decision-making under uncertainty can be used to model the observed inertia in the market. One of the classic examples is the no-trade condition introduced by Dow and Werlang (1992). Once the trader observes this condition in the market, he becomes "uncertain" about a particular asset and excludes it from his portfolio and doesn't trade the asset again until the condition disappears. This phenomenon describes some kind of extreme uncertainty aversion in the agent who will have different degrees of uncertainty regarding each asset in the market reflecting the different degree of confidence he has in his information set. It may also be that the investor is uncertain about the market as a whole in that he does not see value in any alternative to his current position. This implies that his position will change only if there is another portfolio which clearly dominates his existing portfolio.

\subsubsection{The Market entry/ exit Decision}

Theoretical support for preferences with trading inertia has been introduced by Bewley (1986) (see also Bewley (2002), Ghirardato, Maccheroni and Marinacci (2004)) and we now provide a short description of the simplified version of the Bewley's approach that we will employ.

Uncertainty Averse Preferences. Let $S$ be a set of states (of the market) and let $\mathcal{B}$ be the $\sigma$-algebra of its Borel sets. An act is a measurable bounded function $f: S \rightarrow \mathbb{R}$ and let $L \subset \mathbb{R}^{S}$ be the set of all acts on $S$, i.e., a set of random payoffs available at the moment for decision-making. In our case we consider acts as the return the agent receives from his trades. Effectively, $L$ represent a set of alternative strategies in the market to which the trader is restricted.

There is a binary preference relation $\succ_{u a}$ (stands for "uncertainty aversion") defined on $L$ and let it satisfy the following axioms.

A1. Monotonicity If $f(s)>g(s)$ for all $s \in S$ then $f \succ_{\text {ua }} g$. 
A2. Transitivity If $f \succ_{u a} g$ and $g \succ_{u a} h$ then $f \succ_{u a} h$.

A3. Openness For all $f \in L,\left\{g \in L: g \succ_{u a} f\right\}$ is open $L$.

A4. Independence For all $f, g, h \in L$ and for all $\alpha \in(0,1), g \succ h$ if and only if $\alpha f+(1-\alpha) g \succ_{u a} \alpha f+(1-\alpha) h$.

Theorem 2.1. (Bewley, 2002) If $\succ_{\text {ua }}$ satisfies Axioms A1-A4, then there is a closed convex set $\mathcal{P}$ of probability measures on $S$ such that

(i) for all $f$ and $g$ and $B \in \mathcal{B}$ we have $f \succ_{u a} g$ if and only if $E_{P}(f)>E_{P}(g)$ for all $P \in \mathcal{P}$;

(ii) for all $P \in \mathcal{P}, P(B)>0$ for each non-empty $B \in \mathcal{B}$.

The set of probability measures $\mathcal{P}$ reflects the trader's uncertainty. The key point in the preceding theorem is that the preference relation $\succ_{u a}$ is not complete leading to a set of probability measures $\mathcal{P}$ rather than a unique measure as in the expected utility theory. This means that there may exist two acts which are "incomparable" and the decision-maker can not distinguish which is better nor in fact whether he is indifferent as he does not have sufficient information to evaluate the different options. The notion of incomparability is critically distinct from indifference. The latter means that if the decision-maker is indifferent between $f$ and $g$ he will definitely prefer $f+\varepsilon$ rather than $g$ if $\varepsilon>0$. In the case of incomparability the investor needs more information beyond $f$ in order to compare two alternatives. This may imply that the decision-maker is not fully rational as discussed in Bewley (2002). If the decision-maker can unambiguously distinguish between two acts then we say that acts $f$ and $g$ are "comparable" and denote this by $f \lessgtr_{u a} g$.

There are different solutions as to how to act when there are incomparable portfolios in the market. One is to randomly choose one of them, another is to assume that the investor has a subjective distribution over the set of priors (a probability measure over probability measures) and carries out some form of averaging with respect to his beliefs. This approach leads to Bayesian Model Averaging and its generalization as discussed in Klibanoff, Marinacci and Mukerji (2005). Instead we adopt the inertia approach proposed in Bewley (2002). This implies that the decision-maker will change his portfolio only if a new portfolio strictly dominates it. In order to formalize this we denote by $f_{t}$ the optimal portfolio for the investor at time $t$.

Inertia Assumption For each $t_{1}<t_{2}, f_{t_{1}} \neq f_{t_{2}} \Leftrightarrow f_{t_{2}} \succ_{u a} f_{t_{1}}$.

This means that the next choice of the investor will need to strongly dominate the preceding position otherwise they coincide (the previous position will not be changed). He will not update the position in three further cases: if the alternative is worse than the current one, if he is indifferent between the alternative and the current position (i.e., their expected values with respect to all priors coincide) and if the alternative is "incomparable" with the current position. Thus, if the agent does not see any strictly 
better alternative to his current portfolio he will not trade until the situation changes. If a new alternative arises which is preferable according to every measure in the prior set, the trader will change his current position. In a real market this inertia is also justified by the presence of transaction costs since an investor would have to pay to switch to an incomparable portfolio which would not be rational.

Although this representation of Bewley's preferences allows us to model trading inertia, it does not provide guidance as to which alternative to choose when faced with several "incomparable" positions each of which is strictly better than the current position. For example, Bewley's preferences do not provide an answer as to what the decision-maker holding the portfolio $f$ should do if there exist $g$ and $h$ such that $g \succ_{u a} f$ and $h \succ_{u a} f$. It may happen that $g$ and $h$ are not comparable. If this is the case, the decision-maker will get a signal that he needs to change his current portfolio, given there are better portfolios than $f$ in the market (both $g$ and $h$ in our case) but he does not know which alternative, $g$ or $h$ to choose.

In order to fill this gap we propose two different preference relations in the space of risky payoffs and construct a composite indicator which the decision-maker uses. The first indicator is based on Bewley's preferences $\succ_{u a}$ as described above which represents the trader's perception of uncertainty and serves as a market timing indicator informing the trader that he should alter his current position. The second indicator, $t d$, (stands for "trading") changes the trading direction and determines the quantity traded. We denote the corresponding preference relation by $\succeq_{t d}$. We do not provide any specific axiomatization for the $\succeq_{t d}$ preference relation here as it may be any subjective predictor based on a complete preference relation that the trader is willing to use: either based on the expected utility model or a technical indicator or simply the trader's intuition.

The composite preference relation $\succeq$ is then defined as follows:

$$
g \succeq f \Leftrightarrow\left(g \lessgtr_{u a} f\right) \wedge\left(g \succeq_{t d} f\right) .
$$

Effectively decision-making based on the preference relation $\succeq$ is split into two stages: market timing and trading. The uncertainty aversion preference relation $\succ_{u a}$ does not indicate whether one asset is better than another; rather it provides the degree of confidence for the trader that the $t d$ indicator has predictive power at the particular point of time. It gives a signal whether it is possible to say that there is an asset structure which unambiguously dominates the current position. If this is the case then the $t d$ indicator specifies the clear action of the trader. This trading strategy reflects the "rules-of-thumb" used by technical traders in reality. Indeed, as we have already mentioned, generally technical traders use several indicators in order to be confident they correctly predict the future market direction. Such a composite indicator is more robust since the trading signal is confirmed by both the $t d$ and $u a$ rules.

In order to specify the preference relation more precisely we shall make use of a 
simple example. Assume that there are two assets in the market - one risky and one risk-free. The agent has only three possibilities: invest his wealth in the risk-free asset, invest everything in risky asset or take a short position in the risky asset which is equal to his current wealth. The current wealth level is denoted by $W_{0}$. The current price of the risky asset is $p_{0}$ and its future price is a positive random variable $p$. The gross return of the risk-free asset is $1+r$. In order to define the set of priors for the model we fix a measure $P_{0}$ on the probability space $(S, \mathcal{B})$. We assume that all measures in the set $\mathcal{P}$ are absolutely continuous with respect to the measure $P_{0}$. By the Radon-Nikodym theorem for every measure $Q \in \mathcal{P}$ there exists a non-negative random variable $\eta_{Q}$ with $E_{P_{0}}\left(\eta_{Q}\right)=1$, such that $d Q=\eta_{Q} d P_{0}$. Therefore, we can identify the set of priors $\mathcal{P}$ with the set of their Radon-Nikodym derivatives with respect to the probability measure $P_{0}$.

The price expectation under the measure $Q$ can be expressed as $E_{Q}(p)=\tilde{p}+k_{Q}$, where $\tilde{p}=E_{P_{0}}(p)$ and $k_{Q}=\operatorname{cov}_{P_{0}}\left(p, \eta_{Q}\right)$. Indeed, $E_{Q}(p)=E_{P_{0}}\left(\eta_{Q} p\right)=\operatorname{cov}_{P_{0}}\left(p, \eta_{Q}\right)+$ $E_{P_{0}}(p) E_{P_{0}}\left(\eta_{Q}\right)=k_{Q}+\tilde{p}$

Let the set of Radon-Nykodym derivatives of the measures in $\mathcal{P}$ satisfy the condition $C=\left\{\operatorname{cov}_{P_{0}}\left(p, \eta_{Q}\right): Q \in \mathcal{P}\right\}=\left[-k_{\min }, k_{\max }\right]$ with $k_{\min }, k_{\max }>0$. This assumption characterises the set of priors of the decision-maker.

Let the investor initially only hold the risk-free asset. Then, according to Theorem 2.1. under the above preferences he will decide to switch to the risky asset if $E_{Q}\left(\frac{p}{p_{0}}\right)>$ $E_{Q}(1+r)=1+r$ for all $Q \in \mathcal{P}$, or equivalently $\tilde{p}+k>p_{0}(1+r)$ for all $k \in\left[-k_{\min }, k_{\max }\right]$. Thus, the agent takes a long position if $\tilde{p}>p_{0}(1+r)+k_{\min }$.

If the agent decides to double his holding in the risk-free asset, he borrows $\frac{W_{0}}{p_{0}}$, converts it into cash and invests in the risky asset. At the end of the next period the investor buys $\frac{W_{0}}{p_{0}}$ shares of the risky asset and repays his debt. Thus, the final wealth can be calculated by $W_{1}=2 W_{0}(1+r)-\frac{W_{0} p}{p_{0}}$ and the return of the short position is $2(1+r)-\frac{p}{p_{0}}$.

The investor will prefer the short position to the risk-free asset if $2(1+r)-\frac{E_{Q}(p)}{p_{0}}>$ $1+r$ or equivalently $\tilde{p}<p_{0}(1+r)-k_{\max }$. Combining these two inequalities we conclude that if $p_{0}(1+r)-k_{\max } \leq \tilde{p} \leq p_{0}(1+r)+k_{\min }$ the decision-maker decides to keep his portfolio unchanged according to the inertia assumption $3^{3}$ In the case $k=k_{\min }=k_{\max }$ (a symmetric band) the latter inequality is simplified to $\left|\tilde{p}-p_{0}(1+r)\right| \leq k$.

The main implication of the example is that there exists a no-trade band around the predicted value of the alternative portfolio which determines the market timing condition. That is, if the value of the proposed portfolio lies within the band then the investor does not rebalance his current portfolio and the converse implies the "trade" signal.

Note that our no-trade band is different from the no-trade condition of Dow and

\footnotetext{
${ }^{3}$ We can also obtain the inertia band under more relaxed assumption for the multiple prior set, e.g., $C=\left\{\operatorname{cov}_{P_{0}}\left(p, \eta_{Q}\right): Q \in \mathcal{P}\right\} \subset \mathbb{R}$ is bounded and $\inf C=-k_{\min }$ and $\sup C=k_{\max }$.
} 
Werlang (1992). Under Dow and Werlang's condition the investor exits the market and does not re-enter until the condition vanishes. In our case the trader does not exit the market but waits and holds his current portfolio until a better alternative arises.

We consider the simplest case with two assets in the market - long and short positions in the foreign currency. If denote by $f$ the position held at time $t$ which was bought at time $t_{0}$ for price $p_{t_{0}}$ then we say that there exists a position $g$ such that $f \lessgtr_{u a} g \Leftrightarrow\left|p_{t_{0}}-p_{t}\right|>k$ for some pre-defined positive $k$, where $p_{t}$ is the current price of the asset $g$. This can be interpreted as implying there is no asset structure in the market which dominates the one held until the transaction price change is predicted to be large enough. The constant $k$ reflects trader's subjective attitude to uncertainty in the market. The larger $k$, the wider the band of inertia which leads to less frequent trading. For the sake of simplicity below we use a symmetric interval for the market timing indicator. Once the price change happens to be big enough the trader uses the $t d$ indicator to determine his action in the market. In our case the $t d$ rule is provided by a genetic algorithm trading rule which is discussed in the following section.

\section{Technical Analysis and Predictability}

The debate as to whether using Technical Analysis results in significant profitability has probably been running ever since the Dow Theory came into existence between 1900-1902 when Charles Dow suggested that the direction of prices in "The Industrial Average", made up of 12 blue chip stocks and "The Rail Average", made up of 20 railroad companies appeared to be based on a set of rules.

In an early study Fama and Blume (1966), investigated the importance of Technical Rules while analyzing foreign exchange markets and Dooley and Shafer (1976) obtained results in favor of the profitability of similar filter rules. Sweeney (1986) confirmed these positive results and proved their statistical significance. Carol Osler has demonstrated in several papers (Osler (2003), Osler (2000), Chang and Osler (1999), Chang and Osler (1995) and Savin, Weller and Zvingelis (2007))the potential for profitability of more sophisticated technical rules in FX markets such as head and shoulder patterns. Whereas most technical indicators are based simply on historical prices or returns, other information also can be useful in order to form expectations of future prices. Neely and Weller (2001) show that including information on US foreign exchange interventions improves the profitability of their trading rules.

However, the practical relevance of much of this research has equally been called into question. Neely and Weller (2003) for instance emphasise the critical role of transaction costs and inconsistences between the data used by practitioners and in academic simulations; although most traders transact in real time the majority of the earlier academic studies (Dooley and Shafer (1983), Sweeney (1986), Levich and Thomas (1993), 
Neely, Weller and Dittmar (1997)) report the profitability from using technical rules but use daily or weekly data which is clearly unrealistic and misrepresents the information set available to the trader in practice when making a trade using technical analysis. The literature in which high-frequency trading rules are investigated is limited. Curcio, Goodhart, Guillaume and Payne (1997) consider intra-day FX data aggregated to one hour and find little or no evidence of profitability outside of periods when the exchange rate is trending. Neely and Weller (2003) using half hourly quote data find considerable out of sample predictability which does not translate into profitability once transaction costs are taken into account which they claim supports the efficiency of the FX market. The research most closely related to our own is that of Michael Dempster (Dempster and Jones (2001)) who applied GP generated rules to FX transaction data with one minute aggregation for trading but with indicators evaluated at fifteen minutes. To quote from their conclusions - they find "the return from the 20 strategy portfolio system trading at fifteen minute entry intervals is small and statistically insignificant and is in fact less than the interest differential between pounds and dollars over the same sample period. ... better excess returns would have be available from a static buy and hold strategy.... When only the best strategy is employed it is modestly and statistically significantly profitable (returning $7 \%$ )".

We seek to extend this literature by focussing on transaction level data - in other words irregularly spaced transacted prices as opposed to quotes or temporally aggregated data and by including the structure of the order book in the information set available to the trader or automatic trading system. Secondly as discussed above we introduce uncertainty into the trading process. We also focus on rigorous testing of both directional change and economic value and use White's reality check to immunise our results from any Data Snooping bias.

\subsection{The Genetic Trading Rule}

We want to consider evaluating predictability as generally as possible and so it is important not to restrict ourselves to examining the performance of a fixed set of prediction and trading rules. The Genetic algorithm (GA) provides an effective method for searching over a huge space of potential rules, both linear and non-linear, at each period. A GA is essentially a computer based optimization procedure which uses the evolutionary principle - the survival of the fittest - to find an optimum. It provides a systematic search process directed by performance rather than a gradient and in principle can find a global optimum in otherwise intractable problems if the required computing resources are available. In practice computational power is limited and so all GA rules, including those derived below, will not necessarily find the best possible performance but the best given the computing and time constraints we have been 
forced to impose on the search process. Never the less the rules selected below will have evolved from searching over millions of competing rules and their performance is therefore known to be at least "good" if not achieving the global optimum. This is obviously sufficient for our purposes since if predictability is found with these "good" rules then we know we must at least have understated the potential degree of predictability that might exist. Moreover our results should have much greater applicability than those who have considered a fixed set of technical rules - however large 4

\subsection{Genetic Algorithm}

Genetic algorithms have been successfully applied in a number of financial applications, most notably for our purposes, Dempster and Jones (2001), Dworman, Kimbrough and Laing (1996), Chen and Yeh (1997b), Chen and Yeh (1997a), Neely et al. (1997), Allen and Karjalainen (1999), Neely and Weller (2001), Chen, Duffy and Yeh (1999), Arifovic (1994), Arifovic (1995), Arifovic (1996), Arifovic (1997).

Starting from an initial set of rules a genetic algorithm evaluates the fitness of various candidate solutions (trading rules) using the given objective function of the optimization problem and provides as an output solutions that have higher fitness values. Two operations of crossover and mutation are applied to create a new generation of decision rules based on the genetic information of the fittest candidate solutions

Crossover operation: for the crossover operation one randomly selects two parents from the population based on their fitness, then take a node within each parent as a crossover point selected randomly and the subtrees at the selected nodes are exchanged to generate two children. One of the offspring then replaces the less fit parent in the population. In our implementation we use a crossover rate of 0.4 for all individuals in the population. This operation combines the features of two parent chromosomes to form two similar offspring by swapping corresponding segments of the parents. in our case these segments are represented by sub-nodes of binary tree. The intuition behind the crossover operator is information exchange between different potential solutions.

Mutation operation: to mutate a rule one selects one of its subtrees at random and replaces it with the new randomly generated tree. This operation guarantees the refreshment of the genetic code within the population. The best $25 \%$ of rules are not mutated at all and the remaining are mutated with probability 0.1 . The intuition behind the mutation operator is the introduction of some extra variability into the population.

The elements of every trading rule are terminals and operations and the rule pro-

\footnotetext{
${ }^{4}$ We are also interested in the simplicity of the rules selected by the genetic program and how these may correspond to robust decision rules that may justified formally in the face of uncertainty as opposed to risk in financial markets.
} 
vides a boolean value as the output. If the value of the rule is "true", it gives the signal to "buy" USD, or equivalently, it indicates the USD-DM exchange rate is increasing. If the rule is "false" - the trader "sells" USD. The rules are represented in the form of randomly created binary trees with terminals and functions in their nodes. We employ the following choices of operations and terminals;

Operations: the function set used to define the technical rules consists of the binary algebraic operations $\{+,-, *, /, \max , \min \}$, binary order relations $\{<,>, \leq, \geq,=\}, \log -$ ical operations $\{$ and, or $\}$ and unary functions $\{a b s,-\}$ of absolute value and change of sign.

Terminals: the terminal set contains the variables $\{$ pr, ret, lagpr1, lagpr2, lagret1, lagret2, maxpr5, maxpr10, maxpr20, minpr5, minpr10, minpr20, avgpr5, avgpr10, avgpr20, avgret5, avgret10, avgret20\}, where the first 6 variables indicate currently observed price and returns of USD in terms of DM and their lag values, maxpr and minpr as well as maxret and minret denote maximum and minimum price over the indicated period of the exchange rate and its return respectively, avgpr and avgret are average value prices and returns over the period. We should make clear that by "period" we mean the irregular instants of time when the transaction is realized.

For the cases when the algorithm searches over order book information we also use the following additional variables: bestbid, bestoffer, bestbidq, bestofferq, quantity, liqbid, liqoff, dpthbid, dpthoffer, time, which represent best bid, best offer, best bid quantity, best offer quantity, transaction quantity, liquidity from the bid side, liquidity from the offer side, market bid depth, market offer depth and duration between transactions in seconds respectively. All their first and second lagged values are also included in the information set.

The terminal set also includes real numbers in the range from 0 to 10 as terminal constants.

The following example illustrates the sort of trading rule that can be generated.

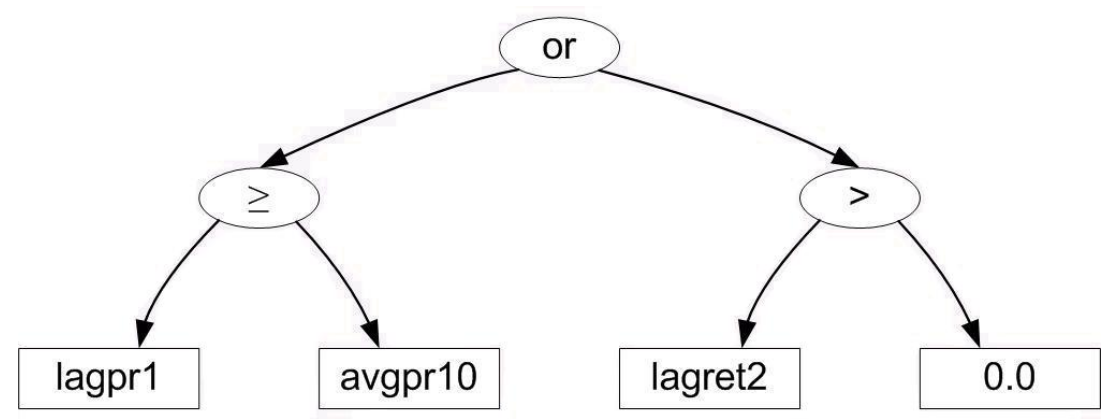

Figure 1: An example of a genetic tree for a trading rule

This example corresponds to the following trading rule: 
- switch to USD if the lagged value of the exchange rate is greater than or equal to the average exchange rate over last 10 periods or the second lag of the return is greater than zero;

- otherwise hold DM.

The evolutionary algorithm can be summarized as follows:

1). Create randomly the initial population $P(0)$ and initialize the number of iterations $i=0$.

$2)$. Set $i:=i+1$.

3). Evaluate fitness of each tree in the population using the fitness function.

4). Generate a new population (i.e. the set of all genetic trees) using the genetic operations (crossover and mutation)

5). Repeat 2)-5) while $i<N$.

In the program we use the population size of 100 individuals and provide 50 iterations of the algorithm (that is, $N=50$ ).

The complexity of trading rules are controlled in a probabilistic manner. In fact, the probability for a binary node to appear in the tree is smaller than the probability of a unary one which prevents the tree to become very large.

\subsection{Fitness functions}

A fitness value also needs to be assigned to each of the generated trees or trading rules in order to solve the optimization problem. We use three different fitness functions. First we consider the percentage of correctly predicted change of directions in the exchange rate by the composite technical rule. Although the trader as described in the previous section, does not make a transaction until the exchange rate changes sufficiently, the information received during the period when the trader remains passive is used to compute the current values. For example, if the exchange rate $e_{t-1}=e_{t}=e$, the values of variables price and lagpr 1 are both set to $e$. We denote the percentage of correct directional change predictions by DC.

As a second fitness function we consider the economic value of the trading rule measured by the cumulative daily returns. We assume that the investor starts with an initial wealth in DM and considers whether to switch all their wealth into USD or take a short position in dollars. The investor is allowed to trade only if the exchange rate level exceeds the $k$ inertia band created by uncertainty as discussed in the previous section. Let $z_{t}$ denote the state of the investor's portfolio at time $t$. That is, $z_{t}=1$ if they take a long position and $z_{t}=-1$ if they are short. We assume $z_{t}$ does not change while the level of the exchange rate $e_{t}$ lies within the $k$-band. The fitness of 
each trading rule is then calculated as

$$
R_{c}=\prod_{t}\left(1+z_{t} r_{t}\right)-1
$$

where $r_{t}=\frac{e_{t}-e_{t-1}}{e_{t-1}}$ is the one-period return of the exchange rate $e_{t}$ For convenience, we present the results adjusted to the daily basis form, i.e., $R=\left(1+R_{c}\right)^{\frac{1}{2}}$ and $R=\left(1+R_{c}\right)^{\frac{1}{3}}$ for in-sample (2 days) and out-of-sample (3 days) returns respectively.

A critical issue is how to take account of transaction costs when calculating the economic value of the trading rules. This provides the third form of the fitness function we consider. Under proportional transaction costs with rate $\theta$ the cumulative return can be calculated as

$$
R_{c}^{\mathrm{TC}}=\prod_{t} \frac{1+z_{t} r_{t}}{(1+2 \theta)^{h\left(z_{t}\right)}}-1
$$

where $h\left(z_{t}\right)=\frac{\left|z_{t}-z_{t-1}\right|}{2} \mathrm{~s}^{5}$

\section{Data}

The data we have used was provided by Reuters and represents all transaction and order book information on USD-DM trades on DM2000-2 electronic dealing system over the week starting 5th October 1998. This electronic market is open 24 hours each day of the week and we have not made any adjustments for overnight periods GMT. The dataset consists of details relating to the 18065 transactions that occured during the week. It includes the transaction prices, best bid and ask quotes, transaction and best quote quantities, the duration between transactions, depth and liquidity on each side of the limit order book. We use the first two days (Monday and Tuesday) as the in-sample period which is used by the genetic programming in order to find those trading rules with the best performance. The out-of-sample period consists of the last three days and is used to examine the significance of the performance of the selected trading rules.

\section{The Formal Testing Framework}

Since the ability to predict the market's direction may not lead to excess profits if returns are greater in absolute value at times when mistakes on direction are made than at times when no mistakes on direction are made we need to consider predictability

\footnotetext{
${ }^{5}$ We have been provided with the transaction costs in terms of spreads used by a major UK based hedge fund.
} 


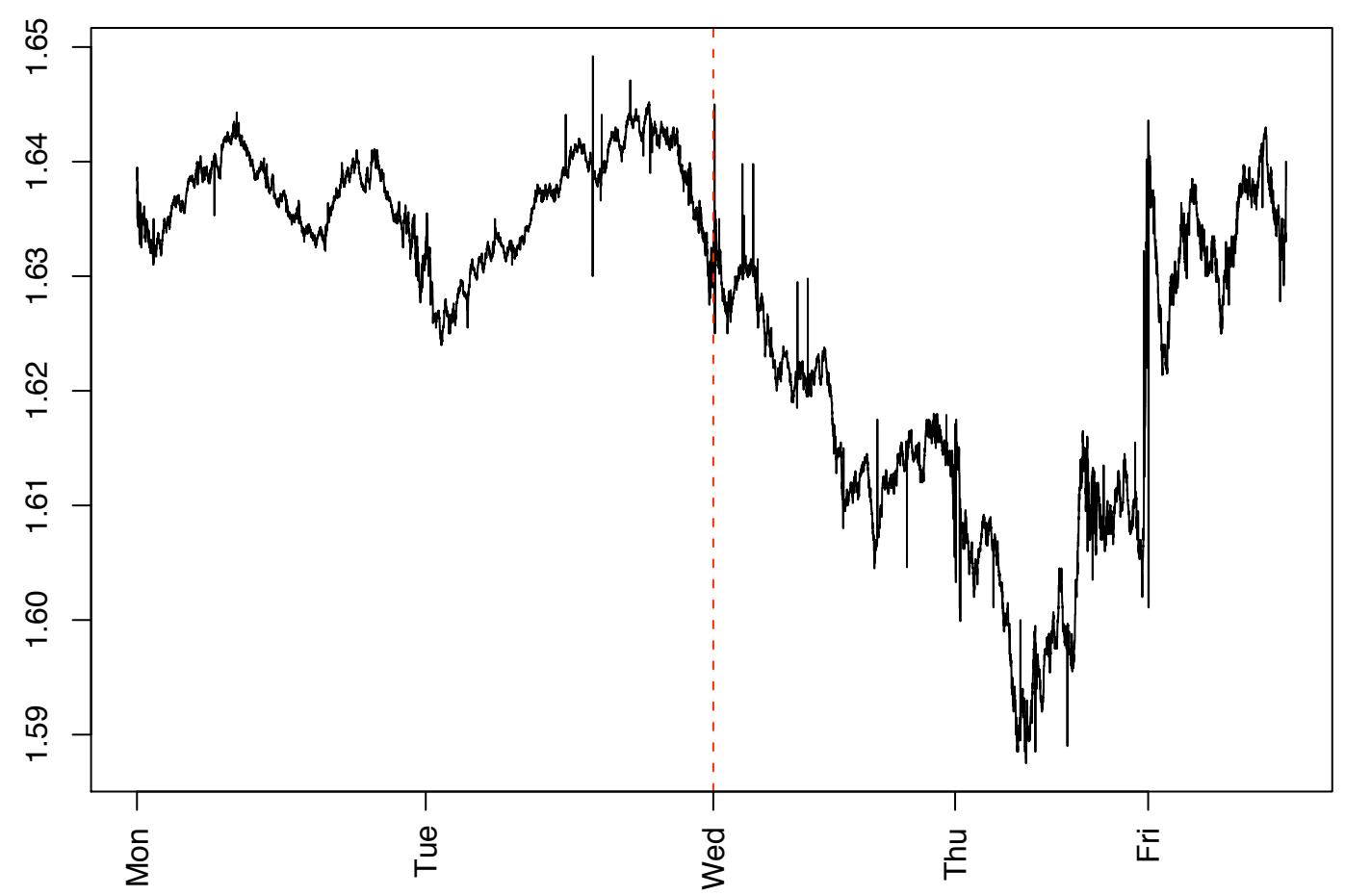

Figure 2: Tick-by-tick USD/DM exchange rate time series from 5.10.1998 to 9.10.1998. The in-sample period Monday - Tuesday, the out-of-sample period Wednesday - Friday.

both in terms of directional accuracy (DA) and economic value or excess predictability (EP) (see Anatolyev and Gerko (2005)). While a DA test like that proposed by Pesaran and Timmermann (see Pesaran and Timmermann (1992), Pesaran and Timmermann (1994)) will be significant in this case an EP statistic will not, hence we need to employ both. We briefly describe the DA and EP tests we have employed in Appendix.

In addition since our data is irregularly spaced and dependent we need to clarify exactly how we have implemented White's Reality Check for Data Snooping. Data snooping involves the re-use of the same sample data in multiple hypothesis testing and not recognising the impact that prior decisions in the testing sequence have on the significance levels to be used at any stage subsequently down the chain. Our GP approach in fact carries out a simple machine search that involves no explicit inference and we also employ out of sample data to examine predictability but never the less the potential for data snooping still exists with the use of genetic algorithms and so we need to take the issue seriously. The correct statistical approach with sequential inference with multiple model selection is to employ Bonferroni Bounds but this would clearly be infeasible in our case with millions of rules to check and so we have no alternative but to employ simulation methods, in fact subsampling as opposed to the stationary bootstrap, to compute the Reality Check. Based on the procedure proposed by White (2000), the Reality Check enables us to calculate true empirical $p$-values of the test statistic based on the null of no predictability beyond the benchmark. The formal framework used for the Reality Check is provided in the Appendix. 
As performance measures for the trading rules we naturally use the fitness functions defined in Section 3. Since the null hypothesis is formulated in terms of ability to beat a benchmark, in the case of testing for directional change we take the natural benchmark as $50 \%$. That is, $\varphi^{1}=D C-50$. For the case of the economic value fitness function we consider a zero return as the benchmark (due to the symmetry present on the foreign exchange market). Thus, $\varphi^{2}=\log (R)$ and $\varphi^{3}=\log \left(R^{\mathrm{TC}}\right)$ for models without and with transaction costs respectively.

Since our data is irregularly spaced and dependent we need to be careful exactly how we have carried out the re-sampling in both the pure price and order book cases.

\section{Pure price information}

The case, where technical indicators are based purely on the historical values of the exchange rate is relatively simple regarding the implementation of the bootstrap. To compute the Reality Check $p$-values, we generate 1000 independent block bootstrap re-samples and construct the empirical distribution consisting of 1000 realizations of $V^{*}$ statistic. In particular, we build a sample of the one-period returns of the exchange rate from moving blocks of random length. The length of each block is geometrically distributed with probability 0.01 (see Politis and Romano (1994))giving a mean block length of 100 transactions. Then the time series of the exchange rate levels is constructed from the sample of bootstrapped returns.

\section{All order book information}

When the trading rules are based on all order book information it becomes more complicated since it is necessary to resample the whole order book. Bootstrapping just the returns time series does not work in this case because the price levels are directly connected to their marks such as the best bid and offer levels, liquidity, depth etc and constructing price levels from bootstrapped returns would break this dependency. Hence, we resample the whole order book using fix length (for simplicity) blocks of 200 transactions and then construct returns of the exchange rate from its levels. In doing so we are faced, however, with possible jumps in price levels which would not be present in the original sample. These jumps would have a considerable impact on the cumulative returns and the genetic algorithm would concentrate on predicting the jumps and this fact can cause a bias of the $p$-values. To avoid this inconvenience we shift blocks of prices and bid and offer levels (the other order book information remains untouched) in such a way that the first price value of a new block coincides with the last price value of the previous block. This implies that since the number of observations is $n=18065$ and the selected block length is equal to 200, we have manually set approximately 90 return values to be equal to 0 . In the original data among 18065 observations, there 
are about 5000 observations with zero return. As specified in Section 2), the investor does not trade until the exchange rate level goes out of the $k$-band. Therefore, we claim that this procedure will have little impact on our results but does enable us to bootstrap irregularly spaced dependent data from an order book.

For both pure price information and all order book information cases, the in-sample period has the same number of observations as the original - 9046 .

Comparing our use of the Reality Check to the existing literature examining profitability of technical rules (for instance Sullivan, Timmermann and White (1999), Hsu and Kuan (2006)) we would claim that the use of the genetic algorithm should provide a much more reliable procedure than employing a fixed universe of technical rules. Indeed, the data-snooping analysis strongly depends on the particular set of possible alternative trading rules which could be used by the investor. Sullivan et al. (1999) consider 7,846 technical indicators while Hsu and Kuan (2006) expand this set up to 39,832 trading rules. However, the genetic programming technique allows us to consider many more strategies depending on the initial parameters of the algorithm (the number of repeats, initial population size, rules' depth, etc). On the one hand, it is impossible to calculate performance for all possible rules. At the same time, however, the Reality Check requires only the maximum of the difference in performance of the real and bootstrapped data. Hence, by setting the maximum of this difference as a fitness function of the algorithm we can simply generate an empirical distribution for the evaluating the $p$-values using the GP procedure. Plots of this distribution are presented below.

\section{Results}

Our aim is to find among the set of all trading rules those which have the best performance in the sense of predicting both correct directional change of the exchange rate and of economic value. We also consider the market with and without transaction costs. In addition we explore the uncertainty market timing issue by incorporating 5 levels of the inertia parameter $k$ representing the investor's attitude to the uncertainty. We employ 3 different fitness functions and two different information sets - past price information and then order book information plus past prices. This immediately shows we have too many different cases to sensibly consider in detail so we will limit our discussion to drawing out several particular results 6

Using the genetic algorithm described in Section 3 we search for the best 20 rules in the sense of the percentage of correct directional predictions. We also report the average of the best 20 rules since this may provide both a more robust measure of performance

\footnotetext{
${ }^{6}$ The full set of results can be obtained from the authors on request.
} 
and more closely reflect how traders use technical rules. In order to produce 20 rules the algorithm needed to be run approximately 25 times in each case since optimal rules that were found were not included twice in order to provide the 20 presented in the tables below. This indicates in the same manner the degree to which the algorithm has actually found the global optimum. Tables 1 - 5 report the performance of the best trading rules, their in-sample and out-of-sample percentage of correct directional predictions (columns 1 and 2) as well as their economic value (cumulative returns adjusted to a daily basis) with and without transaction costs (proportional with the rate $\theta=0.0001$ ) (columns 3 and 4 ) for the five different values of inertia parameter $k$. The heading of each table indicates which fitness function has been used. Columns 5 and 6 report the results of the Pesaran-Timmermann (PT) test, columns 7 and 8 the Anatolyev-Gerko (AG) test and column 9 reports the p value corresponding to White's reality check. The fitness function determines the performance criterion for the RC. A $p$ value below 0.05 indicates rejection of null (at $95 \%$ of confidence) that there is no predictability or profitability in each case. Tables $6-10$ contain the same information about the best 20 rules based both on all order book information and past price information 7 .

If we analyze the tables we can see taking Table 1 as an example that the fitness function used to select the optimal rules was directional change. The PT test (columns 5) clearly shows directional predictability as we reject the null of no predictability for all 20 rules at the $95 \%$ of confidence level including the best performing rule shown in row 1 and the average of all the rules shown in row 21. White's Reality check confirms this as shown by the last column. There is no economic profitability under transactions costs but that is not surprising since the rules were not selected on that basis. As $k$ increases through the following tables then if we look at table 3 when $k=0.001$, this means that a price change has to move the third decimal point in the exchange rate to allow the trader to trade. Now we find clear predictability both in terms of sign and profitability for both the maximum rule and the average again supported by RC even though the fitness function for selected rules is directional change. The average returns for the max rule in this case with transaction costs are $7.37 \%$ on a daily basis. As $k$ increases further, the number of transactions that are allowed can become very small (5239 for $k=0,1494$ for $k=0.0005,738$ for $k=0.001,116$ for $k=0.005$ and 46 for $k=0.01$ in our case) and the reliability of the inference for all tests becomes questionable. When $k=0$ then the trader is allowed to trade at every instant which is not sensible and in this case it is not surprising that we can find no profitability from Table 1 (column 4) under transactions costs.

Tables 6- 10 show the results from the same design with directional change as the

\footnotetext{
${ }^{7}$ As an in-sample period (search period) we use the data for Monday and Tuesday. In order to test the out-of-sample performances of the rules we consider the period from Wednesday.
} 
fitness function but including the order book information in that available to the GA. Table 6 may be compared with Table 1. The results are generally worse and this result is reflected throughout the remaining exercises. Adding the order book information seems to create less reliability and stability in the results. We discuss possible reasons for this below once we have considered all the results.

We also repeat the same analysis with Economic Value as the fitness criterion for rule selection with and without transaction costs. In this case we can see from Table 11 (without transaction costs, $k=0.001$ ) that the AG test indicates economic profitability which is supported by White's RC and the third column shows the daily returns that could be achieved by the max rule $(4.484 \%)$ and by the average of all the rules $(2.19 \%)$. In Table 12 we can see significant profitability with $k=0.005$ using order book information which is supported by all the tests of $(4.418 \%)$ with the max rule and $(1.299 \%)$ under transactions cost - once again values that are lower than under the information set that just included prices.

It is in general difficult to beat the zero return benchmark (as well as buy and hold strategy ${ }^{8}$ when we select rules on the basis of transactions costs since buy and hold incurs transactions costs twice. However Table 13 which introduces transaction costs, with $k=0.005$ shows significant profitability which is supported by the AG test for the max and average rules of roughly $4 \%$ a day with the RC significance levels around $7.5 \%$ and $8.95 \%$.

Throughout all of these tables it is critical to notice the importance of the inertia parameter. It seems that either values of $k=0.001$ or $k=0.005$ deliver the best results fairly consistently. Table 14 collects this information together and shows the results for all fitness functions for the average rules at different values of $k$. This table together with Table 15 provides the critical summary of our results regarding market timing and inertia as captured here in the $k$ parameter. Again if we track along the $k=0.005$ line we will generally find clear directional predictability and profitability. The same holds for Table 15 which collects the same information together for the maximum rule. The same tables showing results for including order book information again indicate the slight reduction in performance that we find from including the structure of the order book in the informational set.

Table 16 and the following distributional plots indicate the probability of losing money, $\Omega$ being the ratio of probability above the break even point to that below it. This measure has been put forward as a general portfolio performance criterion superceeding the Sharpe Ratio by Keating and Shadwick (2002). This is shown quite clearly in the figures that then follow for each case.

\footnotetext{
${ }^{8}$ We have also computed all the simulations using buy and hold as the benchmark and there is little difference between these results and the zero benchmark reported in the tables. Again full results can be provided by the authors on request.
} 
In Table 17 we provide the results for the out of sample performance of several standard technical indicators for different values of $k$ and it is clear their performance is weak in comparison.

Finally maybe one of the most important issues is how to apply the methodology described in this paper in practice. How to recognise, based on the in-sample performance, which of the 20 selected (best) rules will be profitable out-of-sample? One possibility is to take the rule with the maximum in-sample return, which however may not be optimal in many cases, and a more robust and stable choice is the average rule we have described above. This approach also has the disadvantage that it tries to make a prediction for the whole out-of-sample period at once. Perhaps more consistent with reality we have also considered the performance of only one step ahead predictions using a recursive procedure. Once we have got the in-sample dataset we run the GA to find the rule with the best in-sample performance and apply this rule to make a decision for the next period of time. After making the transaction we observe next period's price and update our information set using a rolling window procedure. Based on the updated in-sample dataset we repeat the GA in order to find the trading indicator for the next period and so on.

As an illustrative example consider the use of this recursive strategy with the economic value fitness function without transaction costs. The uncertainty bound is determined by the parameter $k=0.005$ (this choice looks reasonable from the results reported above). The initial in-sample is considered to be Monday-Tuesday and we roll the in-sample window up to the last observation of Friday.

Since the GA is unable to find the global maximum of the fitness function and only approximate it to some extent, the results of the recursive procedure imply different trading rules for every separate recursive run through the data (even for the same dataset). Thus, the final return of the recursive procedure is a random variable because of the random mechanism built in the GA. Therefore, in order to get a more realistic picture of the recursive trading rule we provide 100 independent runs through the dataset for both pure price and all order book information strategies. The average daily return for the pure price information model is $\mu=6.885 \%$ and its standard deviation is $\sigma=1.799$. The respective average and standard deviation from using the order book information are $\mu=3.813 \%$ and $\sigma=2.131$. In the first case the hypothesis $H_{0}: \mu \leq 0$ is rejected with $95 \%$ of confidence while for the second case it is rejected only at $90 \%$ confidence level.

This reflects the same surprising result we found above with the static implementation of the method (that the performance of the strategy which exploits the order book information performs less well than that with just pure price information). Apart from the explanation that the market price acts as a sufficient statistic and so there is no need to use the structure of the order book it may also be that to predict future 
prices the order book contains non-informative or redundant variables which have any little or no predictive power. We can see from the tables that the in-sample performance is usually better for the order book strategies and this seems to suggest that the GA has more to work on when constructing a "good" trading rule. However, its ability to forecast in-sample prices refers more to capturing the characteristics of a particular dataset rather then to its out of sample predictability 9 . Moreover, even for the in-sample period this ability does not appear to be very efficient as the implied trading rules look quite complicated and sophisticated unlike the best pure price rules which can often be very simple indeed. This may suggest the order book rules would not be robust. These sophisticated order book rules are in fact less stable during the genetic selection process because any small mutation can easily "kill" the rule. The probability that a simple rule will mutate is smaller as it is less sensitive and therefore they are more stable. The GA can at least keep their performance as a benchmark for genetic selection for a longer time. Complicated rules are destroyed more frequently and the GA has to re-start with building well performing trading rules from the very beginning. Hence, this process takes more time and machine resources and so is less likely to converge towards the optimum. In order to filter out useless variables by the GA, we would need to increase number of repetitions of the GA substantially and, probably, the population size.

Thus, there are two different ways as to how to use the order book information efficiently. The first is a machine based method - increase computer power, number of repetitions, computing time and the population size. The second is a human based method - very carefully select the variables which need to be included in the information set for the algorithm. Our analysis does show that the order book information does have some predictive power but it is not very efficient probably because of the unclear signals regarding predictability. Alternatively economic theory may have been shown to be correct and the market clearing price is in fact a sufficient statistic.

\section{Conclusions}

This paper has examined the predictability of exchange rates on a transaction level basis using both past transaction prices and the structure of the order book. Formal tests for the ability of genetically derived trading rules, that may be likened to technical rules, are applied to one week of tick-by-tick data on the USD-DM exchange rate drawn from Reuters DM2002 electronic trading system. The Pesaran-Timmermann test shows clear ability to predict directional changes in the exchange rate and the economic value of predictability taking account of transaction costs is shown to be sig-

\footnotetext{
${ }^{9} \mathrm{~A}$ similar problem affects the naive use of Neural Networks.
} 
nificant out-of-sample using the Anatolyev-Gerko test. These conclusions rest critically however on the market timing decisions and the implied frequency of trades which are controlled by what we refer to as an inertia or uncertainty parameter which follows from the Bewley's preferences for decision-making under uncertainty. Some inertia in trading is critical to recover profitability. If the trading system is allowed to trade at every instant it clearly fails to show profitability but when trades are made only when prices changes are of a sufficient magnitude then significant profitability appears under transaction costs. These conclusions are confirmed using White's Reality Check. Somewhat surprisingly we do not find strong evidence that exploiting the order book structure aids predictability.

\section{References}

Abhyankar, A., Sarno, L. and Valente, G.: 2005, Exchange rate and fundamentals: Evidence on the economic value of predictability, Journal of International Economics 66, 325-348.

Allen, F. and Karjalainen, R.: 1999, Using genetic algorithms to find technical trading rules, Journal of Financial Economics 51(2), 245-271.

Anatolyev, S. and Gerko, A.: 2005, A trading approach to testing for predictability, Journal of Business \&f Economic Statistics Vol. 23, Iss. 4; 455-462.

Arifovic, J.: 1994, Genetic algorithm learning and the cobweb model, Journal of Economic Dynamics and Control 18, 3-28.

Arifovic, J.: 1995, Genetic algorithms and inflationary economies, Journal of Monetary Economics 36(219-243).

Arifovic, J.: 1996, The behavior of the exchange rate in the genetic algorithm and experimental economies, Journal of Political Economy 104, 510-541.

Arifovic, J.: 1997, Strategic uncertainty and the genetic algorithm adaptation, in H. Amman and et al (eds), Computational Approaches to Economic Problems, Boston: Kluwer Academic Press.

Bewley, T.: 1986, Knightian decision theory: Part I, Cowles Foundation Discussion Paper No 807 .

Bewley, T.: 2002, Knightian decision theory: Part I, Decisions in Economics and Finance 25, 79-110. 
Chang, K. and Osler, C.: 1995, Head and shoulders: not just a flaky pattern, Staff Report No 4, Federal Reserve Bank of New York.

Chang, K. and Osler, C.: 1999, Methodological madness: technical analysis and the irrationality of exchange rate forecasts, Economic Journal 109, 636-661.

Chen, S., Duffy, J. and Yeh, C.: 1999, Genetic programming in the coordination game with a chaotic best-responce function, Proceedings of the 1996 Evolutionary Programming Conference, San Diego, CA.

Chen, S. and Yeh, C.: 1997a, On the Coordination and Adaptability of the Large Economy: An Application of Genetic Programming to the Cobweb Model, Advances in Genetic Programming II, Cambridge MA, MIT Press.

Chen, S. and Yeh, C.: 1997b, Toward a computable approach to the efficient market hypothesis: An application of genetic programming, Journal of Economic Dynamics and Control 21, 1043-1063.

Curcio, R., Goodhart, C., Guillaume, D. and Payne, R.: 1997, Do technical trading rules generate profits? Conclusions fron the intra-day foreign exchange market, International Journl of Financial Economics 2, 267-280.

Dempster, M. and Jones, C.: 2001, A real time adaptive trading system using genetic programming, Quantitive Finance 1, 397-413.

Dooley, M. and Shafer, J.: 1976, Analysis of short-run exchange rate bahavior: March 1973 to September 1975, International Finance Discussion Paper (76). Federal Reserve Board.

Dooley, M. and Shafer, J.: 1983, Analysis of Short-Run Exchange Rate Bahavior: March 1973 to November 1981, Exchange Rate and Trade Instabilty: Causes, Consequences and Remedies, Harper Business.

Dow, J. and Werlang, S.: 1992, Uncertainty aversion, risk aversion, and the optimal choice of portfolio, Econometrica 60(1), 197-204.

Dworman, G., Kimbrough, S. and Laing, J.: 1996, On automated discovery of models using genetic programming: Bargaining in a three-agent coalitions game, Journal of Management Information Systems 12, 97-125.

Fama, E. and Blume, M.: 1966, Filter rules and stock market tradings, Jounal of Business 39(1), 226-241.

Ghirardato, P., Maccheroni, F. and Marinacci, M.: 2004, Differentiating ambiguity and ambiguity attitude, Journal of Economic Theory 118, 133-173. 
Henrikson, R. and Merton, R.: 1981, On market timing and investment performance II. Statistical procedures for evaluating forecasting skills, Journal of Business 54, 513-533.

Hsu, P.-H. and Kuan, C.-M.: 2006, Re-examining the profitability of technical analysis with White's Reality Check, Working Paper.

Keating, C. and Shadwick, W.: 2002, A universal performance measure, The Journal of Performance Measurement pp. 59-84.

Klibanoff, P., Marinacci, M. and Mukerji, S.: 2005, A smooth model of decision making under ambiguity, Econometrica 73(6), 18491892.

Knight, F.: 1921, Risk, Uncertainty and Profit, Boston: Houghton Mifflin.

Levich, R. and Thomas, L.: 1993, The significance of technical trading rule profits in the foreign exchange market: a bootsrap approach, Journal of International Finance and Money 12(5), 451-474.

Lui, Y.-H. and Mole, D.: 1996, The use of fundamental and technical analysis by foreign exchange dealers : Hong kong evidence, mimeo City University of Hong Kong .

Lyons, R. K.: 2001, The Microstructure Approach to Exchange Rates, MIT Press: Cambridge, MA.

Meese, R. and Rogoff, K.: 1983, Empirical exchange rate models of the seventies: Do they fit out of sample?, Journal of International Economics 14, 3-24.

Neely, C. and Weller, P.: 2001, Technical analysis and central bank intervantion, Journal of International Money and Finance 20(7), 949-970.

Neely, C. and Weller, P.: 2003, Intraday technical trading in the foreign exchange market, Journal of International Money and Finance 22, 223-237.

Neely, C., Weller, P. and Dittmar, R.: 1997, Is technical analysis in the foreign exchange market profitable?, Journal of Financial and Quantitative Analysis 32(4), 405426.

Osler, C.: 2000, Support for resistance: technical analysis and intraday exchange rates, Federal Reserve Bank of New York Review 6 (2), 53-67.

Osler, C.: 2003, Currency orders and exchange rate dynamics: an explanation for the predictive success of technical analysis, Journal of Finance 58(5), 1791-1820. 
Pesaran, H. and Timmermann, A.: 1992, A simple nonparametric test of predictive performance, Journal of Business \& Economic Statistics 10(4), 461-465.

Pesaran, H. and Timmermann, A.: 1994, A generalization of the non-parametric henriksson-merton test of market timing, Economic Letters 44, 1-7.

Politis, D. and Romano, J.: 1994, Large sample confidence regions based on subsamples with minimum assumptions, The Annals of Statistics 22(4), 2031-2050.

Savin, G., Weller, P. and Zvingelis, J.: 2007, The predictive power of head-andshoulders price patterns in the US stock market, Journal of Financial Econometrics 5(2), 245-265.

Sullivan, R., Timmermann, A. and White, H.: 1999, Data-snooping, technical trading rule performance, and the bootstrap, Journal of Finance 54, 1647-1691.

Sweeney, R.: 1986, Beating the foreign exchange market, Journal of Finance 41(3), 163-182.

Taylor, M. and Allen, H.: 1992, The use of technical analyses in the foreign exchange market, Journal of International Money and Finance 11, 304-314.

White, H.: 2000, A Reality Check for data snooping, Econometrica 68, 1097-1126. 


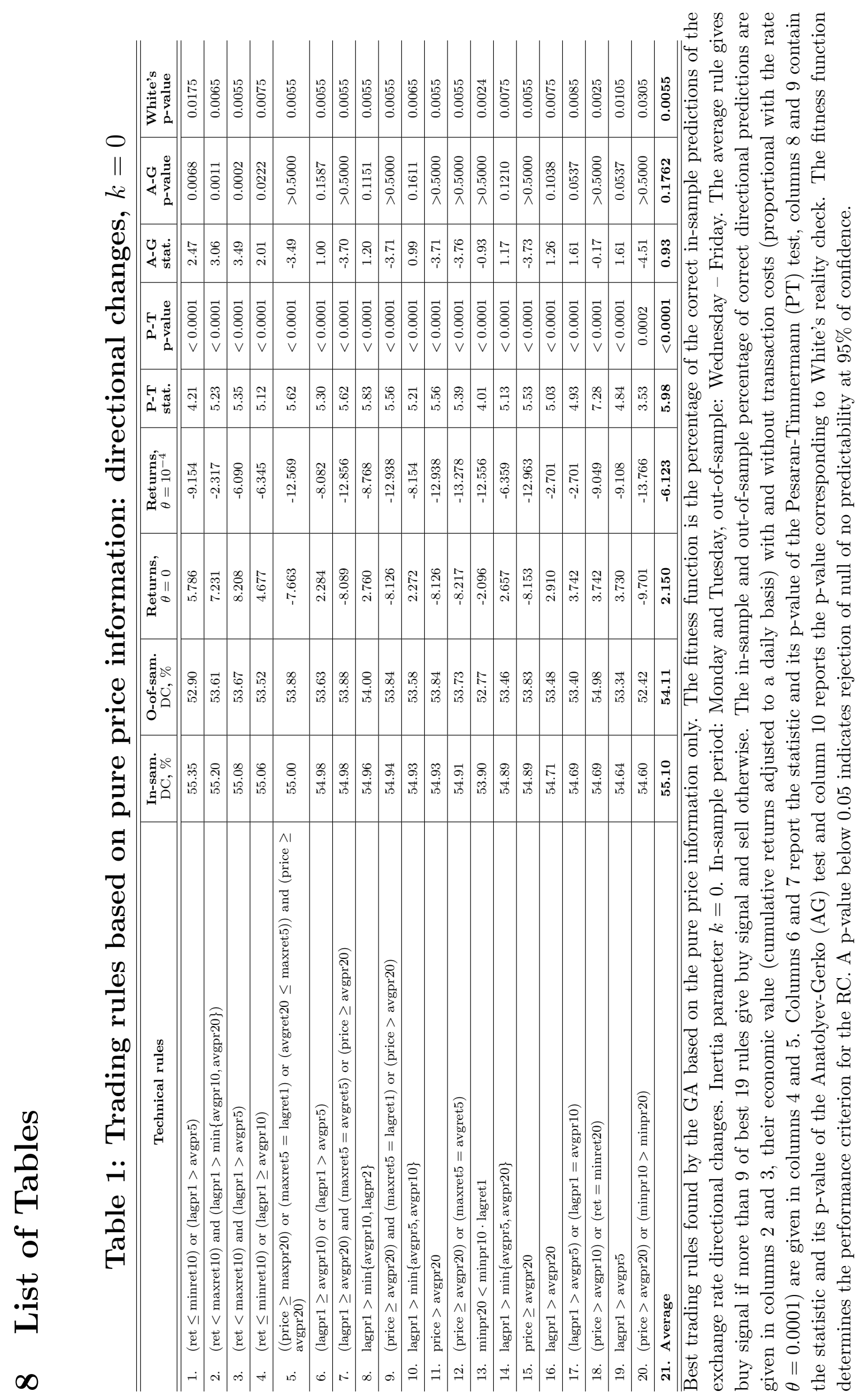




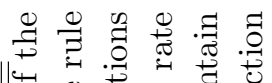

(t)

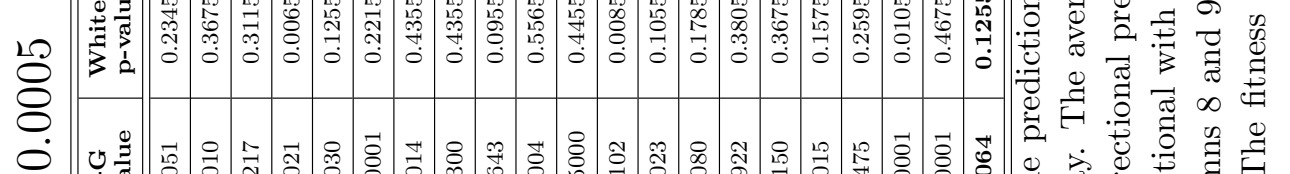
II

$\underset{0}{2}$

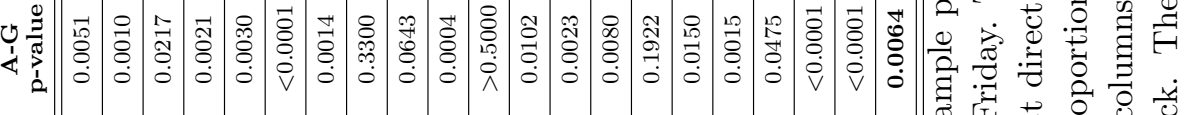

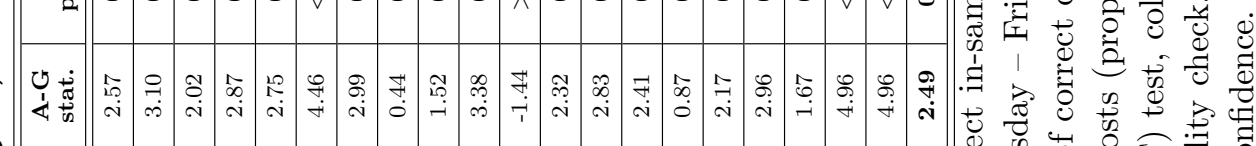

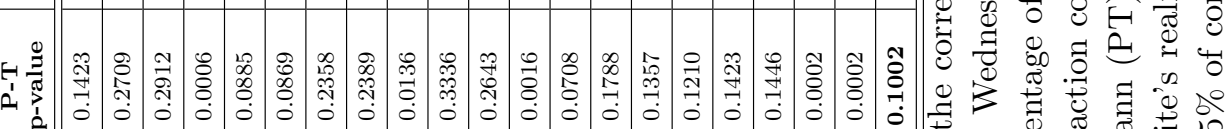

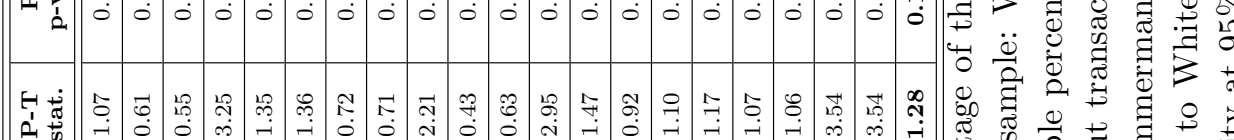

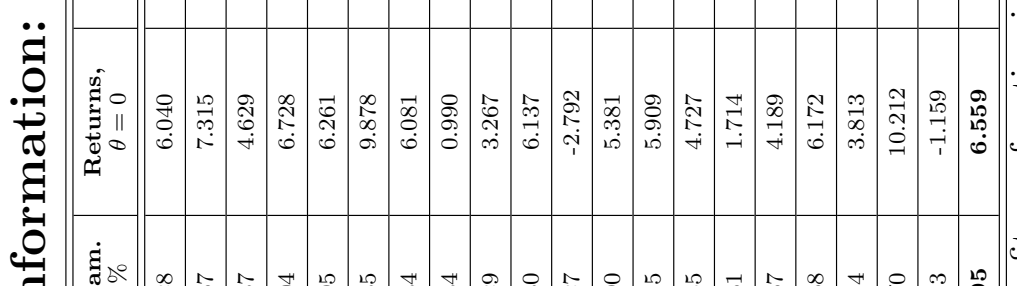

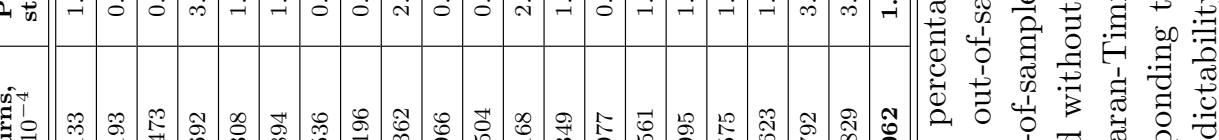

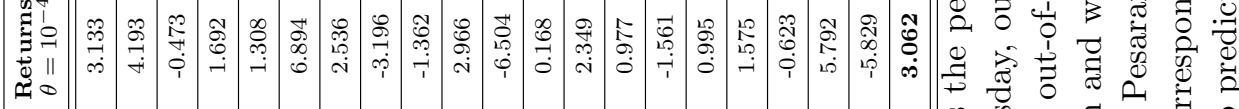

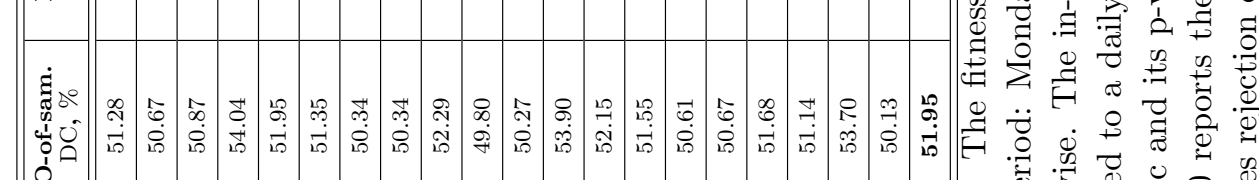
U.

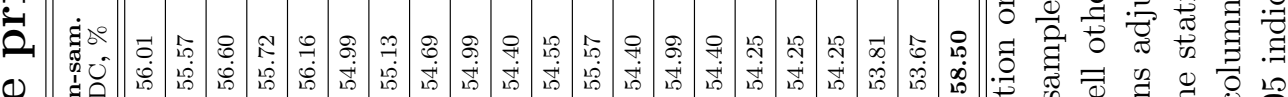

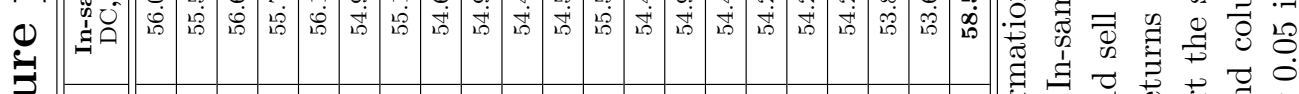

$$
\begin{aligned}
& 3 \\
& 0 \\
& 0 \\
& 0 \\
& 0 \\
& 0 \\
& 0 \\
& 0 \\
& 0
\end{aligned}
$$

రే

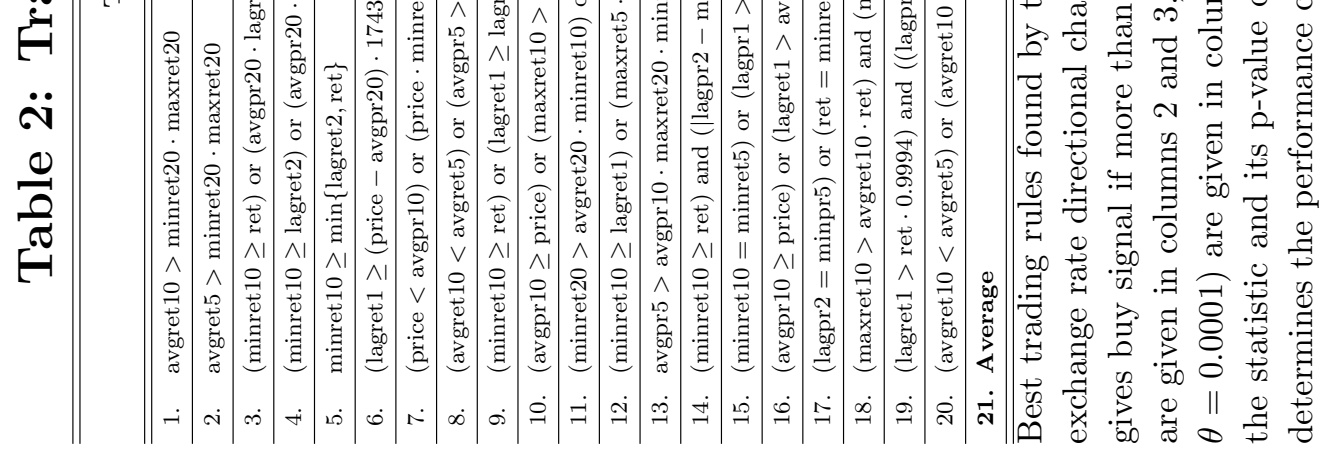




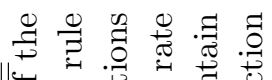

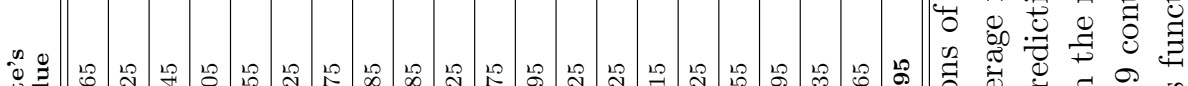

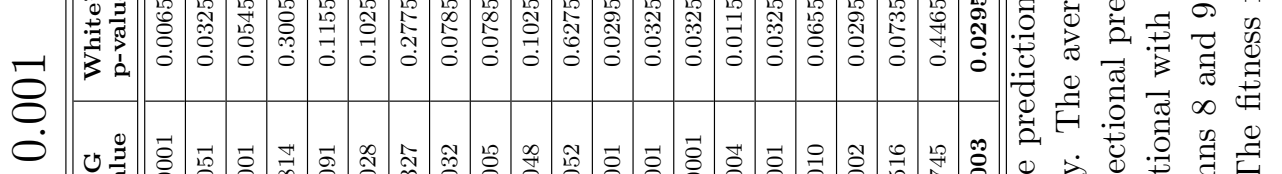

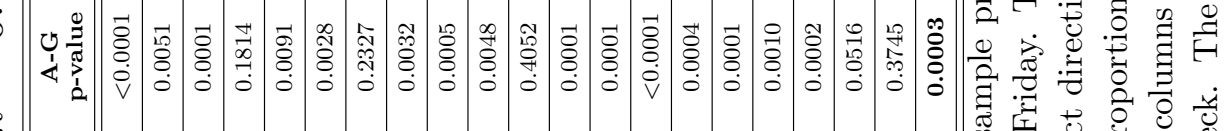

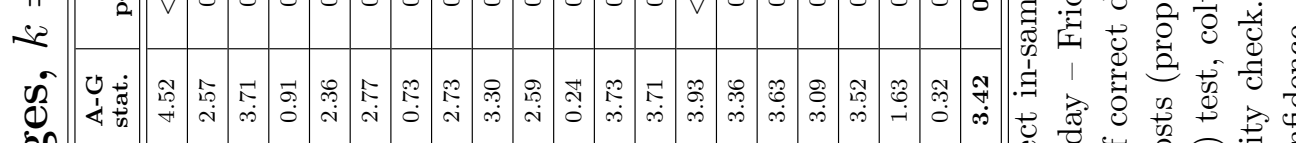

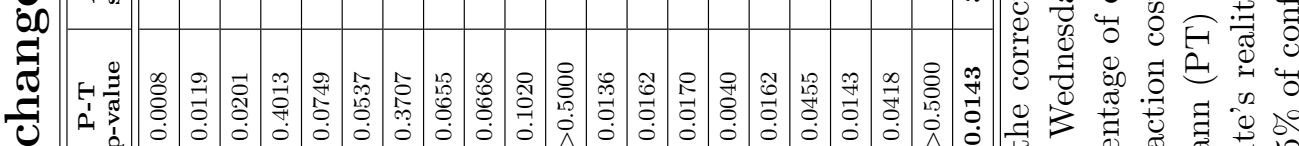

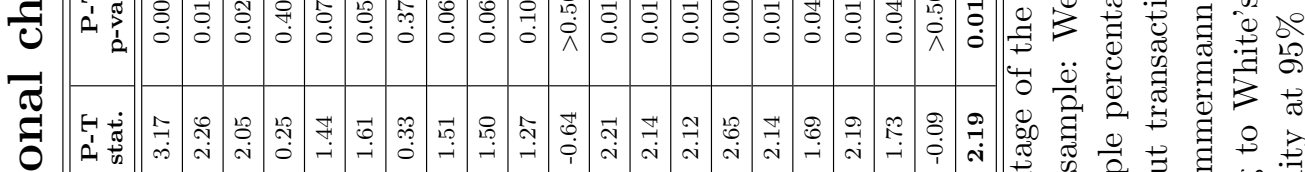

:

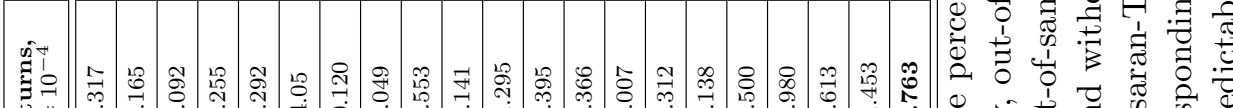

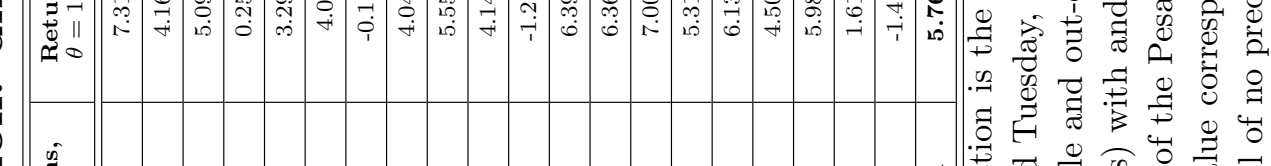

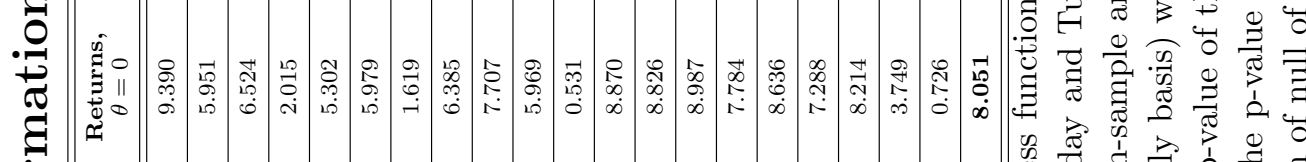

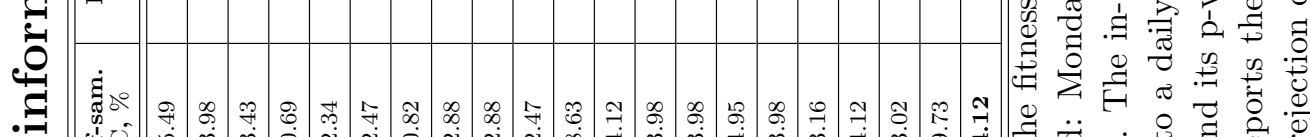

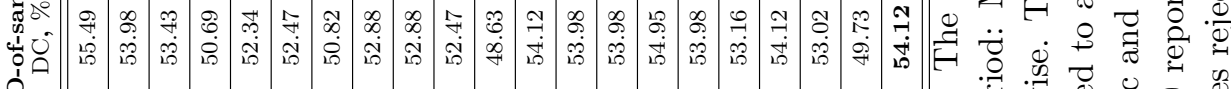

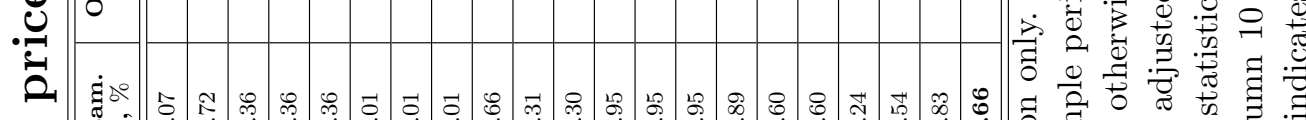

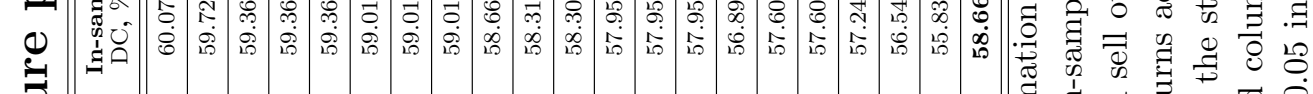

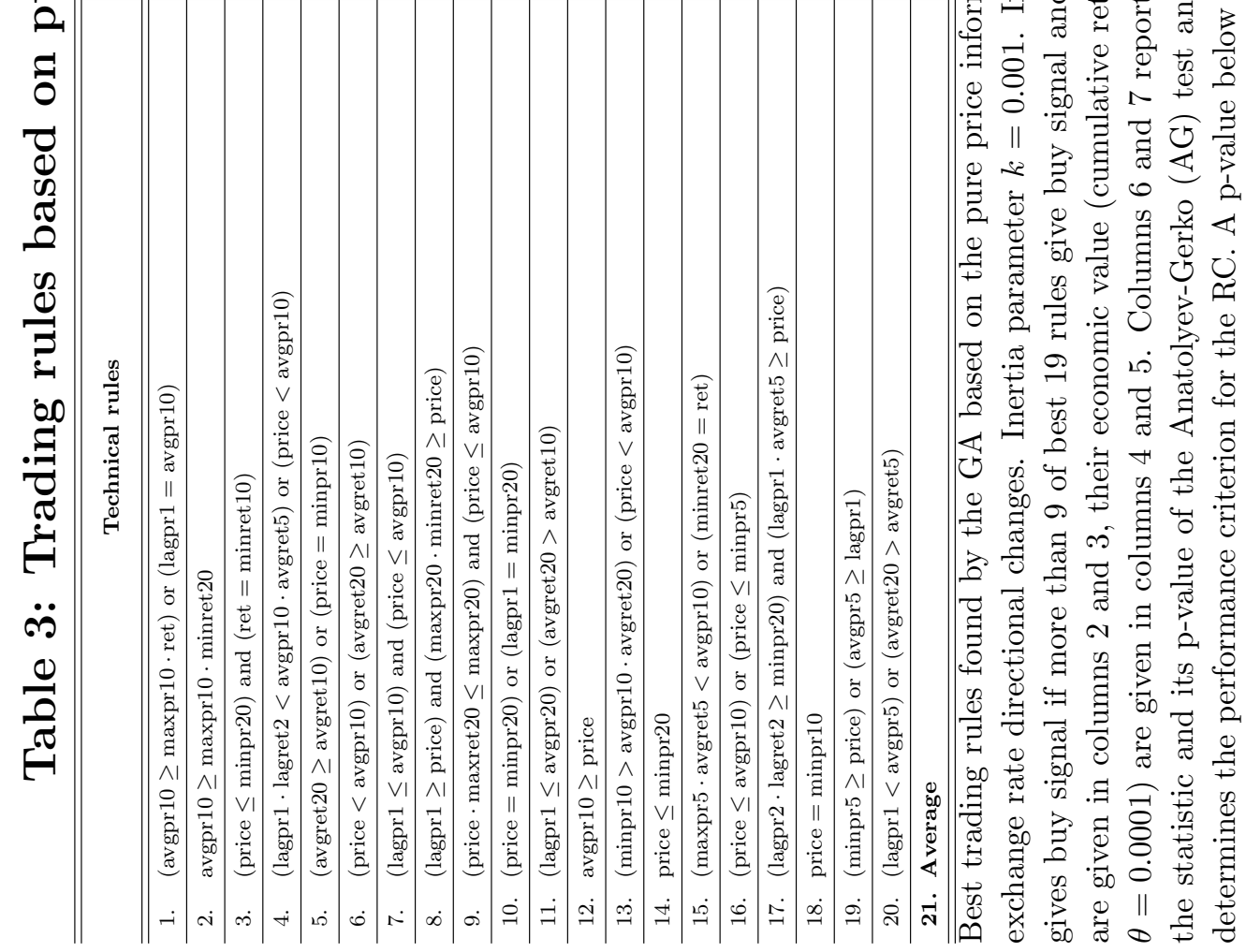




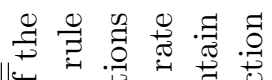

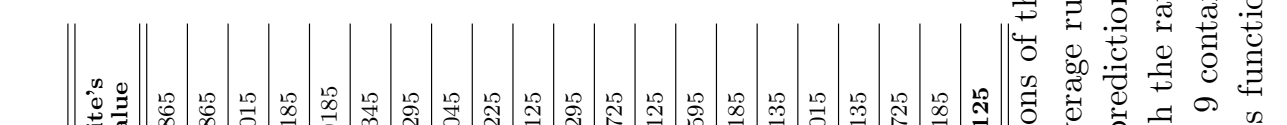

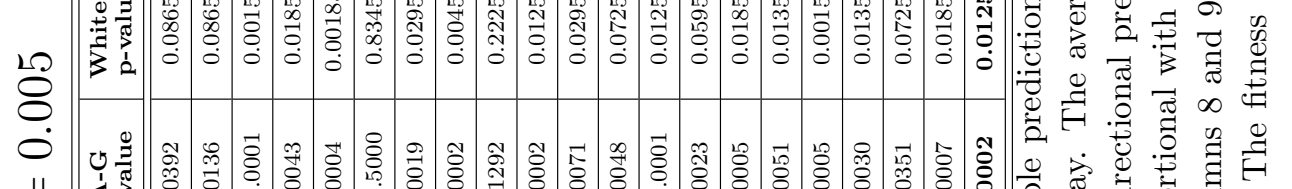
1.

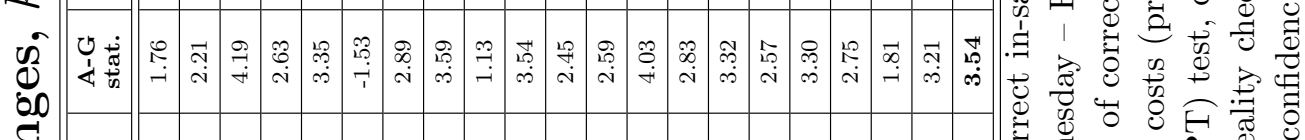

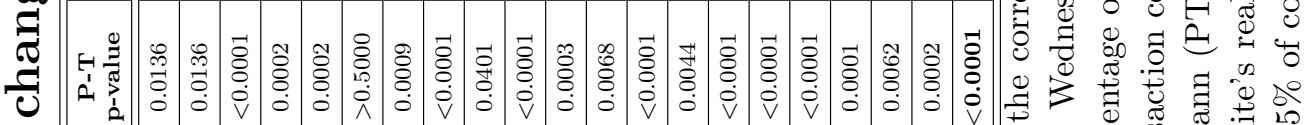

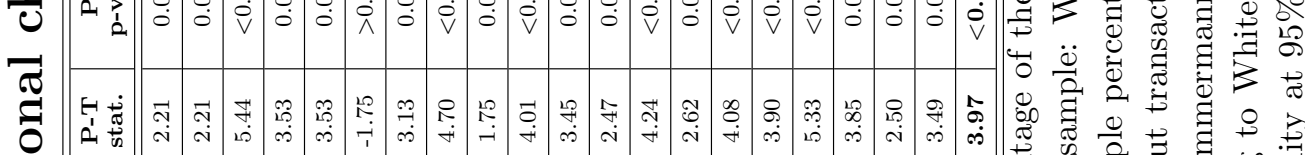

艎

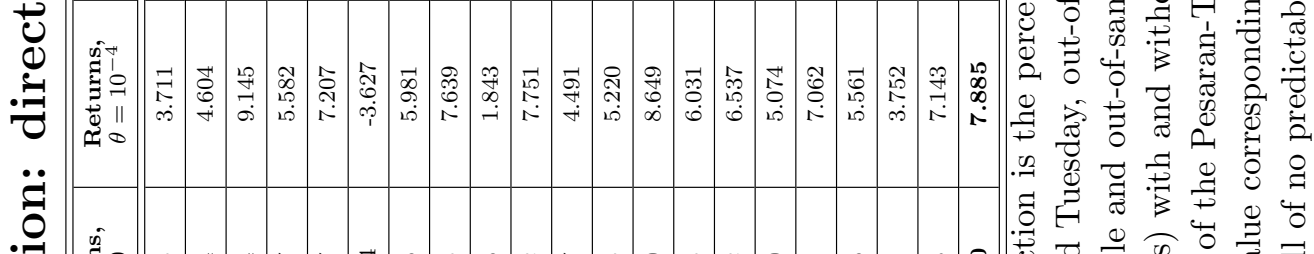

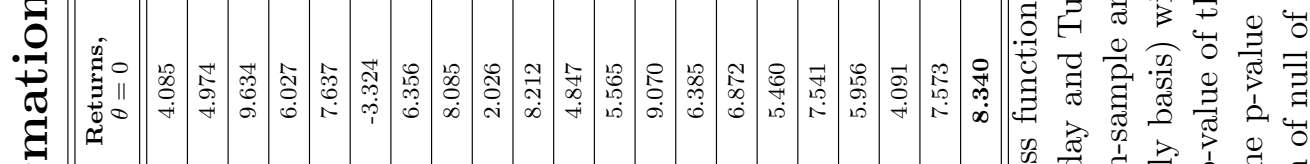

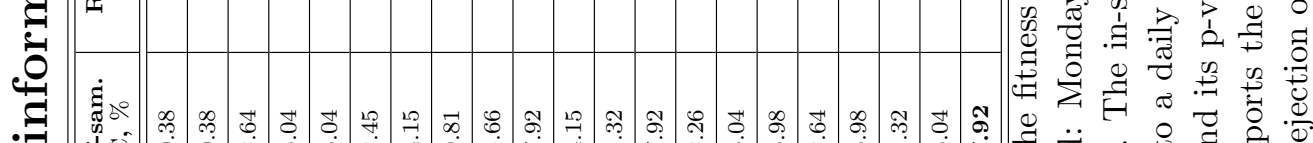

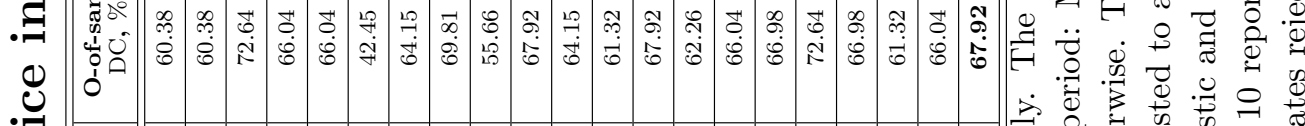

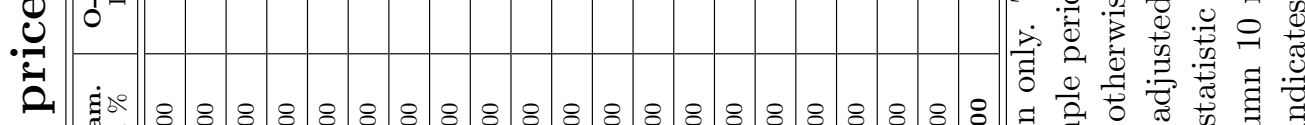

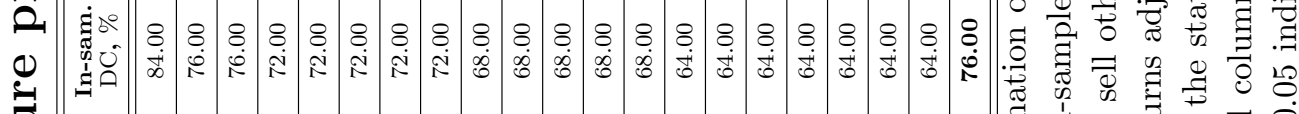

$$
\text { อี }
$$

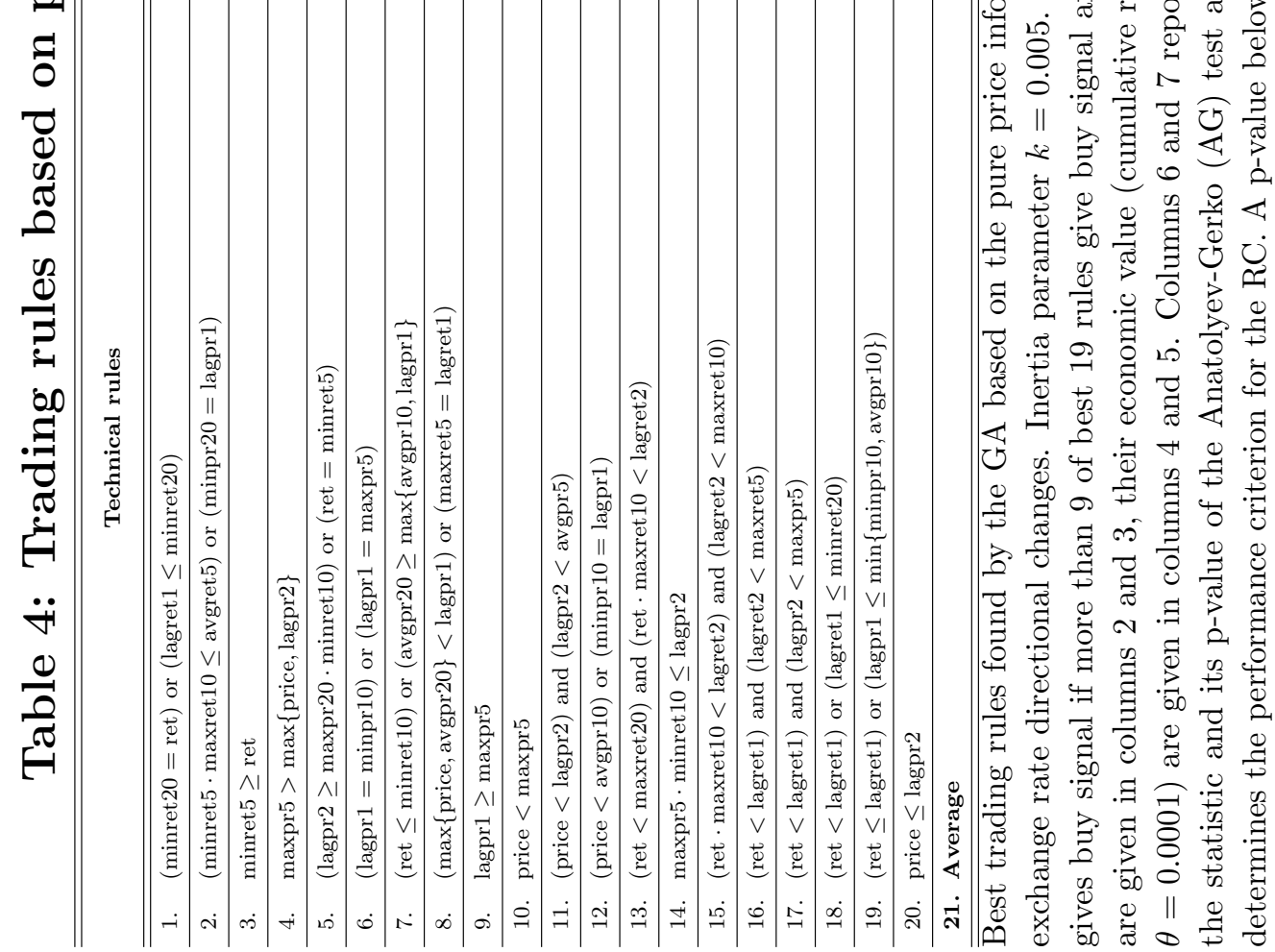




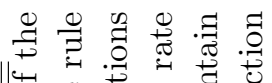

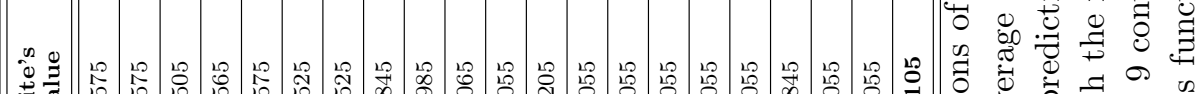

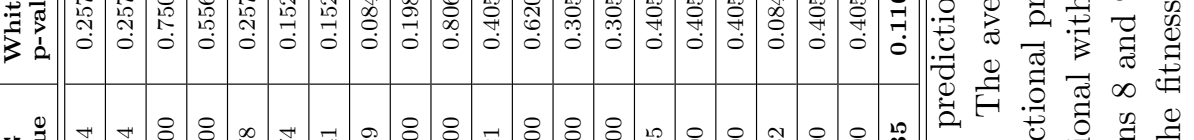

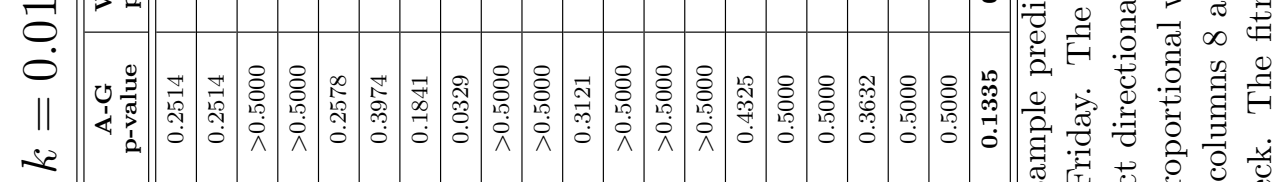

की

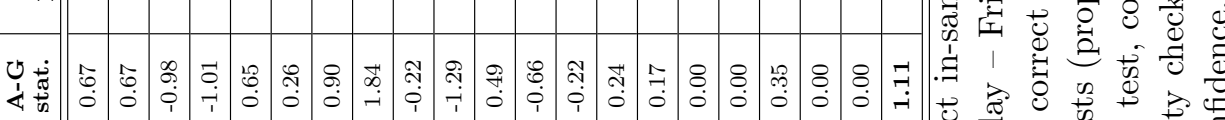

苗 F 每

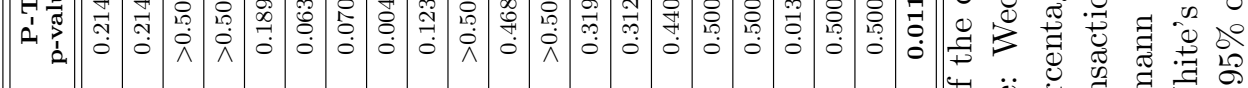

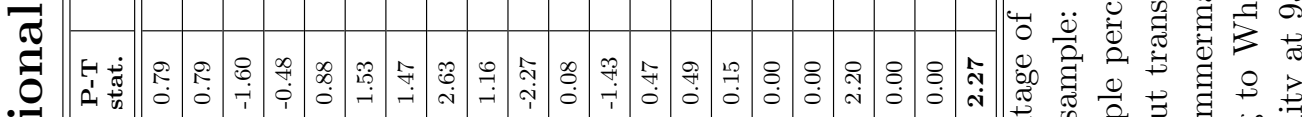

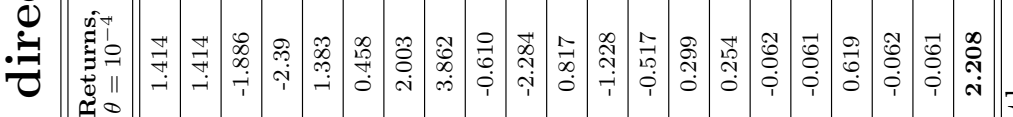

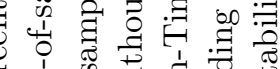
n

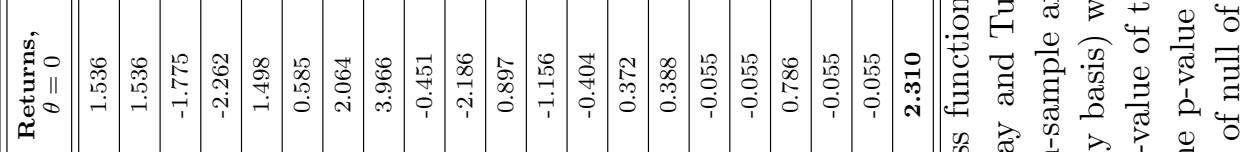

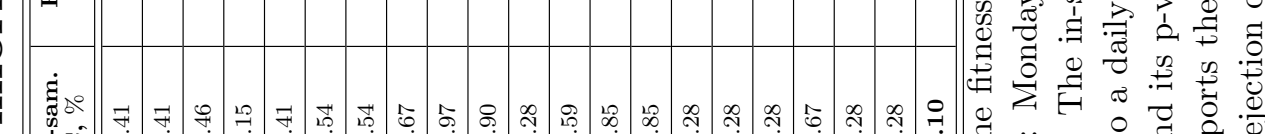

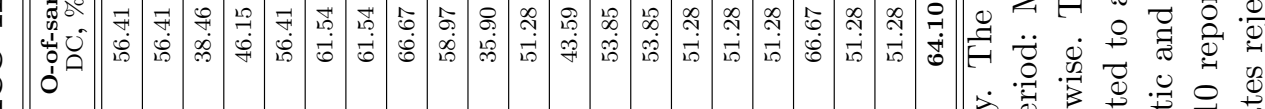

至 0
0

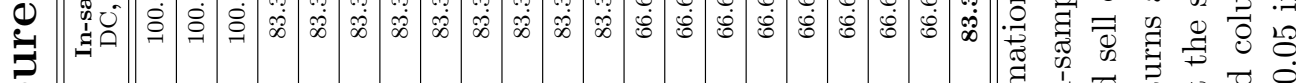

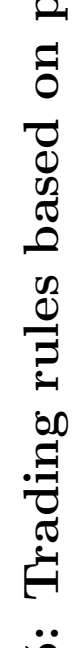

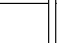

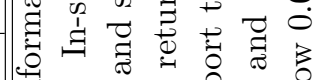
嶑

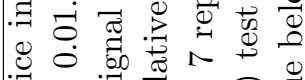

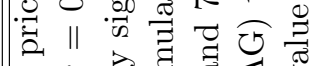

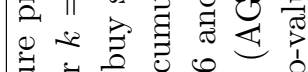

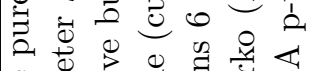

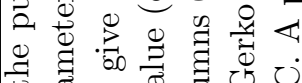

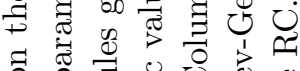
б

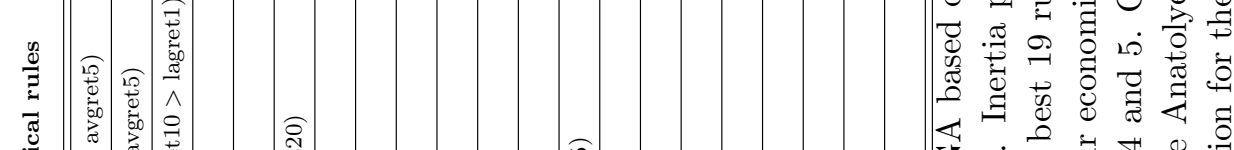

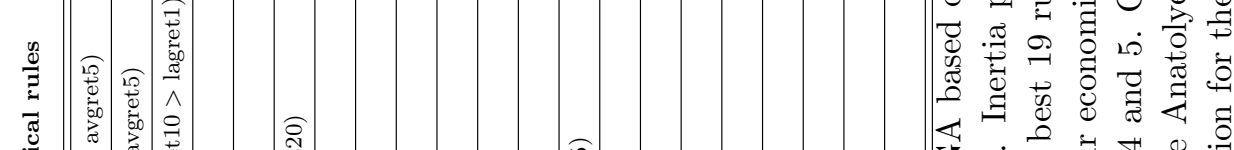

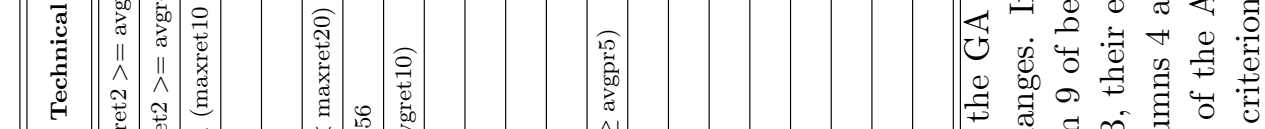

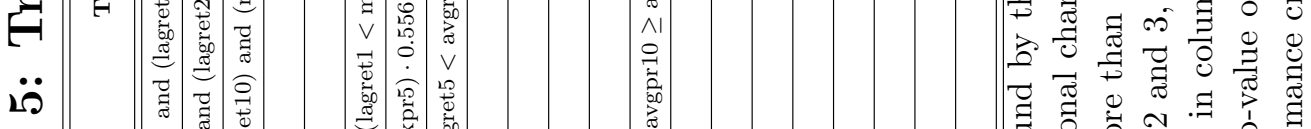

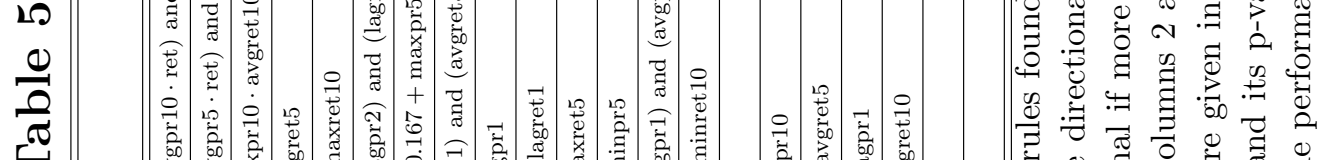

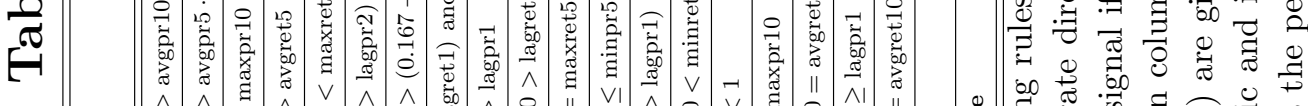

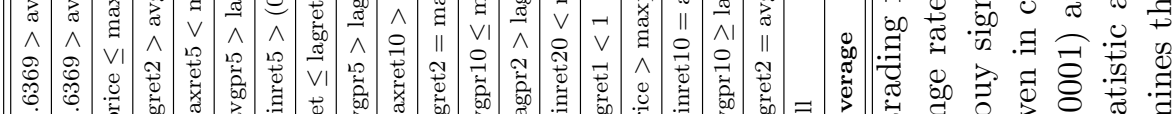

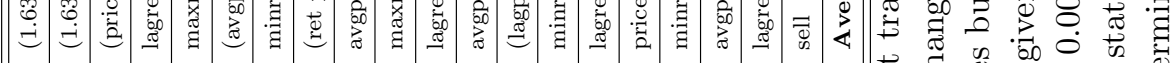

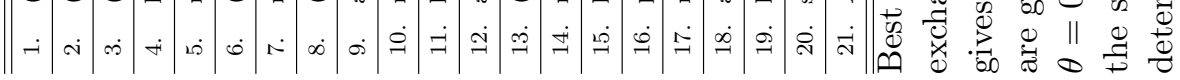




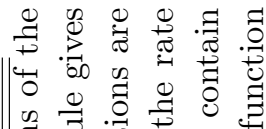

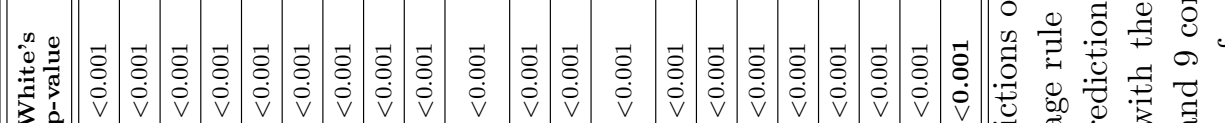

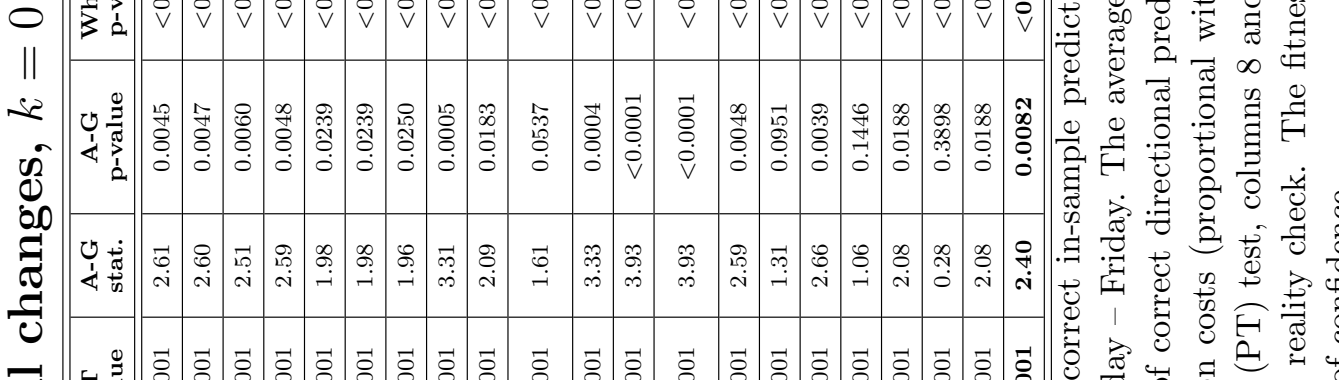

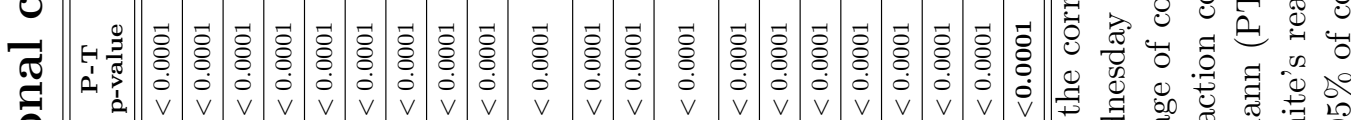

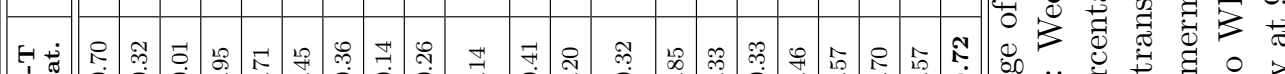

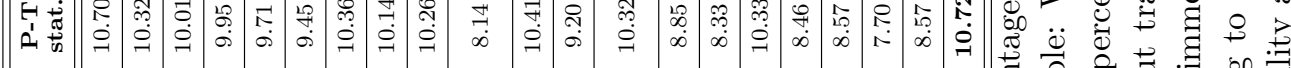

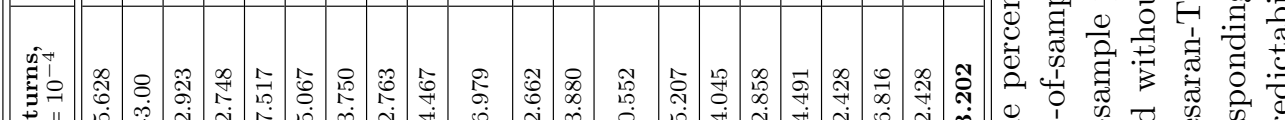

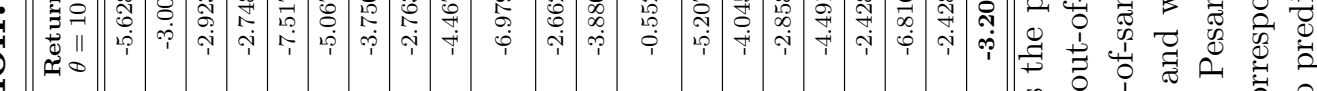

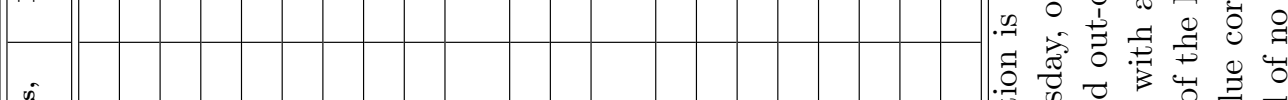

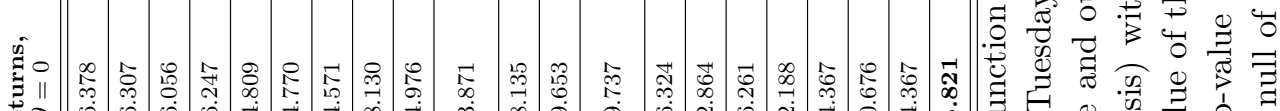

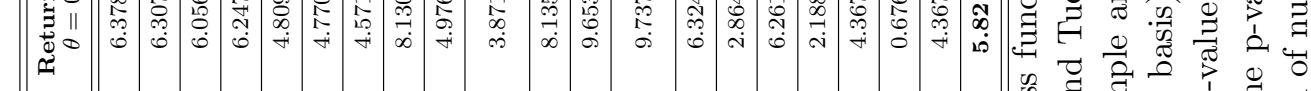

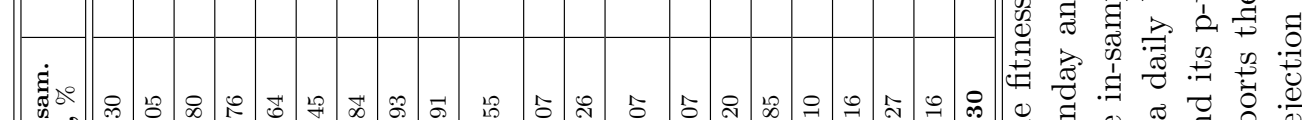

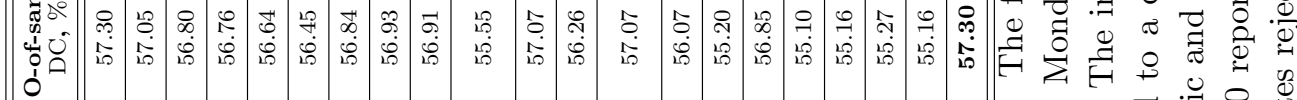

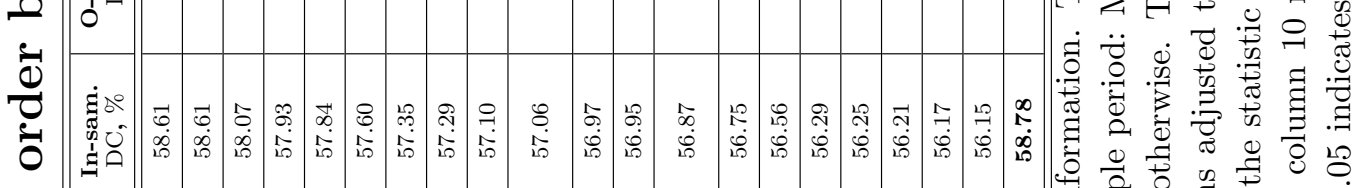

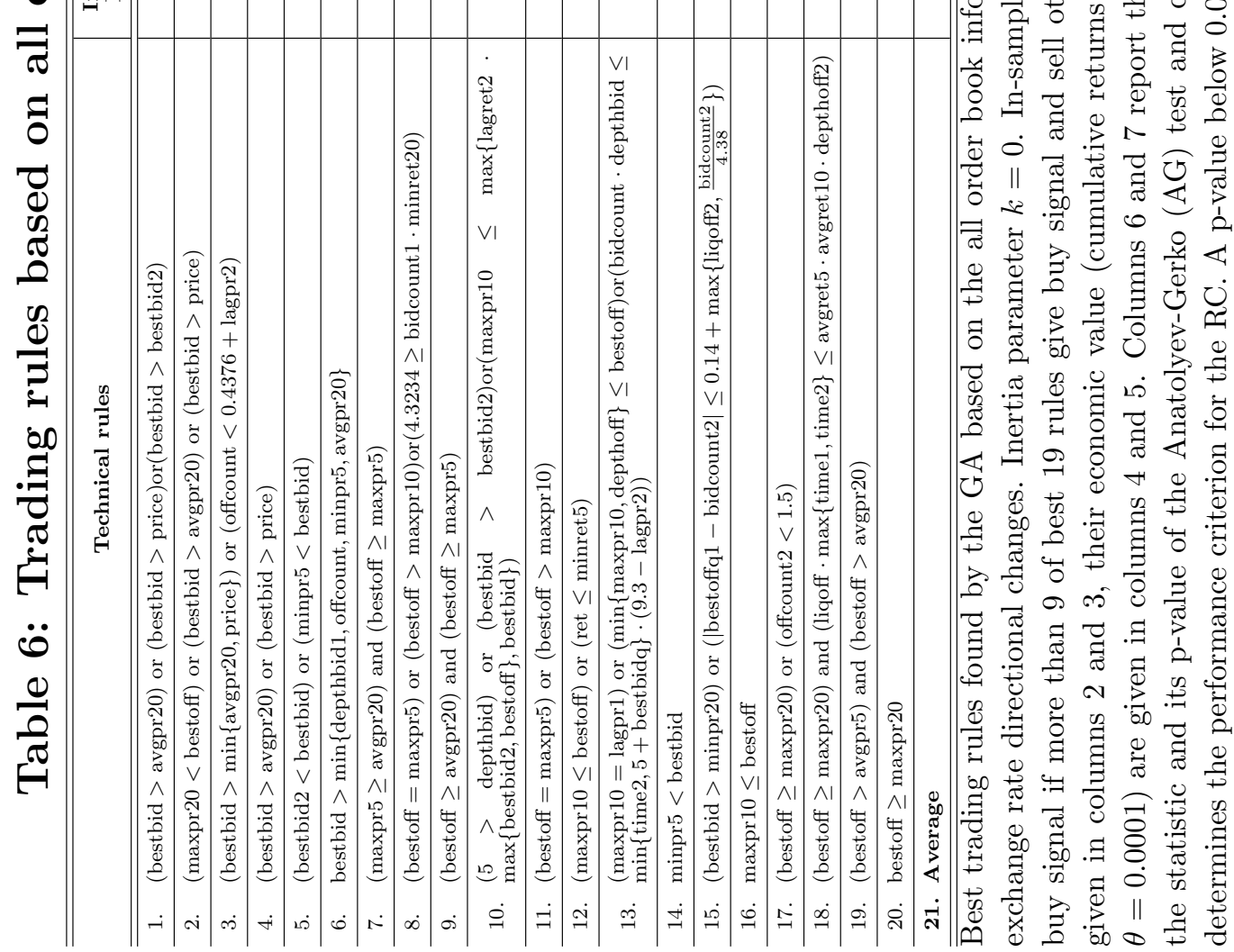




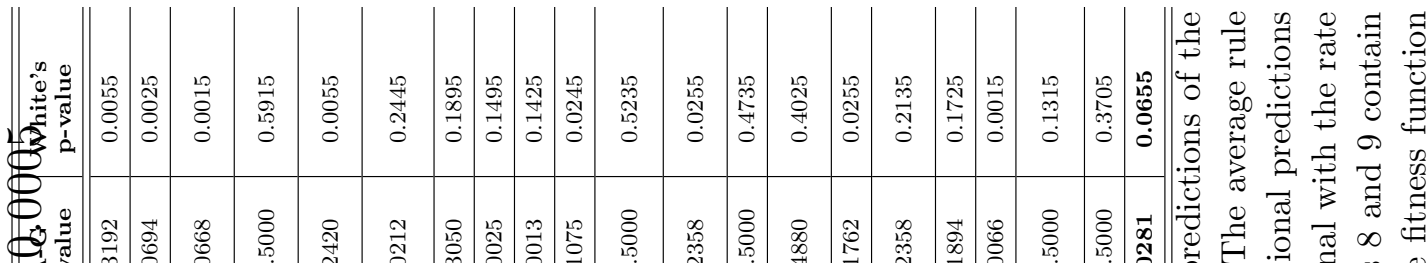

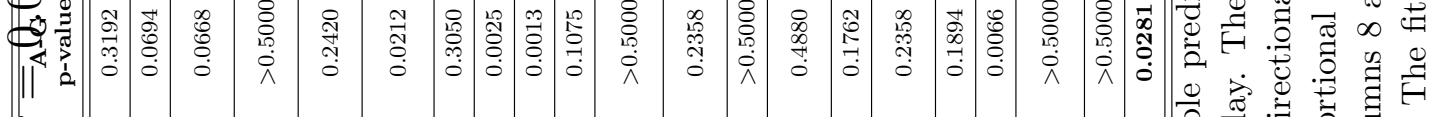

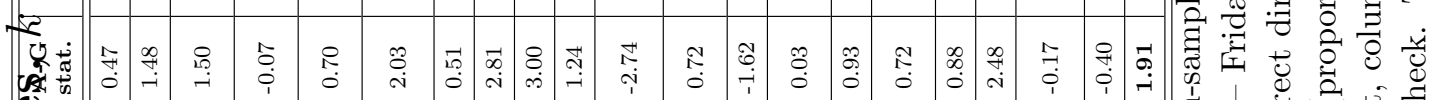

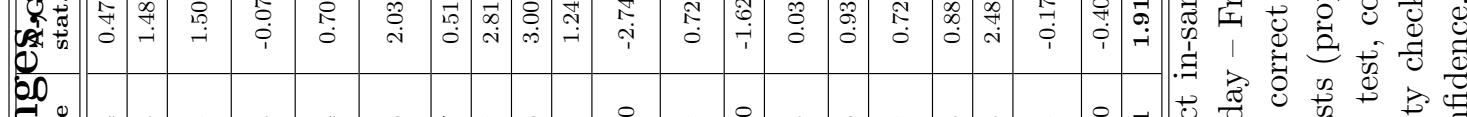

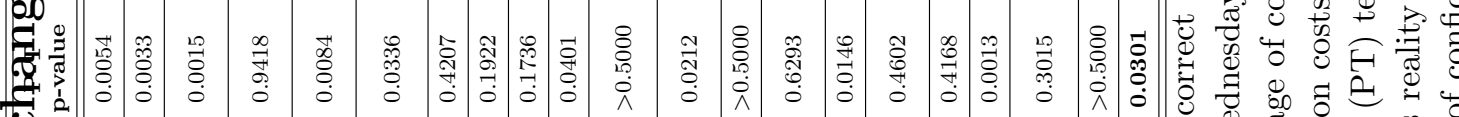
Cosen

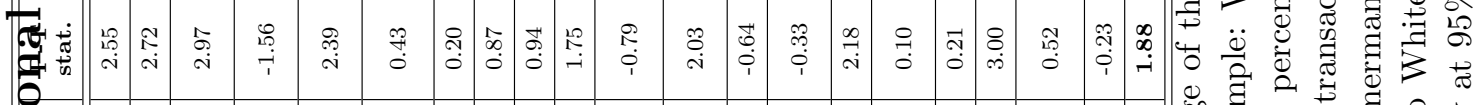

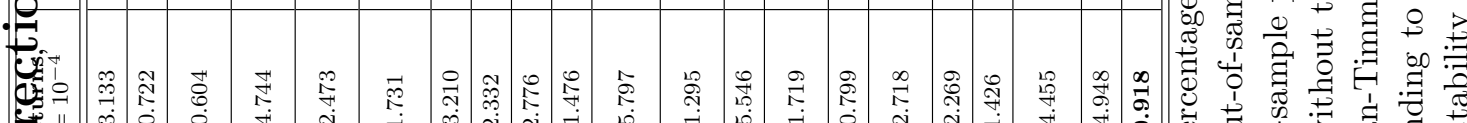

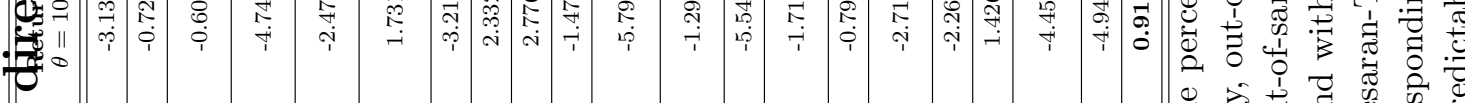
菏.

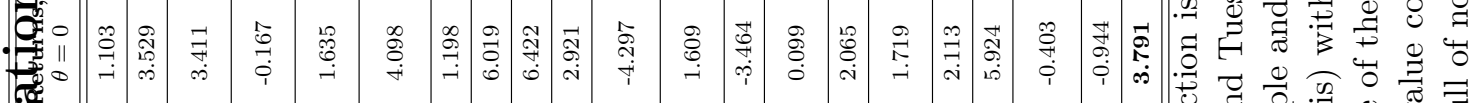
每

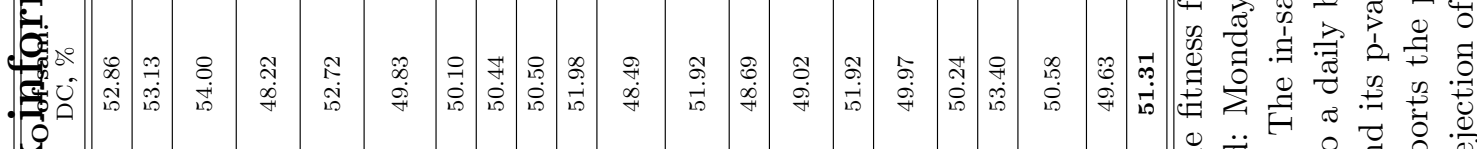

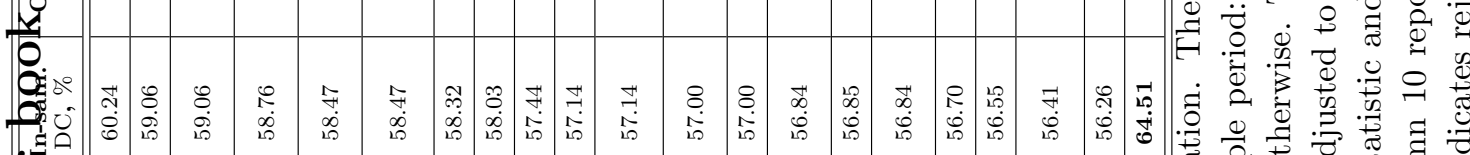

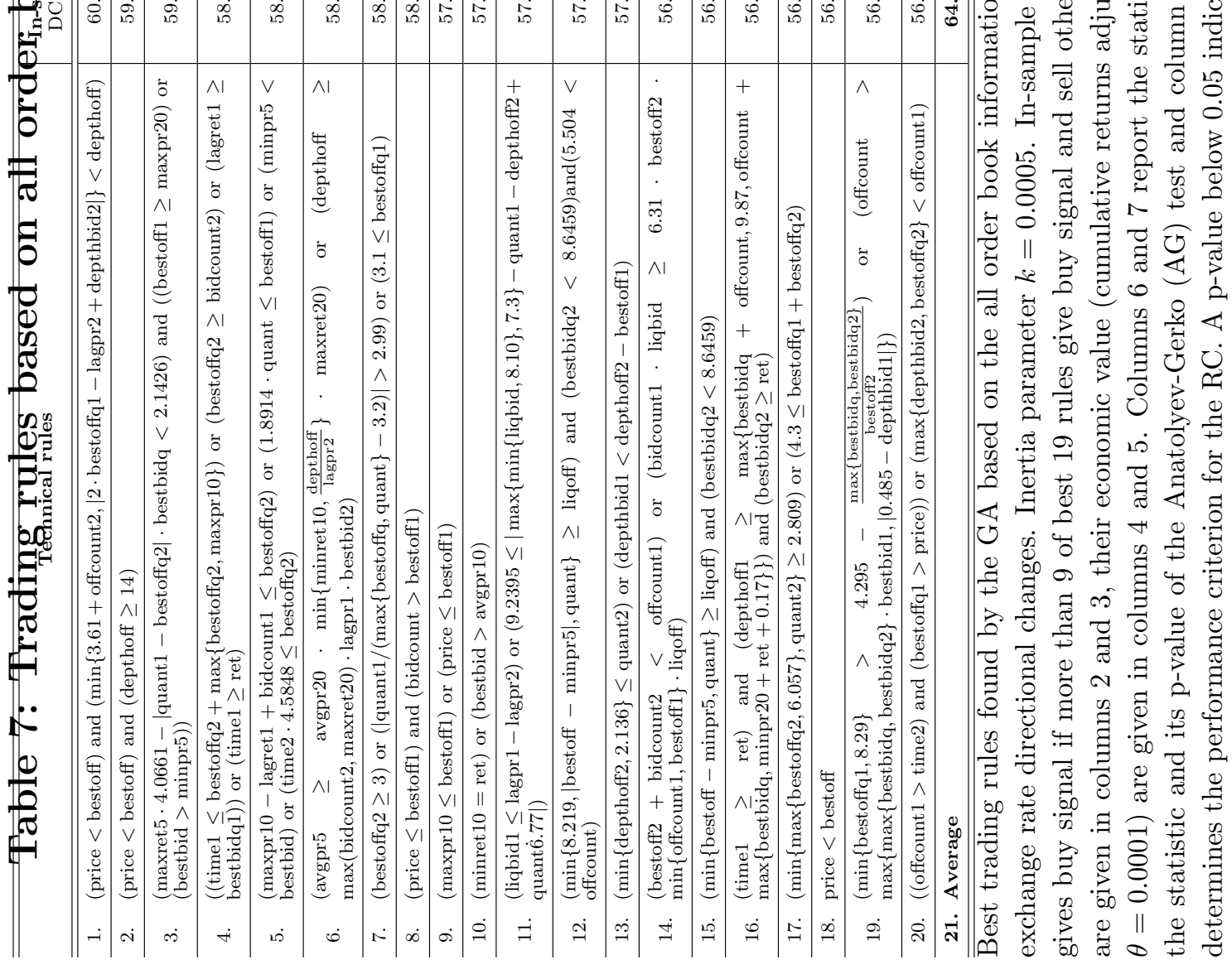




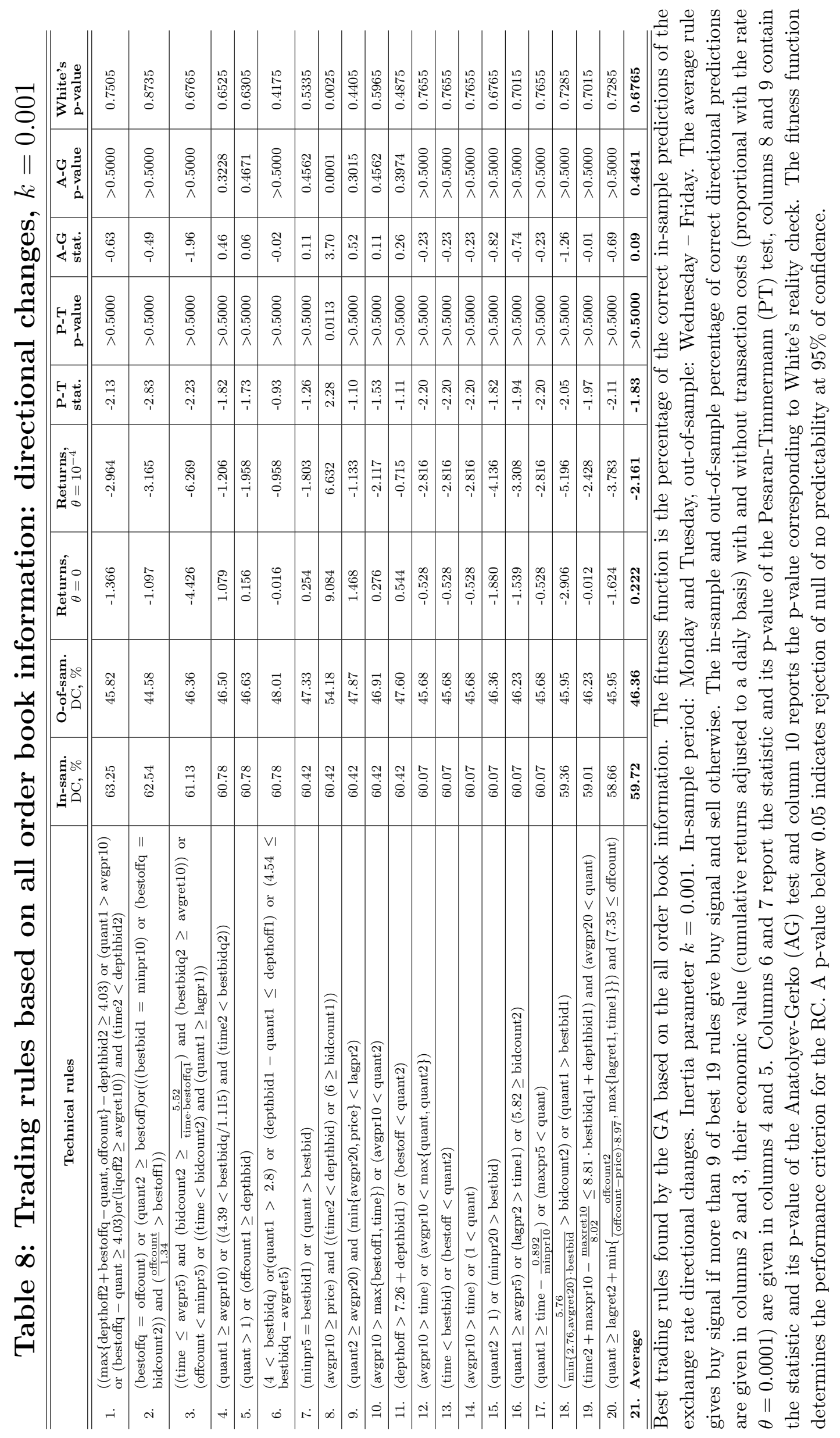




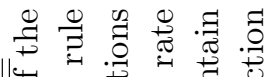

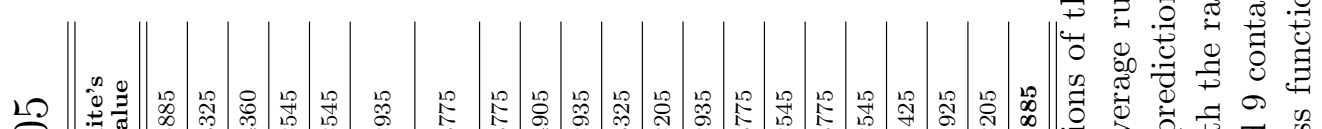

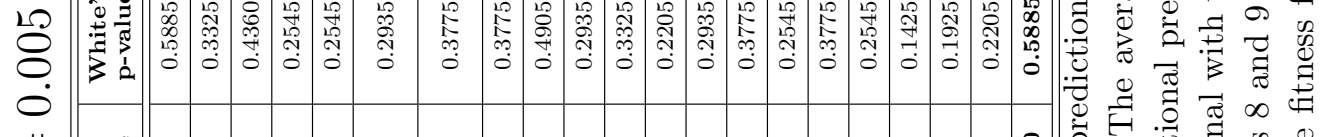

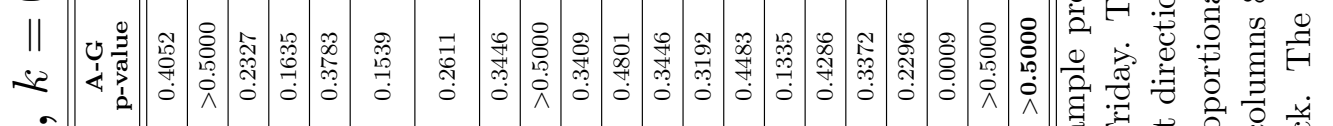

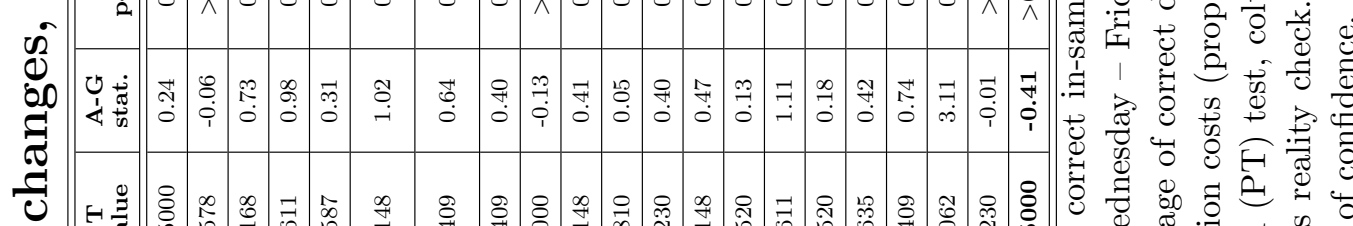

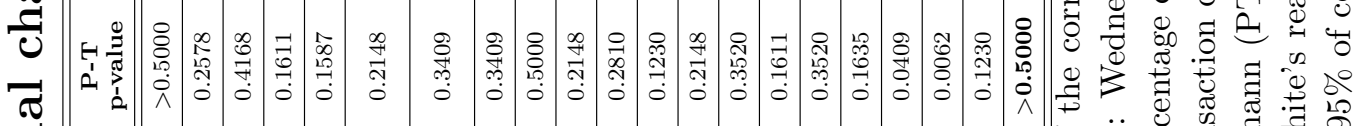

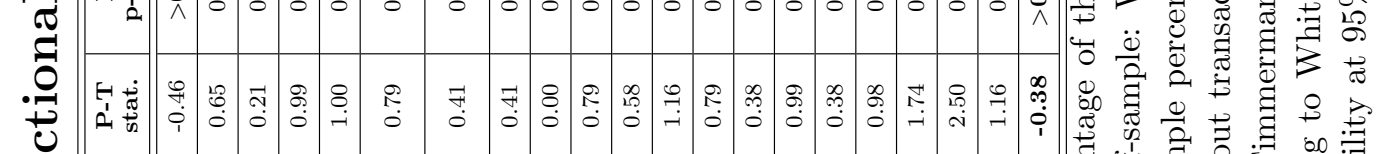

党

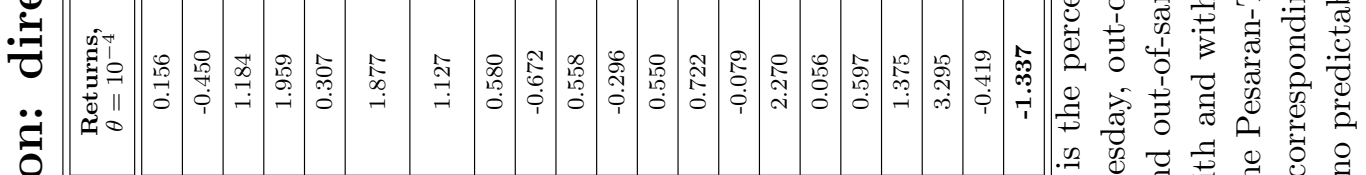

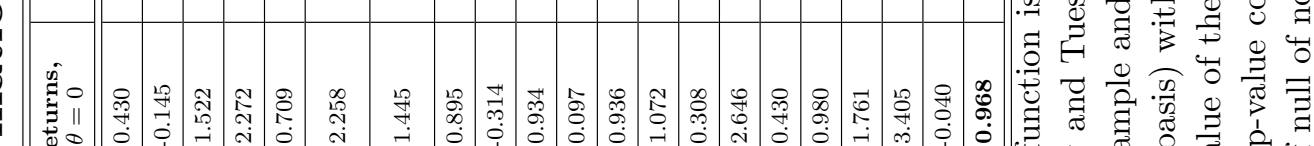
등

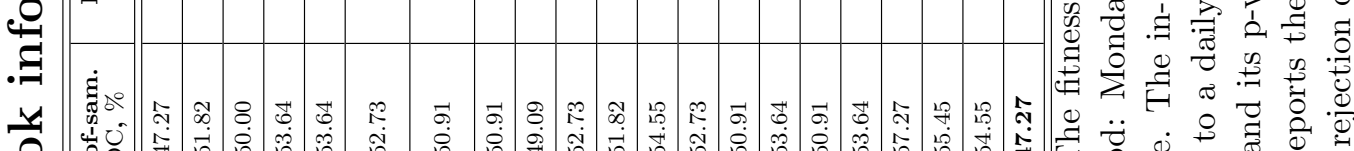

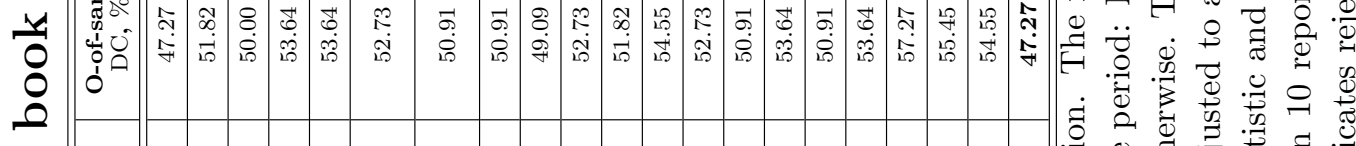

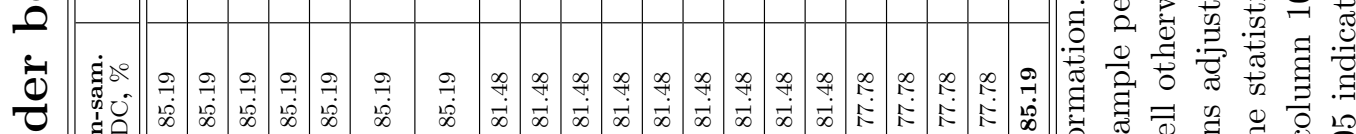
或

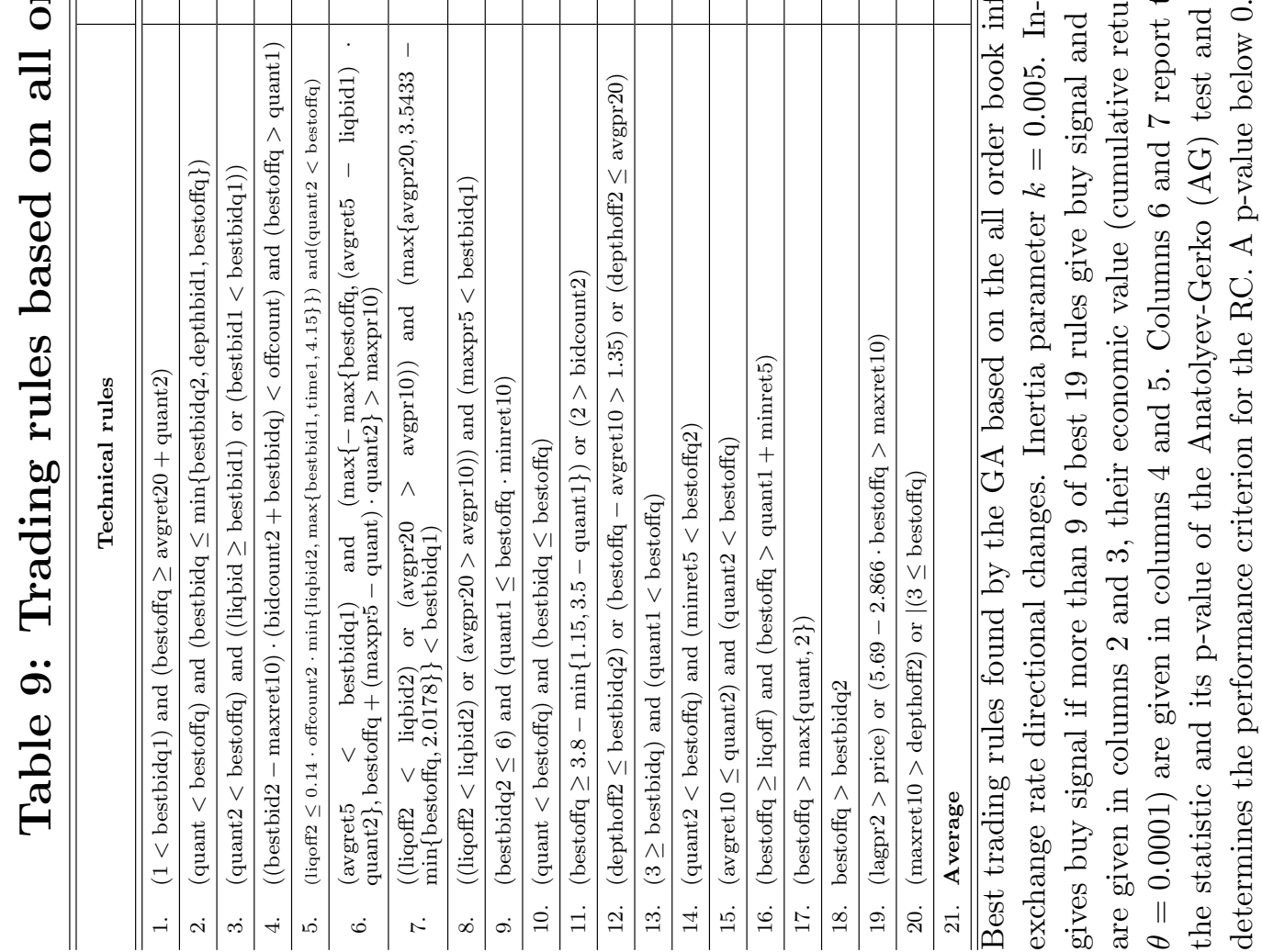




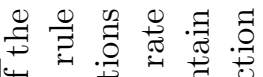

-

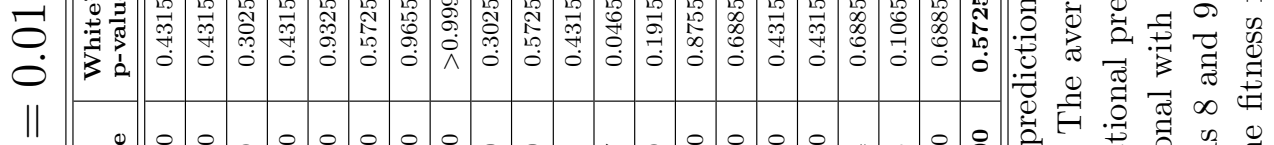

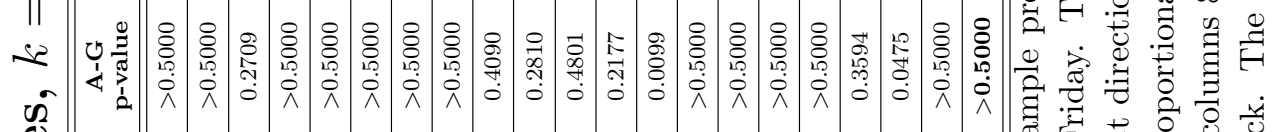

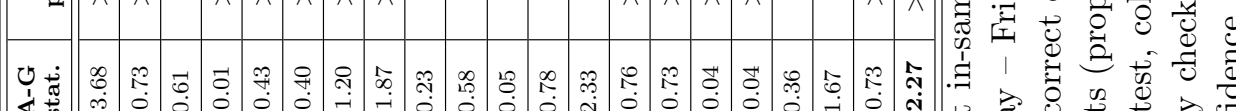

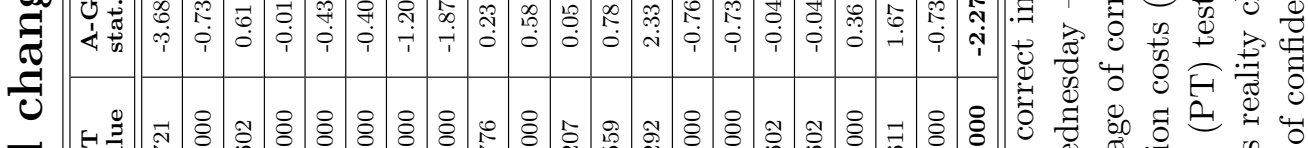

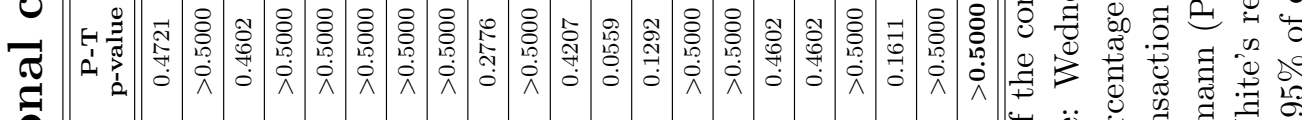
草 :

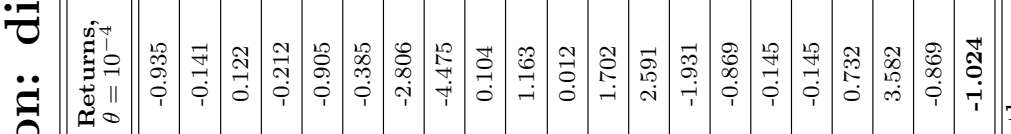
少 क

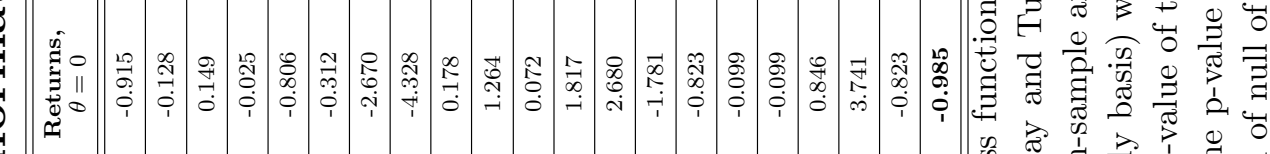

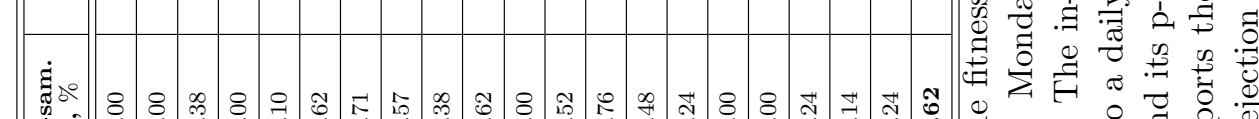

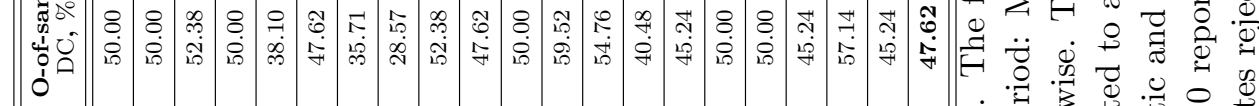
ర)

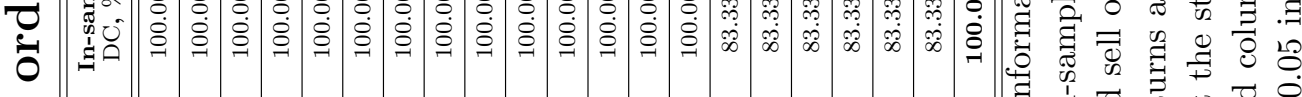

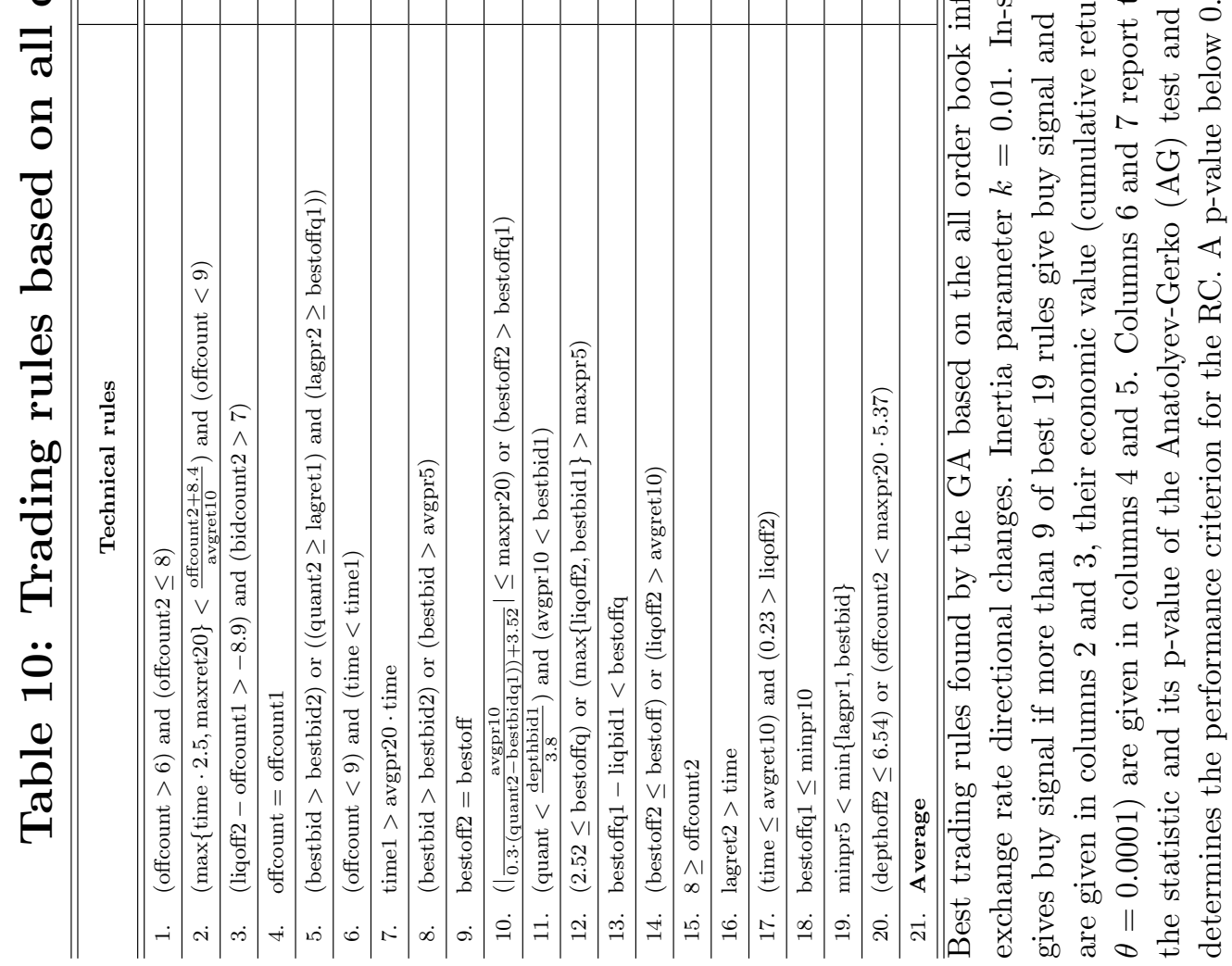




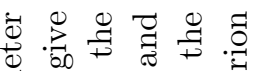

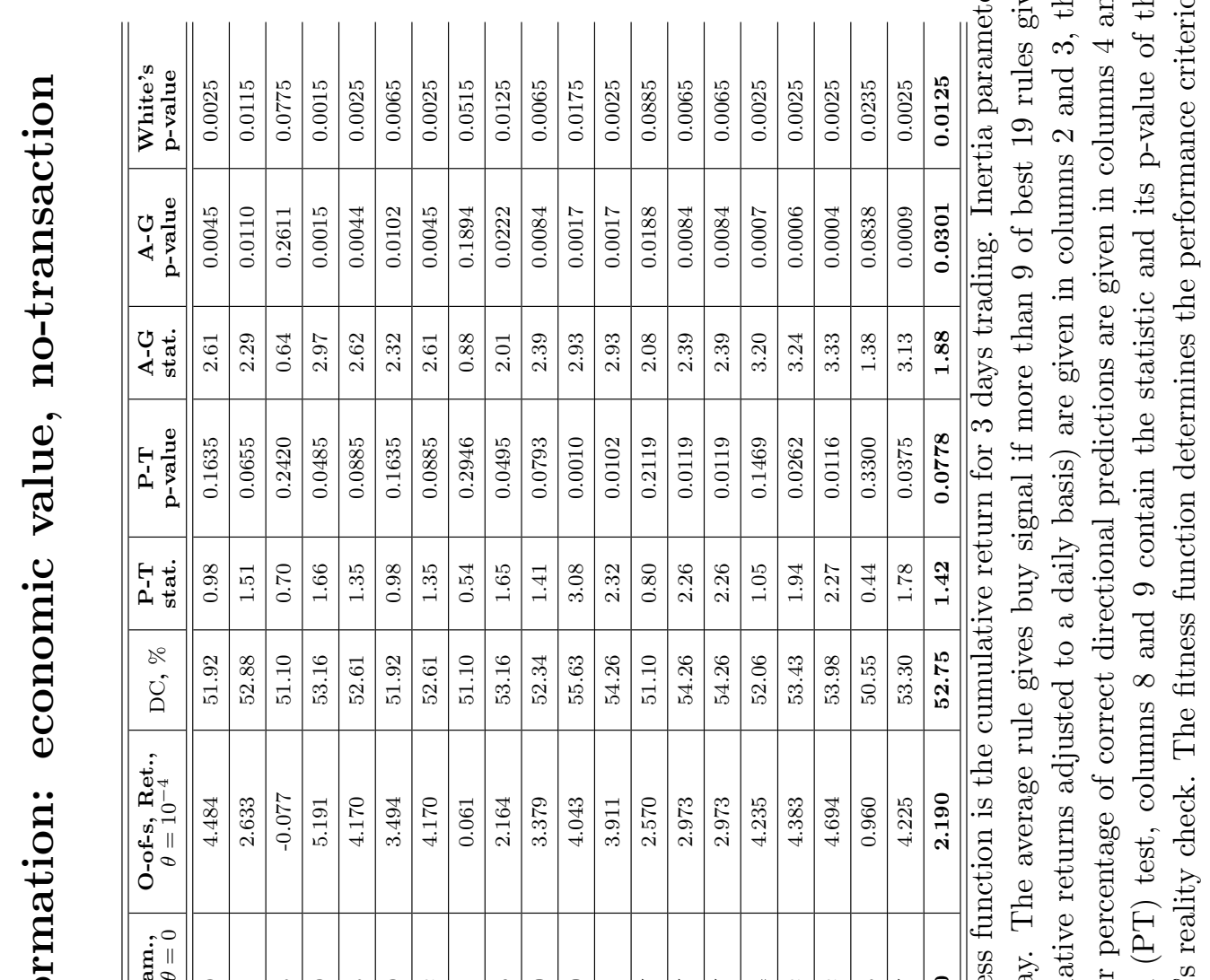

घiI

.$\Xi$

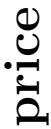
H 完导元

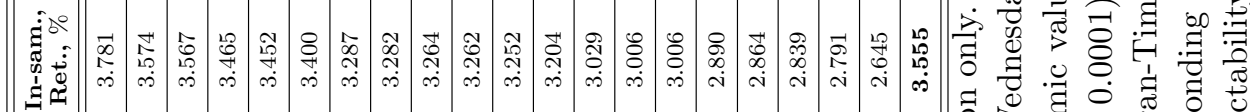

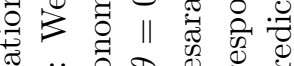

$\stackrel{0}{\Xi}$

б.

每

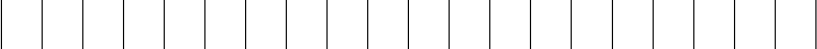

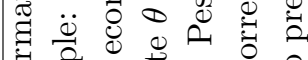

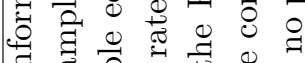
व

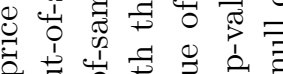

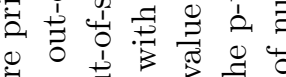

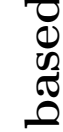

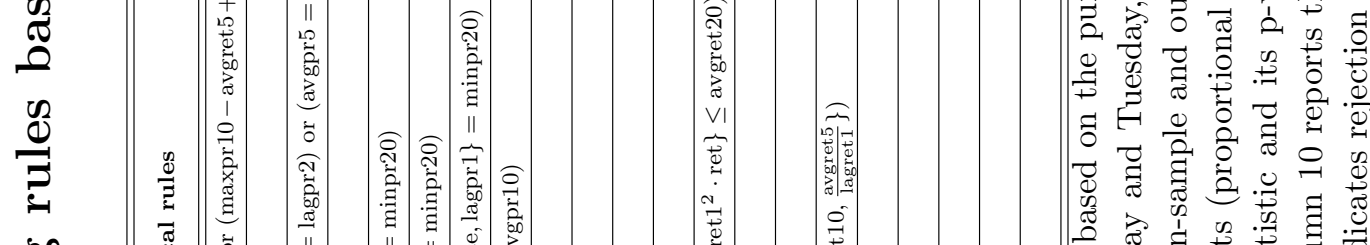

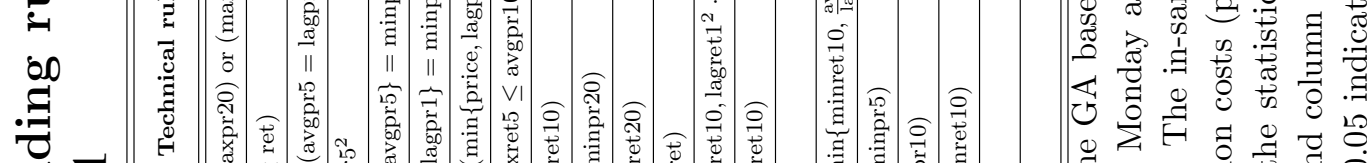

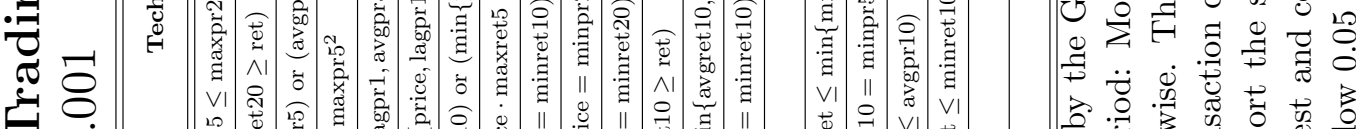

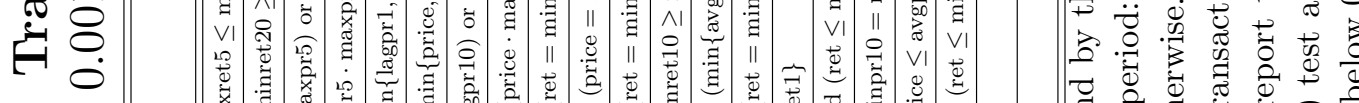

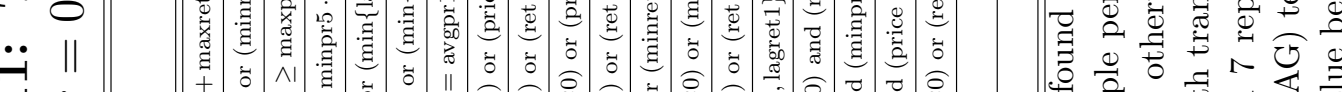

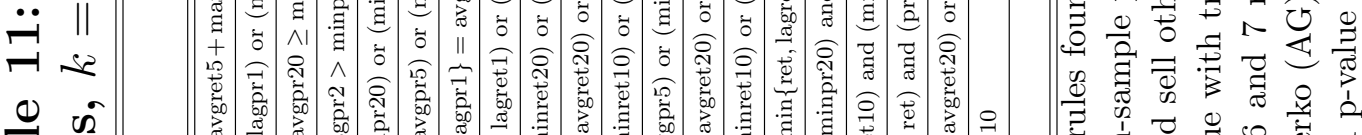

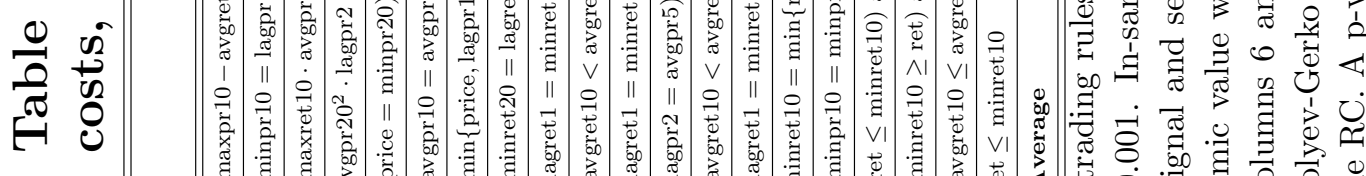

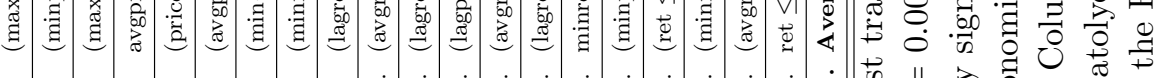

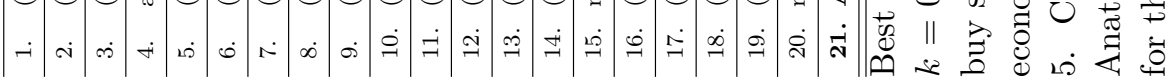




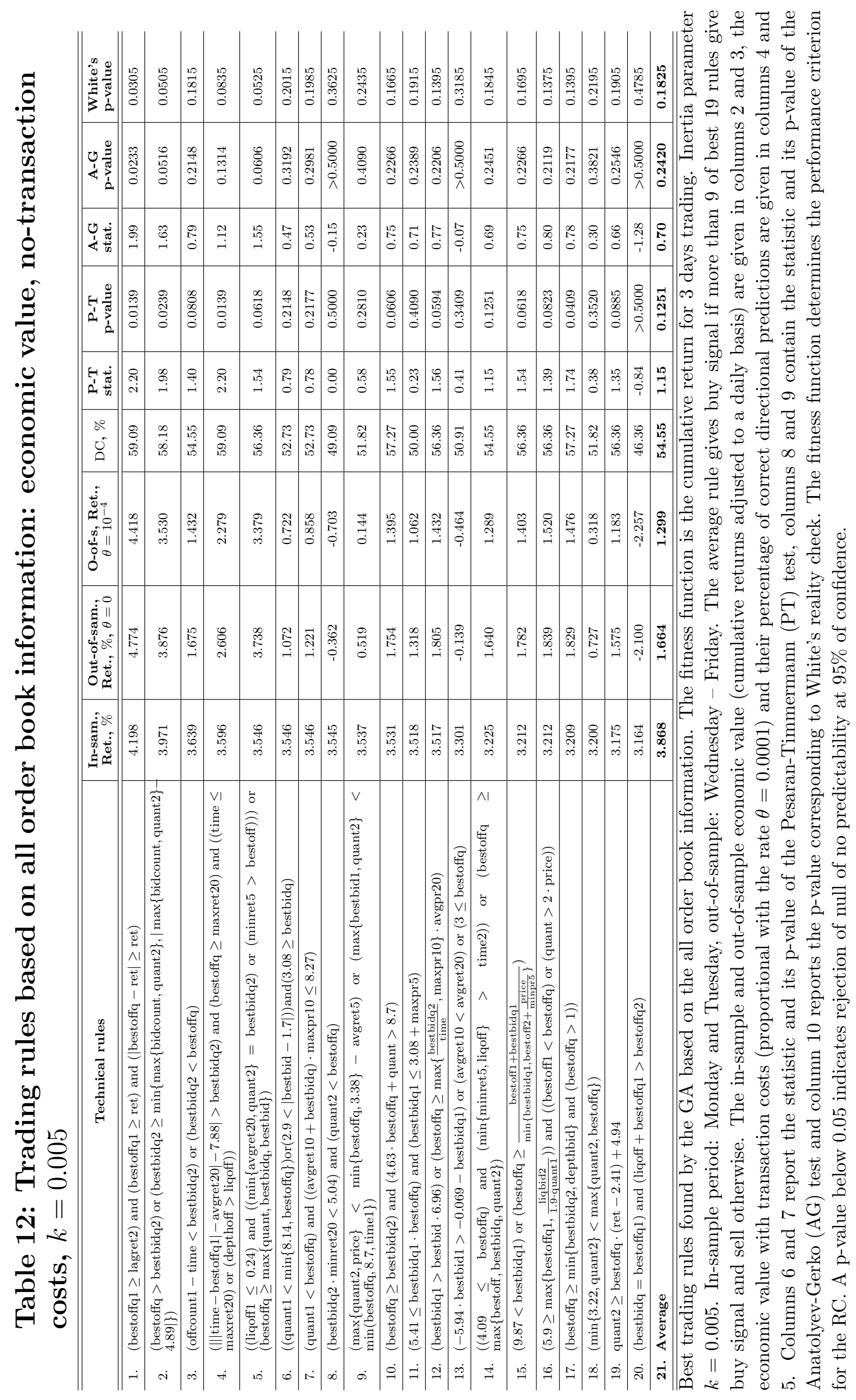




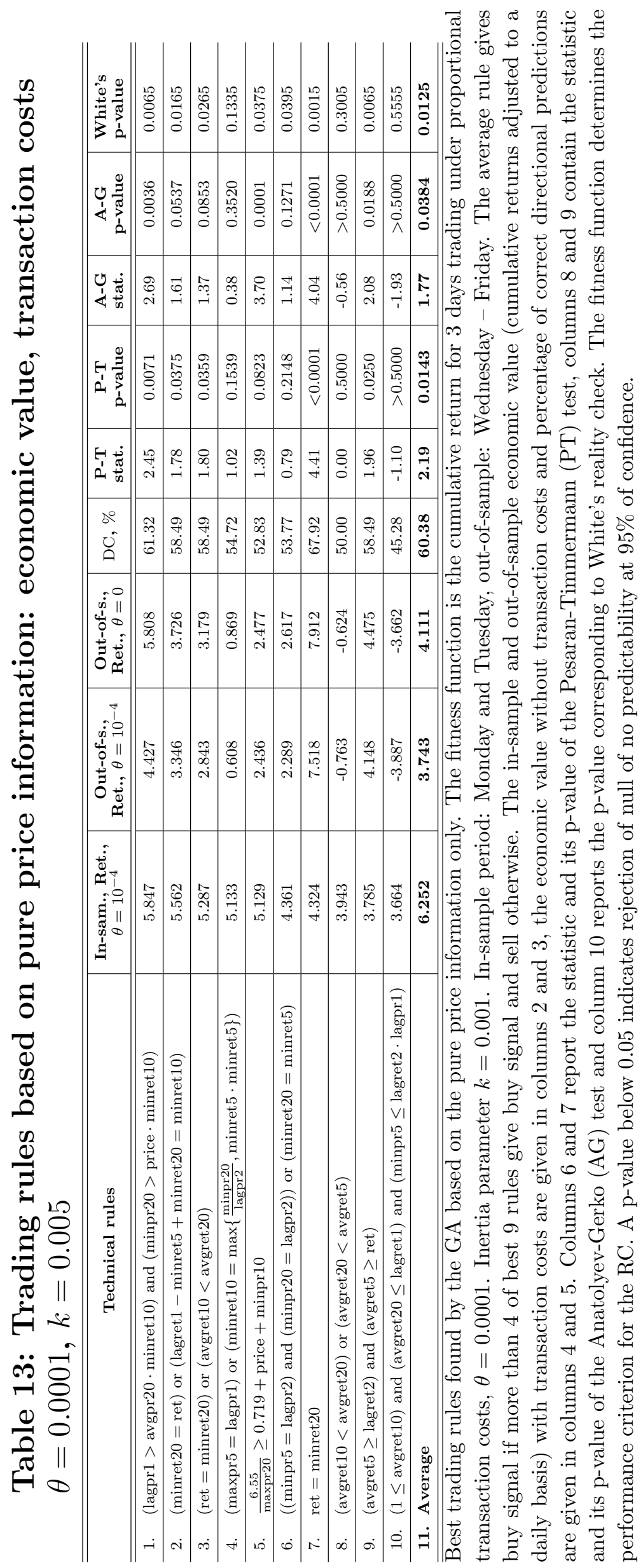




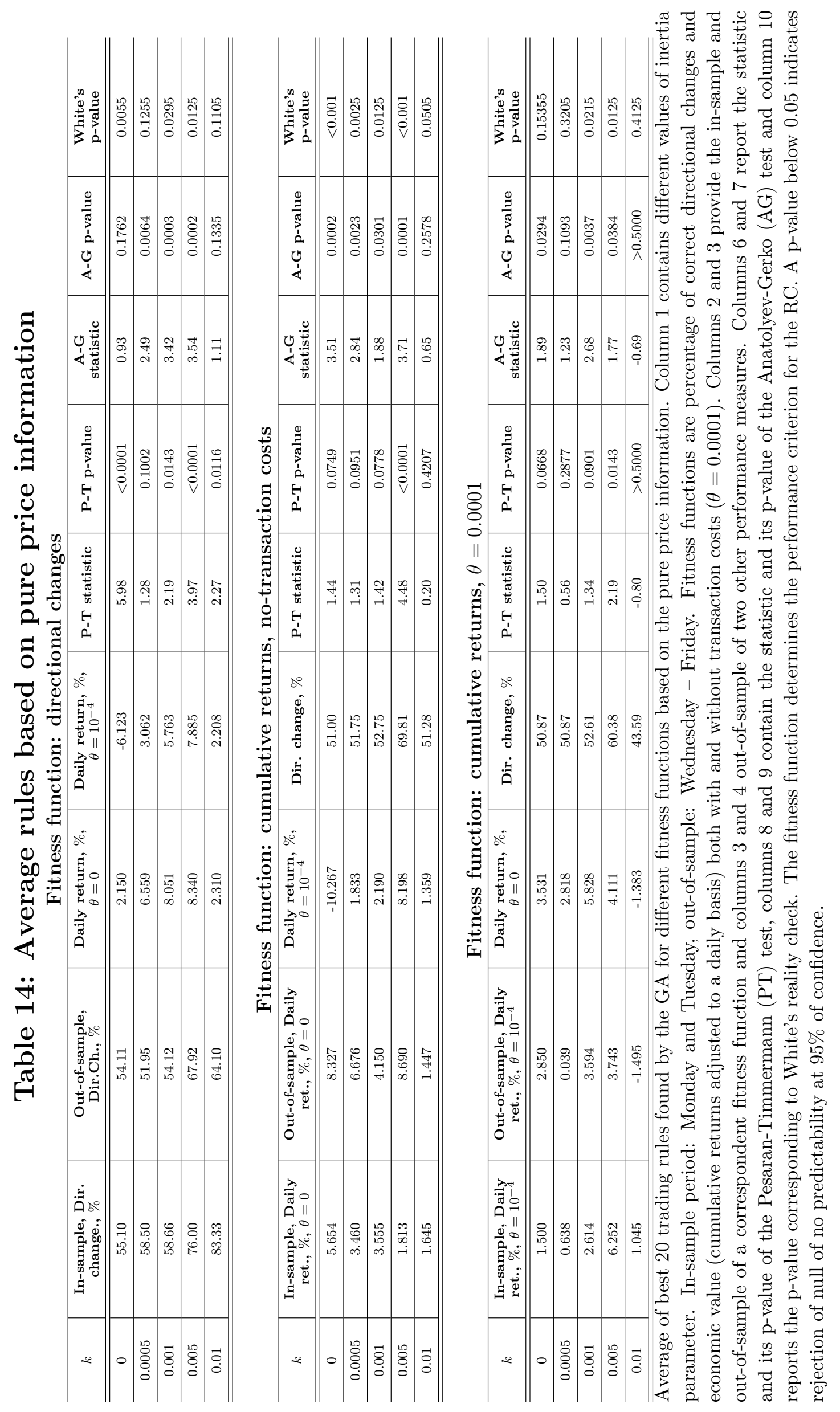




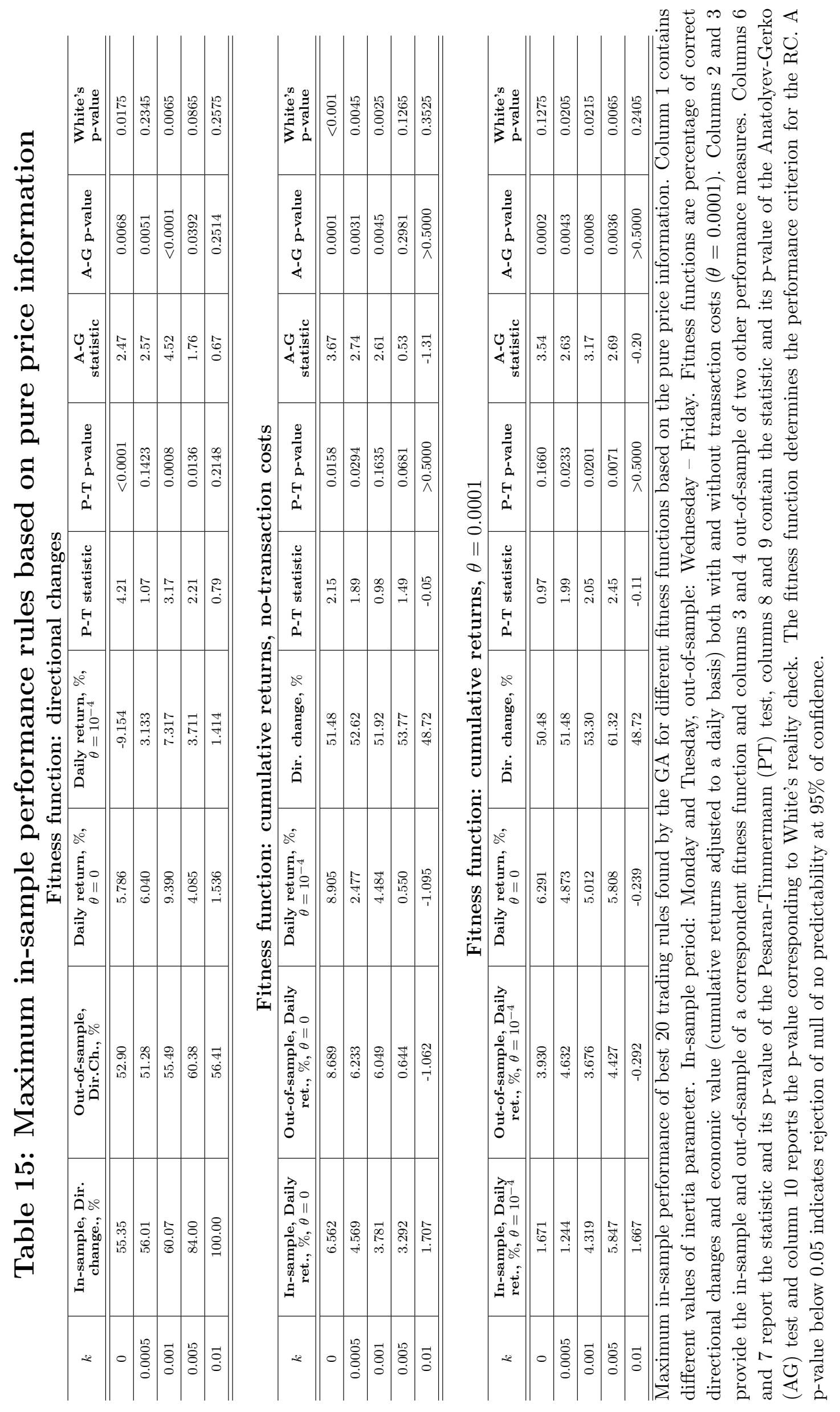




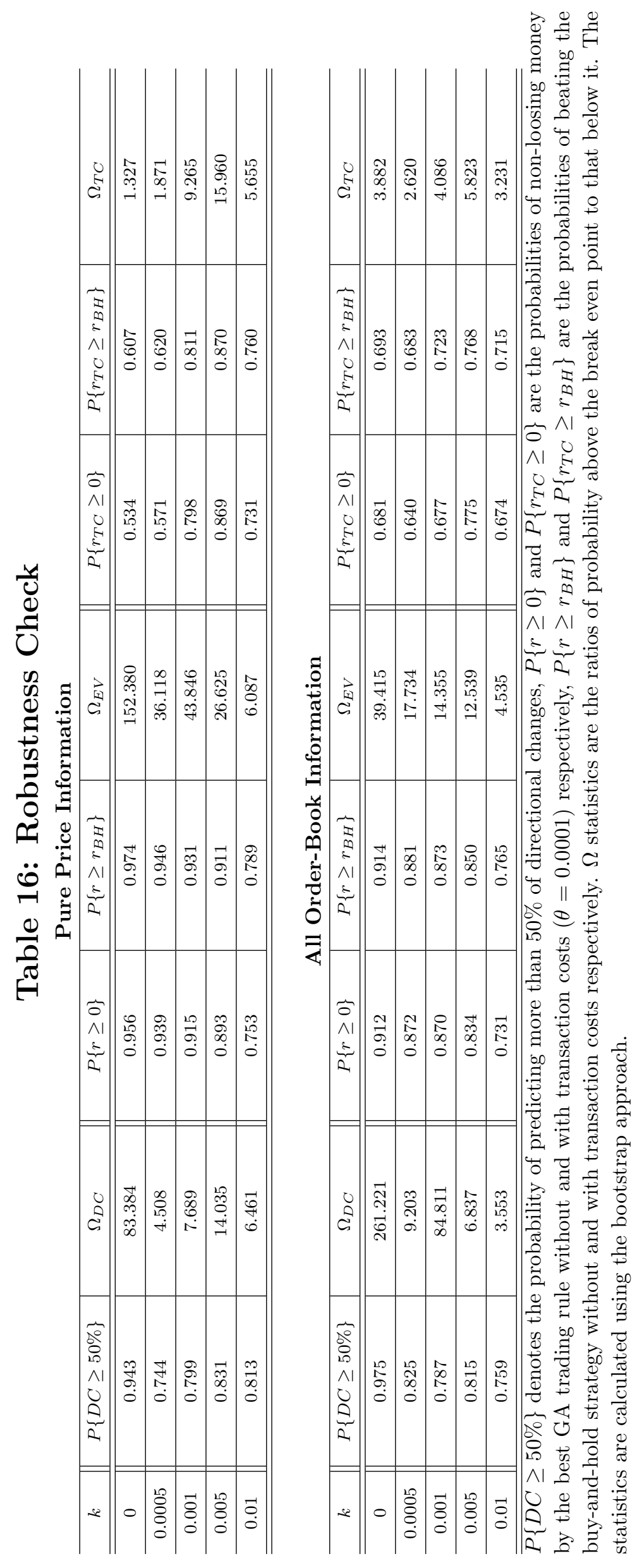




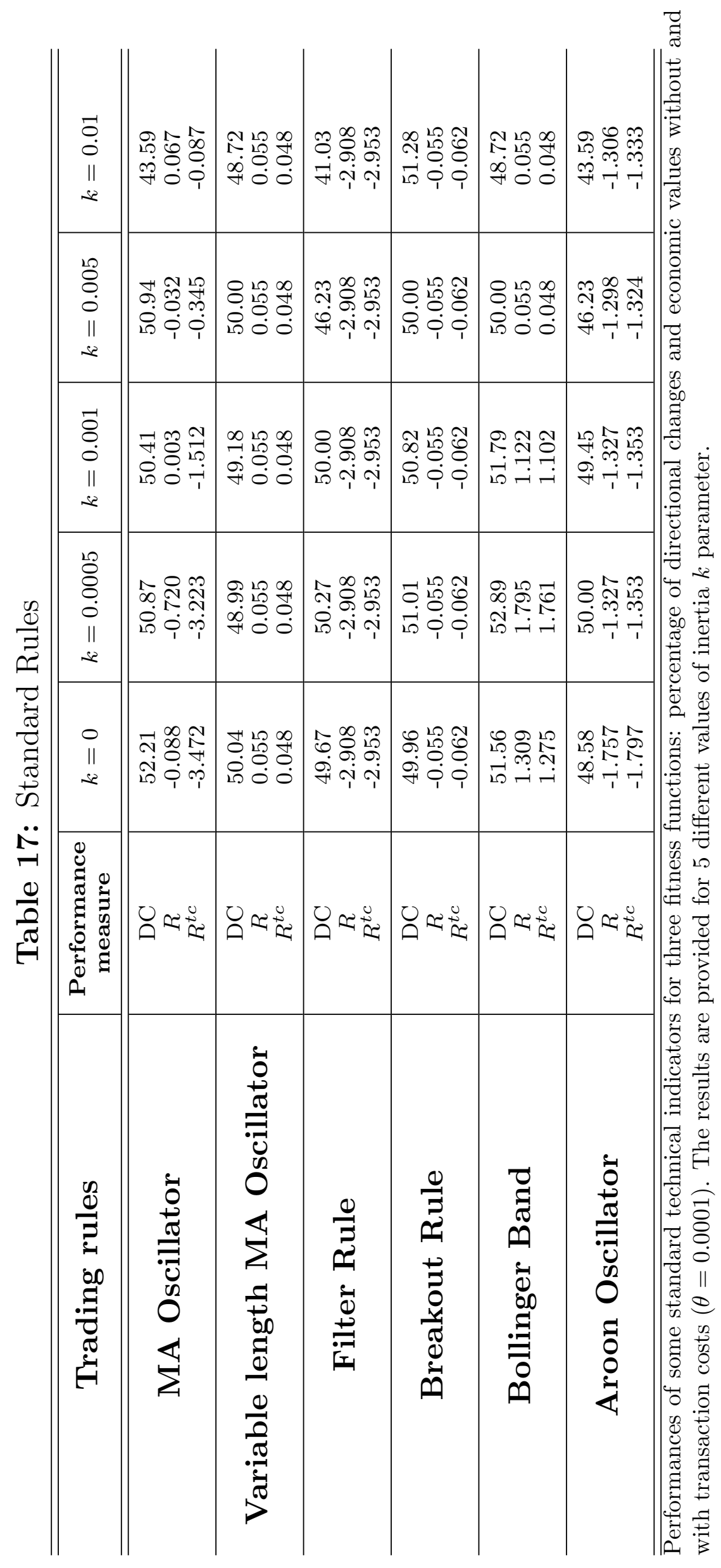




\section{Bootstrap distributions}

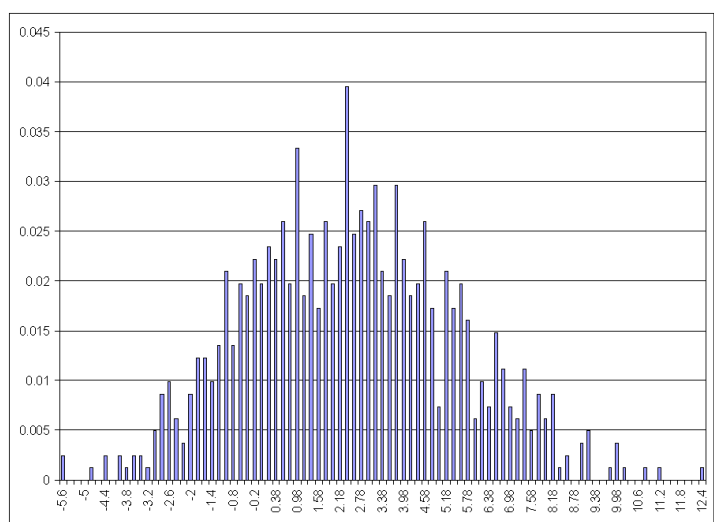

Figure 3: Bootstrap distribution of maximum of DC based on pure price information net of $50 \%$. $k=0.001$

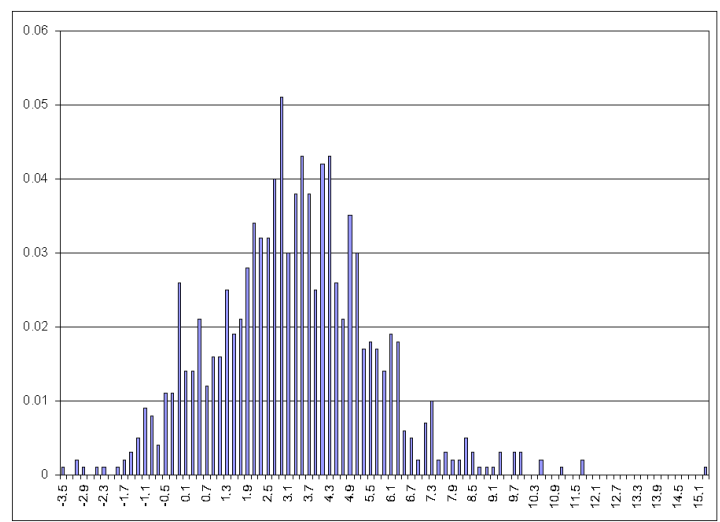

Figure 5: Bootstrap distribution of maximum of $R$ based on pure price information net of buyand-hold. $k=0.001$

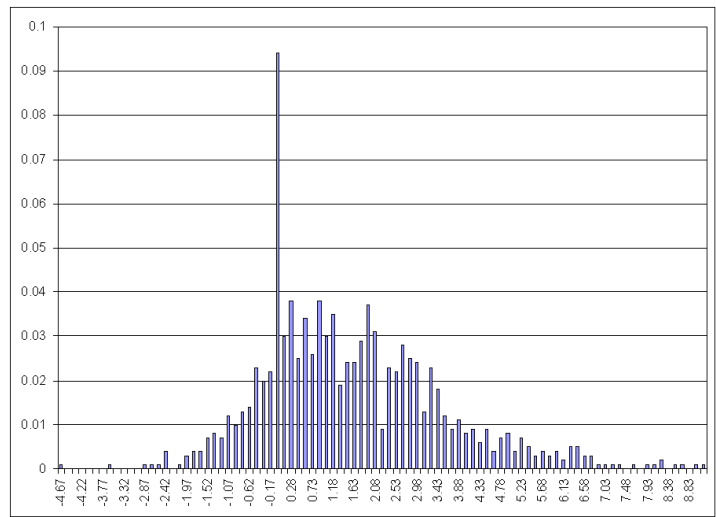

Figure 7: Bootstrap distribution of max of $R^{\mathrm{TC}}$ based on pure price information net of buy-andhold, $\theta=0.001$. $k=0.001$
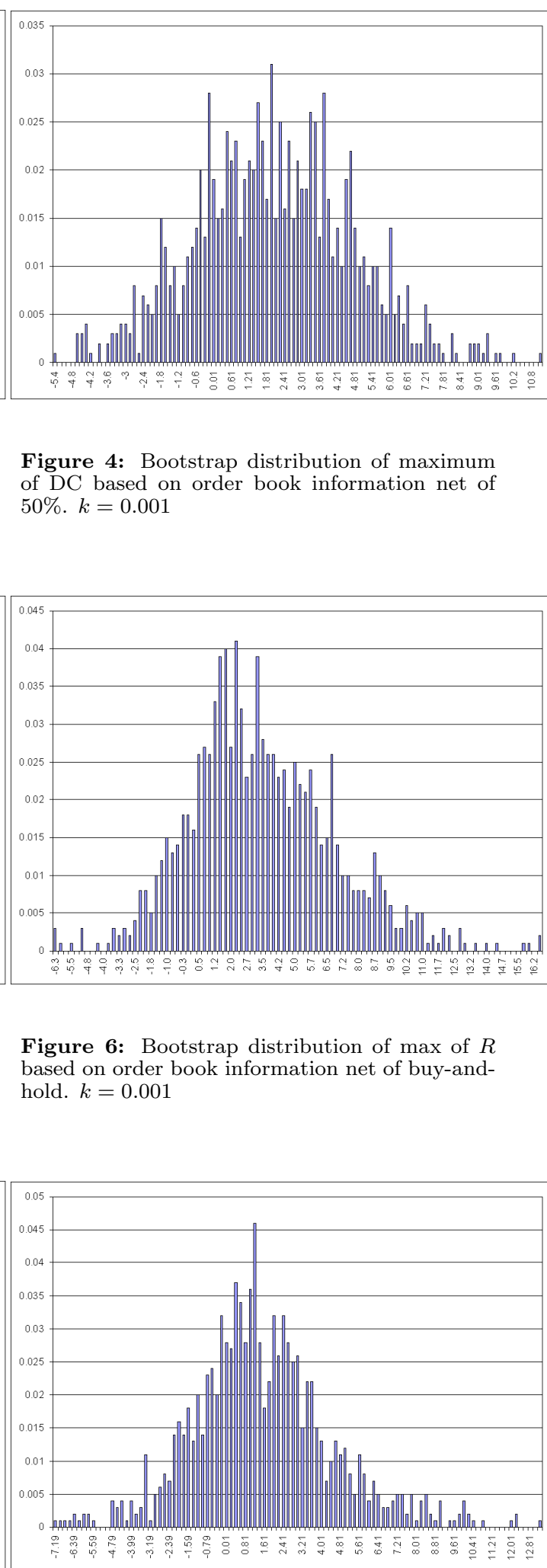

Figure 4: Bootstrap distribution of maximum of DC based on order book information net of $50 \% . k=0.001$

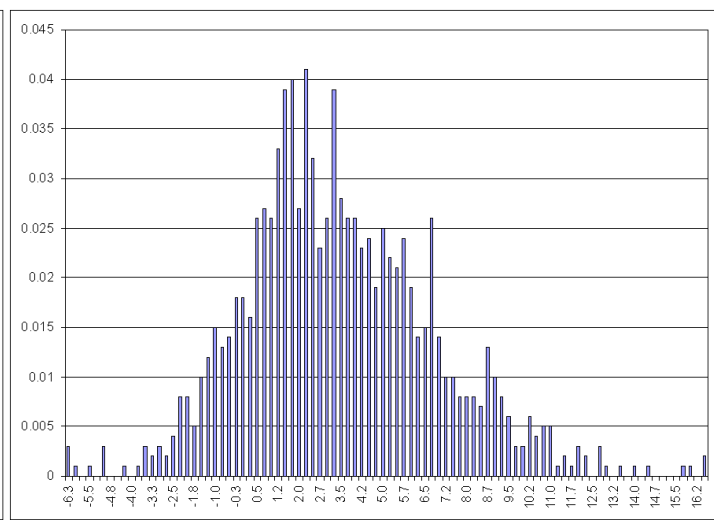

Figure 6: Bootstrap distribution of max of $R$ based on order book information net of buy-andhold. $k=0.001$

Figure 8: Bootstrap distribution of max of $R^{\mathrm{TC}}$ based on order book information net of buy-andhold, $\theta=0.0001$. $k=0.001$ 


\section{Appendix}

\subsection{Pesaran-Timmermann Test}

The Pesaran-Timmermann statistic is used to test the null of no market timing or that the proportion of correct predictions equals the proportion which can be expected under the null of independence between the realised and predicted values. Let $e_{t}$ be the realised value of the exchange rate and $z_{t}-$ its forecast. Define the probabilities

$$
\begin{array}{ll}
P_{11}=P\left(z_{t}<0, e_{t}<0\right), & P_{12}=P\left(z_{t}<0, e_{t} \geq 0\right), \\
P_{21}=P\left(z_{t} \geq 0, e_{t}<0\right), & P_{22}=P\left(z_{t} \geq 0, e_{t} \geq 0\right) .
\end{array}
$$

The diagonal elements of this contingency table provide the proportion of correct predictions. $P_{i j}$ denotes the probability of a realisation in the cell of the $i^{\prime}$ th row and $j^{\prime}$ th column of the contingency table. In general, the Pesaran-Timmermann test considers a number of categories $(i, j \in\{1, \ldots, m\}$; we only need to consider $m=2$. Denote by $P_{i 0}=\sum_{j=1}^{m} P_{i j}$ the probability of cells in the $i^{\prime}$ th row and $P_{0 j}=\sum_{i=1}^{m} P_{i j}$ the probability of cells in the $j^{\prime} t h$ column. The null hypothesis is expressed as

$$
H 0: \sum_{i=1}^{m}\left(\hat{P}_{i i}-\hat{P}_{i 0} \hat{P}_{0 i}\right)=0
$$

The test is based on the standardised statistic

$$
s_{n}=\sqrt{n} V_{n}^{-\frac{1}{2}} S_{n} \stackrel{a}{\sim} N(0,1),
$$

where $n$ is the number of observations, and

$$
\begin{aligned}
& S_{n}=\sum_{i=1}^{m}\left(\hat{P}_{i i}-\hat{P}_{i 0} \hat{P}_{0 i}\right) \\
& V_{n}=\left(\frac{\partial f(\mathbf{P})}{\partial \mathbf{P}}\right)_{\mathbf{P}=\hat{\mathbf{P}}}^{\prime}\left(\hat{\Psi}-\hat{\mathbf{P}} \hat{\mathbf{P}}^{\prime}\right)\left(\frac{\partial f(\mathbf{P})}{\partial \mathbf{P}}\right)_{\mathbf{P}=\hat{\mathbf{P}}}
\end{aligned}
$$

$\hat{\Psi}$ is an $m^{2} \times m^{2}$ diagonal matrix with $\hat{\mathbf{P}}$ as its diagonal elements,

$$
\left(\frac{\partial f(\mathbf{P})}{\partial \mathbf{P}}\right)_{\mathbf{P}=\hat{\mathbf{P}}}=\left\{\begin{array}{cc}
1-P_{0 i}-P_{i 0} & \text { for } i=j \\
-P_{j 0}-P_{0 i} & \text { for } i \neq j
\end{array}\right.
$$

When $m=2$ this test is asymptotically equivalent to the Henriksson-Merton test of market timing (see Henrikson and Merton (1981)).

\subsection{Anatolyev-Gerko Test}

The Anatolyev and Gerko (Anatolyev and Gerko (2005)) test of mean predictability is based on both market timing and a trading rule. Essentially this is a Hausman 
test that compares two estimates of mean returns from a simple trading rule, both of which will be consistent under the null of no predictability but will differ under the alternative.

Let $r_{t}$ be the observed log-returns of the exchange rate and $\hat{r}_{t}$ be their forecasts for $t=1, \ldots, n$. The forecasts depend on the past information $\mathcal{F}_{t-1}=\left\{r_{t-1}, r_{t-2}, \ldots\right\}$. Let the trading rule of the investor be based on the forecast variable $\hat{r}_{t}$, in particular, the investor takes a long position in USD if $\hat{r}_{t} \geq 0$ and a short position in dollars if $\hat{r}_{t}<0$. Then the one-period return from using the trading strategy is $R_{t}=\operatorname{sign}\left(\hat{r}_{t}\right) \cdot r_{t}$. The null hypothesis is conditional mean independence so that $H_{0}: E\left(r_{t} \mid \mathcal{F}_{t-1}\right)=$ const or that $\hat{r}_{t}$ and $r_{t}$ are independent. The expected one-period return $E\left(R_{t}\right)$ can be consistently estimated under the null by two estimators:

$$
A_{n}=\frac{1}{n} \sum_{t} R_{t}
$$

and

$$
B_{n}=\left(\frac{1}{n} \sum_{t} \operatorname{sign}\left(\hat{r}_{t}\right)\right)\left(\frac{1}{n} \sum_{t} r_{t}\right)
$$

$A_{n}$ estimates the average return from using the trading strategy whereas $B_{n}$ estimates the average return from using the benchmark strategy that issues buy/sell signals randomly with probabilities corresponding to the proportion of buys and sells implied ex post by the trading strategy. When $r_{t}$ is predictable investing in the trading strategy will generate higher returns than the benchmark and the difference between $A_{n}$ and $B_{n}$ will be sizable. The variance of the difference $A_{n}-B_{n}$ is

$$
V=\operatorname{Var}\left(A_{n}-B_{n}\right)=\frac{4(n-1)}{n^{2}} p_{\hat{r}}\left(1-p_{\hat{r}}\right) \operatorname{Var}\left(r_{t}\right),
$$

where $p_{\hat{r}}=\operatorname{Pr}\left\{\operatorname{sign}\left(\hat{r}_{t}\right)=1\right\}$. The estimator for the variance is $\hat{V}=\frac{4}{n^{2}} \hat{p}_{\hat{r}}\left(1-\hat{p}_{\hat{r}}\right) \sum_{t}\left(r_{t}-\right.$ $\bar{r})^{2}$ with $\hat{p}_{\hat{r}}=\frac{1}{2}\left(1+\frac{1}{n} \sum_{t} \operatorname{sign}\left(\hat{r}_{t}\right)\right)$. The excess profitability statistic is then given by

$$
E P=\frac{A_{n}-B_{n}}{\sqrt{\hat{V}}} \stackrel{d}{\rightarrow} N(0,1)
$$

under the null hypothesis.

\subsection{White's Reality Check}

The main idea behind the Reality Check is as follows; let $\varphi_{k},(k=1, \ldots, M)$ denote the performance measure of the $k$-th trading rule relative to some benchmark performance or rule. The aim is to test whether there is a rule within the population that delivers superior performance to the benchmark. The null hypothesis is then stated as;

$$
H_{0}: \max _{k=1, \ldots, M} \varphi_{k} \leq 0
$$


in other words there is no rule that delivers positive returns relative to the benchmark i.e. beats the benchmark. To test this null, we need the distribution under the null, White (2000) suggested using the stationary bootstrap method of Politis and Romano (1994) to estimate the distribution of the test statistic $V=\max _{k=1, \ldots, M} \varphi_{k}$. If we denote by $\varphi_{k, j}^{*}$ the performance measure of the $k$-th trading rule calculated using $j$-th bootstrap sample. The empirical distribution can be obtained using bootstrap realizations

$$
V_{j}^{*}=\max _{k=1, \ldots, M}\left(\varphi_{k, j}^{*}-\varphi_{k}\right), j=1, \ldots, B
$$

It shown in White (2000) that the distributions of $V$ and $V^{*}$ are asymptotically equivalent. Comparing the value of the statistic $V$ with the quantiles of the empirical distribution of $V^{*}$ we obtain the Reality Check $p$-values which are suitable for testing the null hypothesis. 


\section{List of other working papers:}

\section{8}

1. Roman Kozhan and Rozalia Pal, Firms' Investment under Financial Constraints: A Euro Area Investigation, WP08-07

2. Roman Kozhan and Mark Salmon, On Uncertainty, Market Timing and the Predictability of Tick by Tick Exchange Rates, WP08-06

3. Roman Kozhan and Mark Salmon, Uncertainty Aversion in a Heterogeneous Agent Model of Foreign Exchange Rate Formation, WP08-05

4. Roman Kozhan, Non-Additive Anonymous Games, WP08-04

5. Thomas Lux, Stochastic Behavioral Asset Pricing Models and the Stylized Facts, WP08-03

6. Reiner Franke, A Short Note on the Problematic Concept of Excess Demand in Asset Pricing Models with Mean-Variance Optimization, WP08-02

7. Alexandra Dias, Semi-parametric estimation of joint large movements of risky assets, WP08-01

\section{7}

1. Timur Yusupov and Thomas Lux, The Efficient Market Hypothesis through the Eyes of an Artificial Technical Analyst: An Application of a New Chartist Methodology to High-Frequency Stock Market Data, WP07-13

2. Liu Ruipeng, Di Matteo and Thomas Lux, True and Apparent Scaling: The Proximity of the Markov- Switching Multifractal Model to Long-Range Dependence, WP07-12

3. Thomas Lux, Rational Forecasts or Social Opinion Dynamics? Identification of Interaction Effects in a Business Climate Survey, WP07-11

4. Thomas Lux, Collective Opinion Formation in a Business Climate Survey, WP07-10

5. Thomas Lux, Application of Statistical Physics in Finance and Economics, WP07-09

6. Reiner Franke, A Prototype Model of Speculative Dynamics With Position-Based Trading, WP07-08

7. Reiner Franke, Estimation of a Microfounded Herding Model On German Survey Expectations, WP07-07

8. Cees Diks and Pietro Dindo, Informational differences and learning in an asset market with boundedly rational agents, WP07-06

9. Markus Demary, Who Do Currency Transaction Taxes Harm More: Short-Term Speculators or Long-Term Investors?, WP07-05

10. Markus Demary, A Heterogenous Agents Model Usable for the Analysis of Currency Transaction Taxes, WP07-04

11. Mikhail Anufriev and Pietro Dindo, Equilibrium Return and Agents' Survival in a Multiperiod Asset Market: Analytic Support of a Simulation Model, WP07-03

12. Simone Alfarano and Michael Milakovic, Should Network Structure Matter in Agent-Based Finance?, WP07-02

13. Simone Alfarano and Reiner Franke, A Simple Asymmetric Herding Model to Distinguish Between Stock and Foreign Exchange Markets, WP07-01

\section{6}

1. Roman Kozhan, Multiple Priors and No-Transaction Region, WP06-24

2. Martin Ellison, Lucio Sarno and Jouko Vilmunen, Caution and Activism? Monetary Policy Strategies in an Open Economy, WP06-23

3. Matteo Marsili and Giacomo Raffaelli, Risk bubbles and market instability, WP06-22

4. Mark Salmon and Christoph Schleicher, Pricing Multivariate Currency Options with Copulas, WP06-21 
5. Thomas Lux and Taisei Kaizoji, Forecasting Volatility and Volume in the Tokyo Stock Market: Long Memory, Fractality and Regime Switching, WP06-20

6. Thomas Lux, The Markov-Switching Multifractal Model of Asset Returns: GMM Estimation and Linear Forecasting of Volatility, WP06-19

7. Peter Heemeijer, Cars Hommes, Joep Sonnemans and Jan Tuinstra, Price Stability and Volatility in Markets with Positive and Negative Expectations Feedback: An Experimental Investigation, WP06-18

8. Giacomo Raffaelli and Matteo Marsili, Dynamic instability in a phenomenological model of correlated assets, WP06-17

9. Ginestra Bianconi and Matteo Marsili, Effects of degree correlations on the loop structure of scale free networks, WP06-16

10. Pietro Dindo and Jan Tuinstra, A Behavioral Model for Participation Games with Negative Feedback, WP06-15

11. Ceek Diks and Florian Wagener, A weak bifucation theory for discrete time stochastic dynamical systems, WP06-14

12. Markus Demary, Transaction Taxes, Traders' Behavior and Exchange Rate Risks, WP06-13

13. Andrea De Martino and Matteo Marsili, Statistical mechanics of socio-economic systems with heterogeneous agents, WP06-12

14. William Brock, Cars Hommes and Florian Wagener, More hedging instruments may destabilize markets, WP06-11

15. Ginwestra Bianconi and Roberto Mulet, On the flexibility of complex systems, WP06-10

16. Ginwestra Bianconi and Matteo Marsili, Effect of degree correlations on the loop structure of scale-free networks, WP06-09

17. Ginwestra Bianconi, Tobias Galla and Matteo Marsili, Effects of Tobin Taxes in Minority Game Markets, WP06-08

18. Ginwestra Bianconi, Andrea De Martino, Felipe Ferreira and Matteo Marsili, Multi-asset minority games, WP06-07

19. Ba Chu, John Knight and Stephen Satchell, Optimal Investment and Asymmetric Risk for a Large Portfolio: A Large Deviations Approach, WP06-06

20. Ba Chu and Soosung Hwang, The Asymptotic Properties of AR(1) Process with the Occasionally Changing AR Coefficient, WP06-05

21. Ba Chu and Soosung Hwang, An Asymptotics of Stationary and Nonstationary AR(1) Processes with Multiple Structural Breaks in Mean, WP06-04

22. Ba Chu, Optimal Long Term Investment in a Jump Diffusion Setting: A Large Deviation Approach, WP06-03

23. Mikhail Anufriev and Gulio Bottazzi, Price and Wealth Dynamics in a Speculative Market with Generic Procedurally Rational Traders, WP06-02

24. Simonae Alfarano, Thomas Lux and Florian Wagner, Empirical Validation of Stochastic Models of Interacting Agents: A "Maximally Skewed" Noise Trader Model?, WP06-01

\section{5}

1. Shaun Bond and Soosung Hwang, Smoothing, Nonsynchronous Appraisal and CrossSectional Aggreagation in Real Estate Price Indices, WP05-17

2. Mark Salmon, Gordon Gemmill and Soosung Hwang, Performance Measurement with Loss Aversion, WP05-16

3. Philippe Curty and Matteo Marsili, Phase coexistence in a forecasting game, WP05-15

4. Matthew Hurd, Mark Salmon and Christoph Schleicher, Using Copulas to Construct Bivariate Foreign Exchange Distributions with an Application to the Sterling Exchange Rate Index (Revised), WP05-14

5. Lucio Sarno, Daniel Thornton and Giorgio Valente, The Empirical Failure of the Expectations Hypothesis of the Term Structure of Bond Yields, WP05-13

6. Lucio Sarno, Ashoka Mody and Mark Taylor, A Cross-Country Financial Accelorator: Evidence from North America and Europe, WP05-12

7. Lucio Sarno, Towards a Solution to the Puzzles in Exchange Rate Economics: Where Do We Stand?, WP05-11

8. James Hodder and Jens Carsten Jackwerth, Incentive Contracts and Hedge Fund Management, WP05-10

9. James Hodder and Jens Carsten Jackwerth, Employee Stock Options: Much More Valuable Than You Thought, WP05-09 
10. Gordon Gemmill, Soosung Hwang and Mark Salmon, Performance Measurement with Loss Aversion, WP05-08

11. George Constantinides, Jens Carsten Jackwerth and Stylianos Perrakis, Mispricing of S\&P 500 Index Options, WP05-07

12. Elisa Luciano and Wim Schoutens, A Multivariate Jump-Driven Financial Asset Model, WP0506

13. Cees Diks and Florian Wagener, Equivalence and bifurcations of finite order stochastic processes, WP05-05

14. Devraj Basu and Alexander Stremme, CAY Revisited: Can Optimal Scaling Resurrect the (C)CAPM?, WP05-04

15. Ginwestra Bianconi and Matteo Marsili, Emergence of large cliques in random scale-free networks, WP05-03

16. Simone Alfarano, Thomas Lux and Friedrich Wagner, Time-Variation of Higher Moments in a Financial Market with Heterogeneous Agents: An Analytical Approach, WP05-02

17. Abhay Abhayankar, Devraj Basu and Alexander Stremme, Portfolio Efficiency and Discount Factor Bounds with Conditioning Information: A Unified Approach, WP05-01

\section{4}

1. Xiaohong Chen, Yanqin Fan and Andrew Patton, Simple Tests for Models of Dependence Between Multiple Financial Time Series, with Applications to U.S. Equity Returns and Exchange Rates, WP04-19

2. Valentina Corradi and Walter Distaso, Testing for One-Factor Models versus Stochastic Volatility Models, WP04-18

3. Valentina Corradi and Walter Distaso, Estimating and Testing Sochastic Volatility Models using Realized Measures, WP04-17

4. Valentina Corradi and Norman Swanson, Predictive Density Accuracy Tests, WP04-16

5. Roel Oomen, Properties of Bias Corrected Realized Variance Under Alternative Sampling Schemes, WP04-15

6. Roel Oomen, Properties of Realized Variance for a Pure Jump Process: Calendar Time Sampling versus Business Time Sampling, WP04-14

7. Richard Clarida, Lucio Sarno, Mark Taylor and Giorgio Valente, The Role of Asymmetries and Regime Shifts in the Term Structure of Interest Rates, WP04-13

8. Lucio Sarno, Daniel Thornton and Giorgio Valente, Federal Funds Rate Prediction, WP04-12

9. Lucio Sarno and Giorgio Valente, Modeling and Forecasting Stock Returns: Exploiting the Futures Market, Regime Shifts and International Spillovers, WP04-11

10. Lucio Sarno and Giorgio Valente, Empirical Exchange Rate Models and Currency Risk: Some Evidence from Density Forecasts, WP04-10

11. Ilias Tsiakas, Periodic Stochastic Volatility and Fat Tails, WP04-09

12. Ilias Tsiakas, Is Seasonal Heteroscedasticity Real? An International Perspective, WP04-08

13. Damin Challet, Andrea De Martino, Matteo Marsili and Isaac Castillo, Minority games with finite score memory, WP04-07

14. Basel Awartani, Valentina Corradi and Walter Distaso, Testing and Modelling Market Microstructure Effects with an Application to the Dow Jones Industrial Average, WP04-06

15. Andrew Patton and Allan Timmermann, Properties of Optimal Forecasts under Asymmetric Loss and Nonlinearity, WP04-05

16. Andrew Patton, Modelling Asymmetric Exchange Rate Dependence, WP04-04

17. Alessio Sancetta, Decoupling and Convergence to Independence with Applications to Functional Limit Theorems, WP04-03

18. Alessio Sancetta, Copula Based Monte Carlo Integration in Financial Problems, WP04-02

19. Abhay Abhayankar, Lucio Sarno and Giorgio Valente, Exchange Rates and Fundamentals: Evidence on the Economic Value of Predictability, WP04-01

\section{2}

1. Paolo Zaffaroni, Gaussian inference on Certain Long-Range Dependent Volatility Models, WP02-12

2. Paolo Zaffaroni, Aggregation and Memory of Models of Changing Volatility, WP02-11

3. Jerry Coakley, Ana-Maria Fuertes and Andrew Wood, Reinterpreting the Real Exchange Rate - Yield Diffential Nexus, WP02-10 
4. Gordon Gemmill and Dylan Thomas, Noise Training, Costly Arbitrage and Asset Prices: evidence from closed-end funds, WP02-09

5. Gordon Gemmill, Testing Merton's Model for Credit Spreads on Zero-Coupon Bonds, WP0208

6. George Christodoulakis and Steve Satchell, On th Evolution of Global Style Factors in the MSCI Universe of Assets, WP02-07

7. George Christodoulakis, Sharp Style Analysis in the MSCI Sector Portfolios: A Monte Caro Integration Approach, WP02-06

8. George Christodoulakis, Generating Composite Volatility Forecasts with Random Factor Betas, WP02-05

9. Claudia Riveiro and Nick Webber, Valuing Path Dependent Options in the Variance-Gamma Model by Monte Carlo with a Gamma Bridge, WP02-04

10. Christian Pedersen and Soosung Hwang, On Empirical Risk Measurement with Asymmetric Returns Data, WP02-03

11. Roy Batchelor and Ismail Orgakcioglu, Event-related GARCH: the impact of stock dividends in Turkey, WP02-02

12. George Albanis and Roy Batchelor, Combining Heterogeneous Classifiers for Stock Selection, WP02-01

\section{1}

1. Soosung Hwang and Steve Satchell, GARCH Model with Cross-sectional Volatility; GARCHX Models, WP01-16

2. Soosung Hwang and Steve Satchell, Tracking Error: Ex-Ante versus Ex-Post Measures, WP01-15

3. Soosung Hwang and Steve Satchell, The Asset Allocation Decision in a Loss Aversion World, WP01-14

4. Soosung Hwang and Mark Salmon, An Analysis of Performance Measures Using Copulae, WP01-13

5. Soosung Hwang and Mark Salmon, A New Measure of Herding and Empirical Evidence, WP01-12

6. Richard Lewin and Steve Satchell, The Derivation of New Model of Equity Duration, WP0111

7. Massimiliano Marcellino and Mark Salmon, Robust Decision Theory and the Lucas Critique, WP01-10

8. Jerry Coakley, Ana-Maria Fuertes and Maria-Teresa Perez, Numerical Issues in Threshold Autoregressive Modelling of Time Series, WP01-09

9. Jerry Coakley, Ana-Maria Fuertes and Ron Smith, Small Sample Properties of Panel Timeseries Estimators with I(1) Errors, WP01-08

10. Jerry Coakley and Ana-Maria Fuertes, The Felsdtein-Horioka Puzzle is Not as Bad as You Think, WP01-07

11. Jerry Coakley and Ana-Maria Fuertes, Rethinking the Forward Premium Puzzle in a Nonlinear Framework, WP01-06

12. George Christodoulakis, Co-Volatility and Correlation Clustering: A Multivariate Correlated ARCH Framework, WP01-05

13. Frank Critchley, Paul Marriott and Mark Salmon, On Preferred Point Geometry in Statistics, WP01-04

14. Eric Bouyé and Nicolas Gaussel and Mark Salmon, Investigating Dynamic Dependence Using Copulae, WP01-03

15. Eric Bouyé, Multivariate Extremes at Work for Portfolio Risk Measurement, WP01-02

16. Erick Bouyé, Vado Durrleman, Ashkan Nikeghbali, Gael Riboulet and Thierry Roncalli, Copulas: an Open Field for Risk Management, WP01-01

\section{0}

1. Soosung Hwang and Steve Satchell, Valuing Information Using Utility Functions, WP00-06

2. Soosung Hwang, Properties of Cross-sectional Volatility, WP00-05

3. Soosung Hwang and Steve Satchell, Calculating the Miss-specification in Beta from Using a Proxy for the Market Portfolio, WP00-04

4. Laun Middleton and Stephen Satchell, Deriving the APT when the Number of Factors is Unknown, WP00-03 
5. George A. Christodoulakis and Steve Satchell, Evolving Systems of Financial Returns: AutoRegressive Conditional Beta, WP00-02

6. Christian S. Pedersen and Stephen Satchell, Evaluating the Performance of Nearest Neighbour Algorithms when Forecasting US Industry Returns, WP00-01

\section{9}

1. Yin-Wong Cheung, Menzie Chinn and Ian Marsh, How do UK-Based Foreign Exchange Dealers Think Their Market Operates?, WP99-21

2. Soosung Hwang, John Knight and Stephen Satchell, Forecasting Volatility using LINEX Loss Functions, WP99-20

3. Soosung Hwang and Steve Satchell, Improved Testing for the Efficiency of Asset Pricing Theories in Linear Factor Models, WP99-19

4. Soosung Hwang and Stephen Satchell, The Disappearance of Style in the US Equity Market, WP99-18

5. Soosung Hwang and Stephen Satchell, Modelling Emerging Market Risk Premia Using Higher Moments, WP99-17

6. Soosung Hwang and Stephen Satchell, Market Risk and the Concept of Fundamental Volatility: Measuring Volatility Across Asset and Derivative Markets and Testing for the Impact of Derivatives Markets on Financial Markets, WP99-16

7. Soosung Hwang, The Effects of Systematic Sampling and Temporal Aggregation on Discrete Time Long Memory Processes and their Finite Sample Properties, WP99-15

8. Ronald MacDonald and Ian Marsh, Currency Spillovers and Tri-Polarity: a Simultaneous Model of the US Dollar, German Mark and Japanese Yen, WP99-14

9. Robert Hillman, Forecasting Inflation with a Non-linear Output Gap Model, WP99-13

10. Robert Hillman and Mark Salmon, From Market Micro-structure to Macro Fundamentals: is there Predictability in the Dollar-Deutsche Mark Exchange Rate?, WP99-12

11. Renzo Avesani, Giampiero Gallo and Mark Salmon, On the Evolution of Credibility and Flexible Exchange Rate Target Zones, WP99-11

12. Paul Marriott and Mark Salmon, An Introduction to Differential Geometry in Econometrics, WP99-10

13. Mark Dixon, Anthony Ledford and Paul Marriott, Finite Sample Inference for Extreme Value Distributions, WP99-09

14. Ian Marsh and David Power, A Panel-Based Investigation into the Relationship Between Stock Prices and Dividends, WP99-08

15. Ian Marsh, An Analysis of the Performance of European Foreign Exchange Forecasters, WP99-07

16. Frank Critchley, Paul Marriott and Mark Salmon, An Elementary Account of Amari's Expected Geometry, WP99-06

17. Demos Tambakis and Anne-Sophie Van Royen, Bootstrap Predictability of Daily Exchange Rates in ARMA Models, WP99-05

18. Christopher Neely and Paul Weller, Technical Analysis and Central Bank Intervention, WP9904

19. Christopher Neely and Paul Weller, Predictability in International Asset Returns: A Reexamination, WP99-03

20. Christopher Neely and Paul Weller, Intraday Technical Trading in the Foreign Exchange Market, WP99-02

21. Anthony Hall, Soosung Hwang and Stephen Satchell, Using Bayesian Variable Selection Methods to Choose Style Factors in Global Stock Return Models, WP99-01

\section{8}

1. Soosung Hwang and Stephen Satchell, Implied Volatility Forecasting: A Compaison of Different Procedures Including Fractionally Integrated Models with Applications to UK Equity Options, WP98-05

2. Roy Batchelor and David Peel, Rationality Testing under Asymmetric Loss, WP98-04

3. Roy Batchelor, Forecasting T-Bill Yields: Accuracy versus Profitability, WP98-03

4. Adam Kurpiel and Thierry Roncalli, Option Hedging with Stochastic Volatility, WP98-02

5. Adam Kurpiel and Thierry Roncalli, Hopscotch Methods for Two State Financial Models, WP98-01 